Portland State University

PDXScholar

Fall 12-5-2018

\title{
The Interplay Between Early Childhood Education and Mental Health: How Students in an In-Service Early Childhood Teacher Education Program Experience Children with Mental Health and Behavioral Challenges in the Classroom
}

Katie Statman-Weil

Portland State University

Follow this and additional works at: https://pdxscholar.library.pdx.edu/open_access_etds

Part of the Early Childhood Education Commons

Let us know how access to this document benefits you.

Recommended Citation

Statman-Weil, Katie, "The Interplay Between Early Childhood Education and Mental Health: How Students in an In-Service Early Childhood Teacher Education Program Experience Children with Mental Health and Behavioral Challenges in the Classroom" (2018). Dissertations and Theses. Paper 4638.

https://doi.org/10.15760/etd.6522

This Dissertation is brought to you for free and open access. It has been accepted for inclusion in Dissertations and Theses by an authorized administrator of PDXScholar. Please contact us if we can make this document more accessible: pdxscholar@pdx.edu. 
The Interplay Between Early Childhood Education and Mental Health:

How Students in an In-Service Early Childhood Teacher Education Program Experience Children with Mental Health and Behavioral Challenges in the Classroom

by

Katie Statman-Weil

A dissertation submitted in partial fulfillment of the requirements for the degree of

Doctor of Education

in

Educational Leadership: Curriculum and Instruction

Dissertation Committee:
Christine Chaillé, Chair
Dot McElhone
William Parnell
Melissa Thompson

Portland State University

2018 


\begin{abstract}
All early childhood educators who work with children between birth and six years of age are likely to encounter young children who experience behavioral and mental health challenges throughout their careers (Egger \& Angold, 2006). Research demonstrates that educators can play a vital role in children's mental health and behavioral development (Cho Blair, Fox, \& Lentini, 2010; Fox \& Hemmeter, 2009; Perry \& Szalavitz, 2017; van der Kolk, 2005; van der Kolk, 2014). However, often early childhood educators do not believe they have the knowledge or tools to accurately identify and successfully handle the unique challenges that arise when working with children with behavioral and mental health issues (Fox \& Hemmeter, 2009; Hemmeter, Fox, Jack, \& Broyles, 2007; Hemmeter, Santos, \& Ostrosky, 2008; Quesenberry, Hemmeter, \& Ostrosky, 2011; Westling, 2010).

Using an Anti-Oppressive Framework, this research study explores, through a qualitative case study design, how students in an in-service teacher education program experience children with mental health and behavioral issues in their classrooms. The following research question was used to guide this study: how do students in an inservice early childhood teacher education program think about, emotionally react to, and engage with children who express mental health issues and challenging behaviors in their classrooms?

This paper begins by discussing the prevalence and needs of children with mental health and behavioral issues in early childhood environments. It then synthesizes the relevant literature related to the phenomenon. Next, it describes and defends a study that offered opportunities for students in an in-service teacher education program to consider
\end{abstract}


their beliefs, emotions, and actions concerning inclusive education. From the research findings, implications for practice are revealed, offering ideas to support teacher education programs in better preparing their students to work with all young learners. Lastly, ideas for future research are elucidated. 


\section{Dedication}

To

the memory of my mother, Leah Statman 


\section{Acknowledgments}

I would like to take this opportunity to appreciate and acknowledge the many people who have contributed to my Ed.D. process and research over the past several years. I feel so lucky to have had such unwavering support from my family, friends, colleagues, and mentors.

First and foremost, to my advisor, Dr. Christine Chaillé - I am deeply grateful for your guidance, kindness, patience, and immense knowledge of early childhood education and research design. Thank you for sharing this knowledge with me and helping me develop as a researcher, scholar, and professional within the field of education. A special thank you for being so supportive of me even when I was distracted by the many events (and children) in my personal life, you always believed that I would be back, and here I am. I will forever be grateful that you agreed to be my advisor and stuck with me into your retirement.

To my committee members, Dr. Dot McElhone, Dr. William Parnell, and Dr. Melissa Thompson - thank you for your commitment to my work. Your expert feedback and insights that you offered to my dissertation proposal and dissertation itself have been invaluable. My dissertation is so much stronger because of all of you. To Dr. Dot McElhone, you made me question everything I had written and everything I believed throughout this process, in the best way possible. I knew I was not done with my dissertation until I felt like I could answer all of your questions. Thank you for your deep commitment to bettering my work until the very end. To Dr. William Parnell, you made my master's program meaningful and inspiring. I can still feel the excitement of sitting in your classes debating and learning through your vast knowledge and strong beliefs about 
what children deserve and what they are capable of. I do not think I would be completing this doctoral program if it were not for the excitement I got from you. Dr. Melissa Thompson, your voice added so much to each of my defenses. You asked poignant questions that made me think more critically about my writing and ideas, thank you for agreeing to be a part of my process.

To my participants - my sincere thank you for offering your time and for sharing your experiences with me. You shared intimate details of your professional lives that allowed me to deeply know you and your work. I was so impressed by who you all are as educators and as people, I hope this shines through in my writing.

To my sister Zoe, I am excited to be crossing this finish line as the same time as you cross your own. I cannot wait to celebrate with you.

To Helene, I learned through watching you what an inclusive educator looked and sounded like. I cannot believe our 20s and 30s have unfolded as they have, but here we are. Thank you for always loving me and believing in me.

To Clair, thank you for being my first friend in the doctoral program. Your keen sense of who I am transformed my life in ways I couldn't have imagined. I will be forever grateful.

To my partner Mark, your support made this possible. Your early mornings caring for our ever changing number of children allowed me the time and space I needed to focus on my work. Thank you for taking time off work so I could complete my research and meet the deadlines I had set for myself. You are truly a delight and a joy to be married to. I hope I can support you half as well as I know you will always support me. 
To my children: you amaze me. Watching you grow is the highlight of my life. I cannot express how much I love each of you and admire you. Thank you for putting up with me as I finished this longstanding project and commitment I made before I met you and realized how much more fun you are than writing. 
Table of Contents

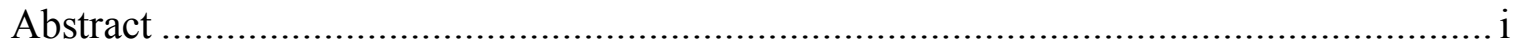

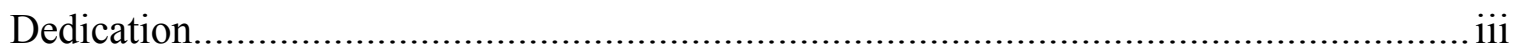

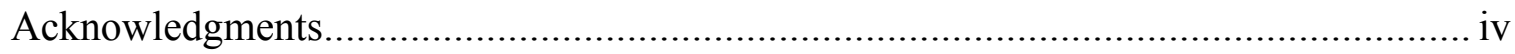

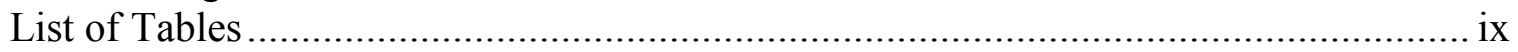

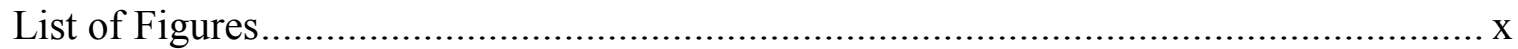

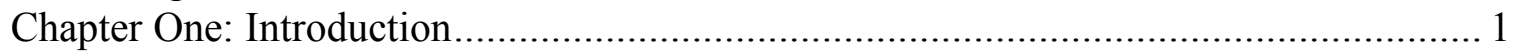

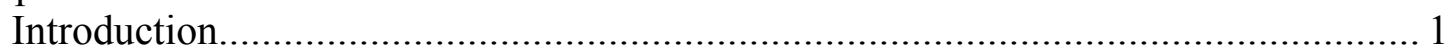

Statement of the Problem ................................................................................. 1

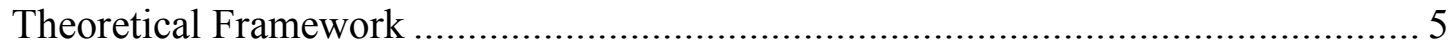

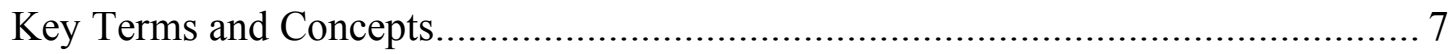

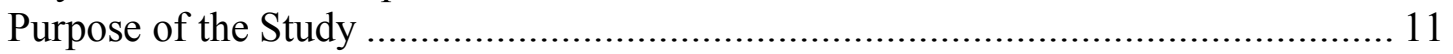

Research Question ........................................................................... 11

Research Methods and Procedures................................................................ 13

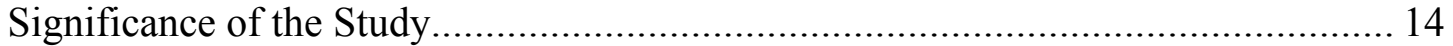

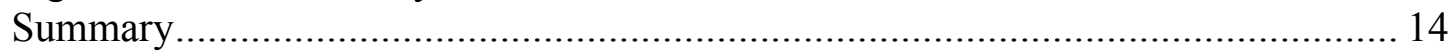

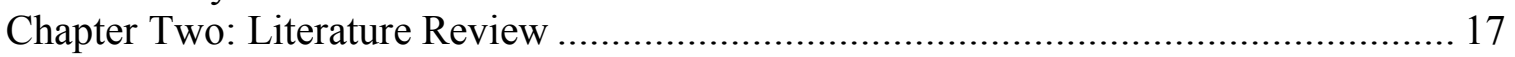

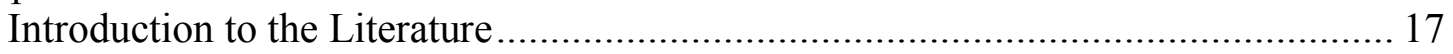

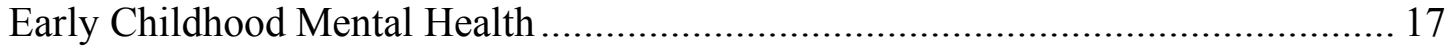

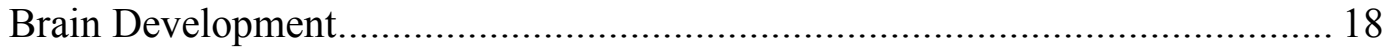

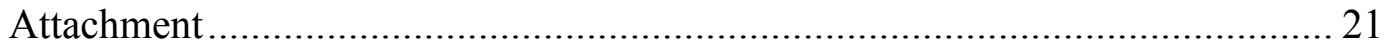

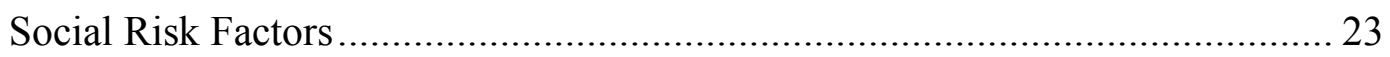

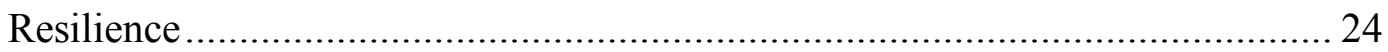

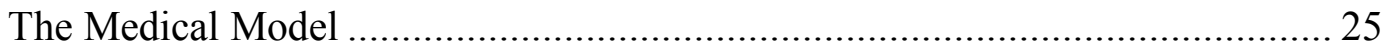

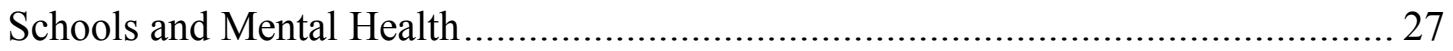

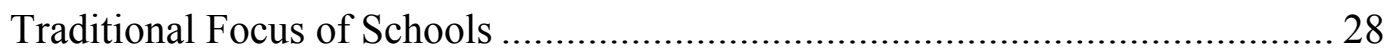

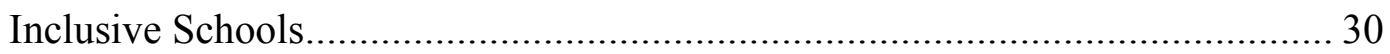

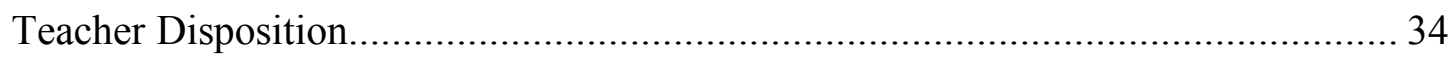

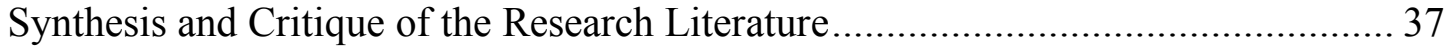

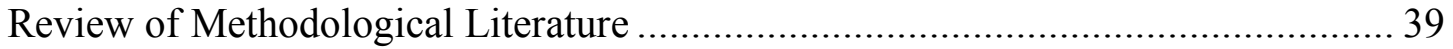

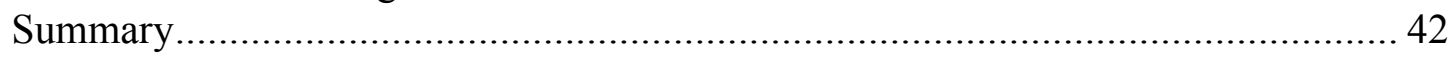

Chapter Three: Research Design and Methodology ................................................ 44

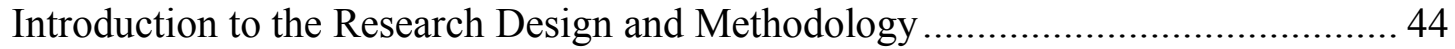

Researcher Position within the Anti-Oppressive Framework ............................. 44

Research Design.................................................................................... 46

Research Question .............................................................................. 46

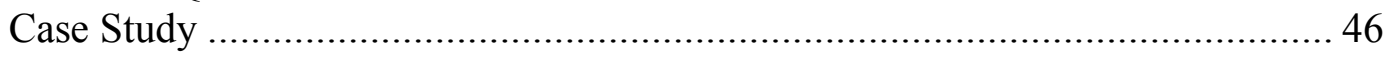

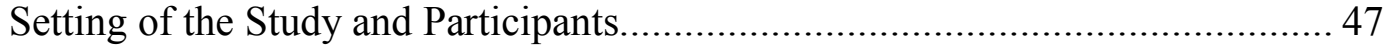

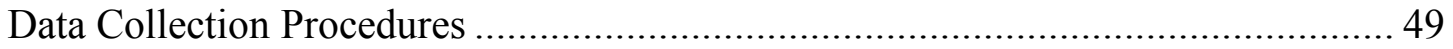

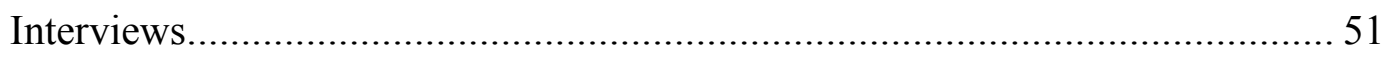

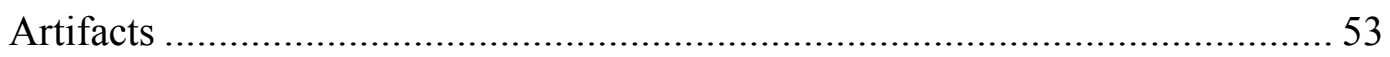

Nonparticipant Observations........................................................... 54

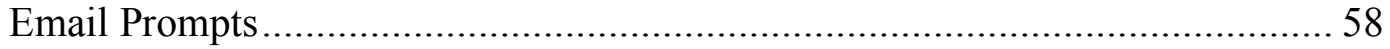

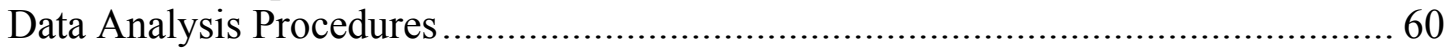

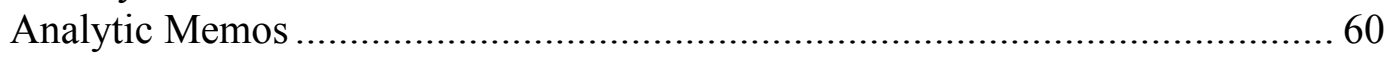


viii

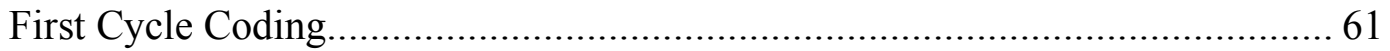

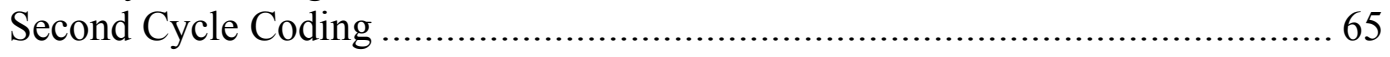

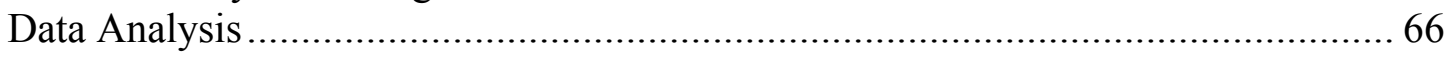

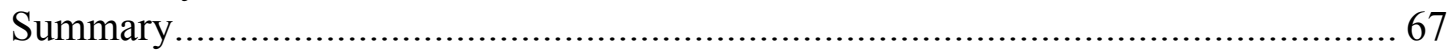

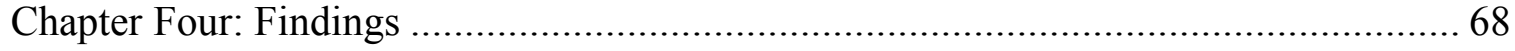

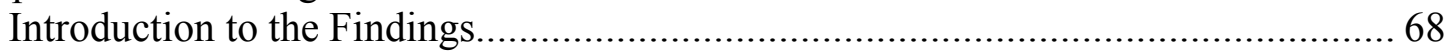

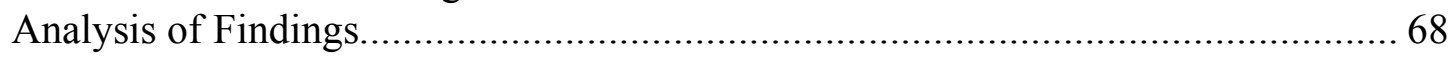

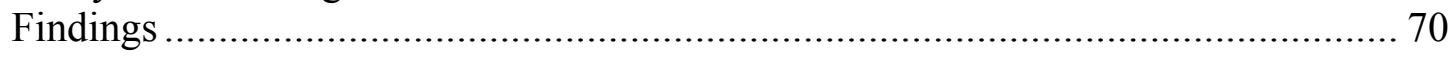

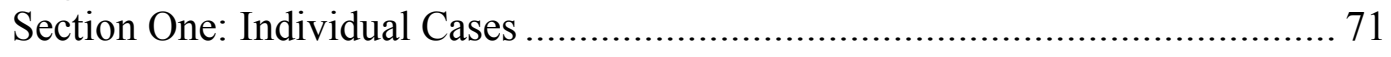

Section Two: Cross-Case Synthesis ............................................................ 95

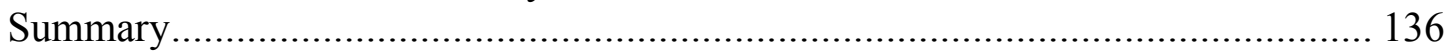

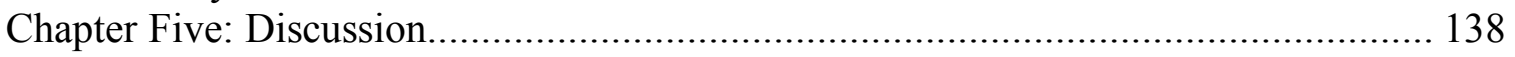

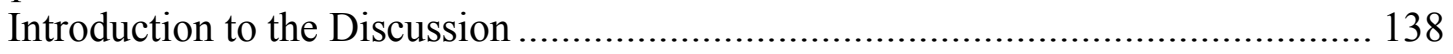

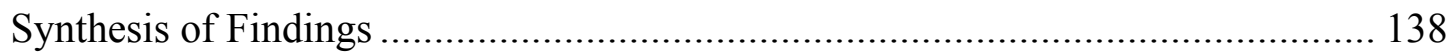

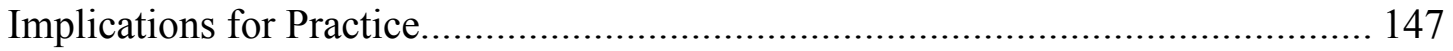

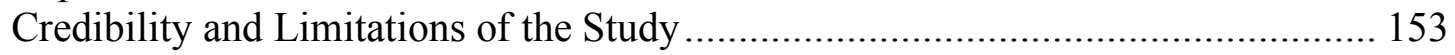

Researcher Bias and Positionality ....................................................... 154

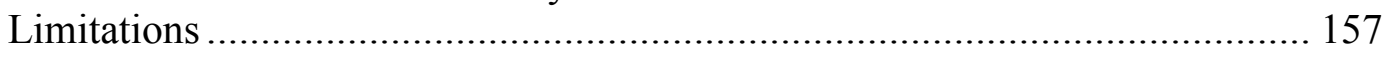

Recommendations for Future Research ..................................................... 158

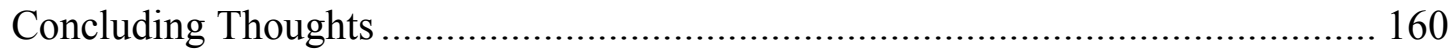

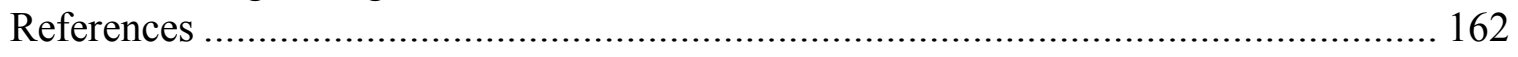

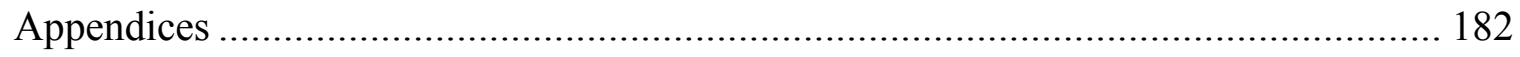

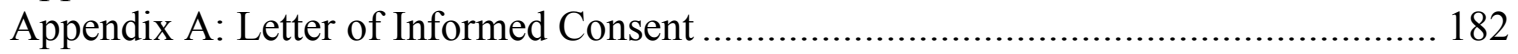

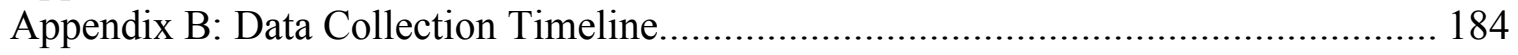

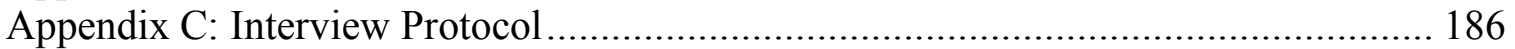

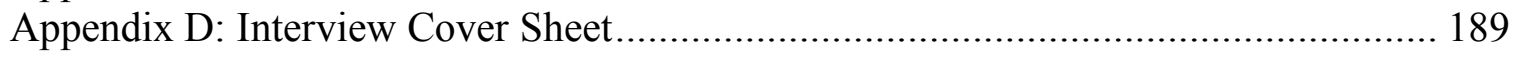

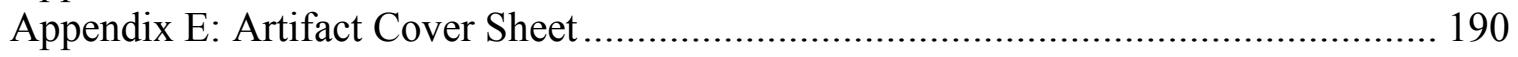

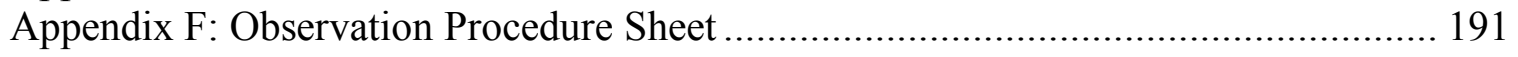

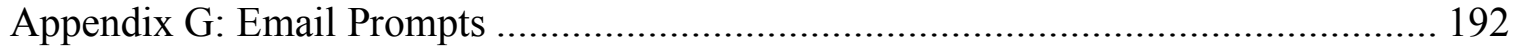




\section{List of Tables}

Table 1: Order of Data Collection $\quad 50$

Table 2: Values Coding

Table 3: In Vivo Coding 63-64

Table 4: Emotion Coding 


\section{List of Figures}

Figure 1: Roxanne's Artifact: The 5 C's of Conflict Resolution

Figure 2: Livia's Artifact: Image of Classroom Agreements

112

Figure 3: Mary's Artifact: Adult-Child Power Relationships

$130-131$ 


\section{Chapter One: Introduction}

\section{Introduction}

This paper offers a qualitative research study that examines how students in an inservice early childhood teacher education program think about, emotionally react to, and engage with children who express mental health issues and challenging behaviors in their classrooms. The intention of this research study is to contribute to the field of education by illuminating teachers' voices as they share about the interplay between mental health and education.

\section{Statement of the Problem}

All early childhood educators who work with children between birth and six years of age are likely to encounter young children who experience behavioral and mental health challenges in their classrooms (National Child Traumatic Stress Network, 2014; Roberts et al., 2012; van der Kolk, 2005; van der Kolk, 2014). Research suggests that serious mental health problems can emerge in children as young as four months old (Zero to Three, 2004; Egger \& Emde, 2011). Ten to fifteen percent of toddlers and preschoolers experience social-emotional and behavioral challenges and fourteen to twenty-six percent

of preschoolers experience a diagnosable mental health disorder (Brennan, Bradley, Ama, \& Cawood, 2003; Briggs-Gowan, Carter, Skuban \& Horwitz, 2001; Egger \& Angold, 2006; Kessler et al., 2005; Rones \& Hoagwood, 2000).

Contemporary research indicates that these early mental health and behavioral issues can and do cause young children to experience delays and difficulties across the developmental domains, which can lead to negative repercussions throughout children's lives (Cho Blair, Fox, \& Lentini, 2010; Fox \& Hemmeter, 2009; National Scientific 
Council on the Developing Child [NSCDC], 2008a; Perry \& Szalavitz, 2017; van der Kolk, 2005). These issues can undermine children's linguistic and communication skills, create challenges in relationships with both peers and teachers, and can negatively influence the themes and modes of young children's play; which can cause young children to socially and academically withdraw from the school environment, leading to low academic attainment (Thomason \& Marusak, 2017; Badenoch, 2008; Blair, Fox, \& Lentini, 2010; McLeod, \& Kaiser, 2004; Wood, Cho Blair, \& Ferro, 2009). Along with poor academic outcomes, those with extreme and complex social emotional needs in their early years are more likely to experience mental health issues as adults, express hostile or disruptive behaviors, and heavily use drugs and alcohol (Egger \& Angold, 2006; Huffman, Mehlinger, \& Kerivan, 2000; Kendall \& Kessler, 2002; Kessler et al., 2005; McCabe and Frede, 2007; NSCDC, 2008a; U.S. Department of Health and Human Services, 1999).

Although the effects of mental health issues can be profound, research indicates that early childhood educators who are able to recognize and support young children's mental health and behavioral challenges in the classroom can greatly reduce the probability that these negative outcomes occur (Campbell, 2014; Brennan, et al., 2003; Shonkoff \& Phillips, 2000; Webster-Stratton, \& Reid, 2010; Wood, et al., 2009). Young children's brains can change and rewire based on healthy, reparative interactions with highly skilled and thoughtful adults (van der Kolk, 2014). Through clear, consistent, and intentional responses to children, teachers can change the way children experience and react to the world around them (Shonkoff \& Phillips, 2000; van der Kolk, 2014). 
Unfortunately, often educators cannot correctly identify and deal with the issues that come up when working with children with behavioral and mental health issues (Fox \& Hemmeter, 2009; Hemmeter, Fox, Jack, \& Broyles, 2007; Hemmeter, Santos, \& Ostrosky, 2008; Quesenberry, Hemmeter, \& Ostrosky, 2011; Westling, 2010). Research demonstrates that teacher preparation programs do not offer their students adequate strategies and resources to work with young children with mental health issues, and teachers themselves say they do not feel prepared to handle the serious behavioral challenges that arise in their classrooms (Hemmeter, et al., 2008; Westling, 2010). Furthermore, frequently educators do not believe supporting children's behavior falls within their role. Practicing teachers often simply want to stop or control behaviors so that academic learning can continue, and do not understand the connection between children's social-emotional development and academic achievement (Hemmeter, et al., 2008; Kauffman, 2004; Severson, Walker, Hope-Doolittle, Kratochwill, Gresham, 2007).

Due to the research demonstrating that educators can play a vital role in children's mental health development, as well as the research showing that teachers do not feel adequately prepared to handle their students' mental health and behavioral challenges, I believe it follows that teacher education is an important place to study teachers' understanding of mental health issues. Offering students in an early childhood teacher education program the opportunity to explore their views of children's mental health and challenging behaviors can support the understanding of how teacher education programs can ensure their students develop the skills and knowledge necessary to support young children with mental health issues and challenging behaviors. 
Further, conducting research within a professional development program is significant because it is often at this time that educators deepen their teacher identities, which influences how they view who they are and what they do in the classroom (Hong, 2007; Hong, 2010). Because teachers often do not see mental health and behavioral support as within their role as educators, it seems imperative that teacher education begins to critically evaluate and confront the ways mental health and challenging behaviors are currently being handled in schools.

The research study presented here describes how students in an in-service early childhood teacher education program think about, emotionally react to, and engage with young children who express mental health issues and challenging behaviors in their classrooms. By understanding how students in an in-service teacher education program view and respond to young children's mental health and challenging behaviors, it is my hope that this research can be a step towards creating more holistic teacher education programs that support educators in better able meeting the needs of young children with behavioral and mental health issues.

This paper is presented in five chapters. The introduction continues by describing the theoretical framework that grounds this research study. It goes on to define the key terms and concepts used throughout this paper. The first chapter then explains the purpose and significance of the study, including the research question and methods. The second chapter reviews the current literature concerning early childhood mental health, the role schools and teachers have played in supporting young children's socialemotional development, and the importance of teacher disposition on children's development and learning. It then integrates these three distinct areas of the literature to 
advocate for this research study exploring the beliefs and behaviors of students in an inservice teacher preparation program as they relate to young children's mental health and challenging behaviors. Lastly, the second chapter concludes by synthesizing the relevant literature related to the qualitative research design. In its third chapter, this paper describes the research design and methodology that was used to explore the research question. Chapter four details the findings of this study by first outlining the individual cases and then sharing a cross-case synthesis to explore the themes and subthemes that emerged from the data analysis. The fifth chapter offers a discussion of the findings and the implications for practice. It then details the impact of my positionality as researcher and the limitations of the study before offerings suggestions for future research.

\section{Theoretical Framework}

Rooted in my background in both social work and education, the theoretical framework underpinning this research study draws on anti-oppressive practice (AOP) and anti-oppressive education (AOE). Together, AOP (Baines, 2017; Barnoff \& Coleman, 2017; Massaquoi, 2017) and AOE (Kumashiro, 2000; Kumashiro, 2001) offer a theoretical basis for analyzing and understanding the ways in which young children's mental health expression and development are socially situated as well as the ways in which teachers perceive and influence the mental health experiences of their students (Barnoff \& Coleman, 2017; Larson, 2008; Massaquoi, 2017).

The heart of this framework has the purpose of challenging inequitable societal relationships and offering voice and power to those who experience oppression (Baines, 2017; hooks, 1994). By using AOP and AOE as a framework, it is possible to explore the influence dominant discourses have on shaping teachers' guidance practices and views of 
children's mental health and behavioral needs. The dominant view of childhood mental health and young children's behaviors focuses on the individual pathology of the child (Egger \& Emde, 2011; Beresford, 2002; Brown, 2017; Larson, 2008; Swanson et al., 2003; Wilson \& Beresford, 2000). Similarly, the dominant discourse within the education field views young learners within a deficit model that sees them as simply "lacking, passive, acted upon, or following a predetermined path set out by adults and/or innate 'development"' (Moss, 2010, p.1). These views do not take into account or try to combat the role societal issues such as prejudice, stereotyping, familial socioeconomic resources, or employment and educational opportunities have on young children and their development (Swanson et al., 2003). From an AOP and AOE lens, not holding children's lived experiences as influential and valuable in their developmental process puts children at risk of simply being labeled and categorized, and ultimately dismissed as beyond help, rather than seen as acted upon as well as active participants in their story development (Beresford, 2002; Cadwell, 1997; Reggio Children, 2010). AOP and AOE offer a lens with which to understand how young children's development and behavior is connected to their social worlds and lived experiences (Baines, 2017).

Using anti-oppressive practice and anti-oppressive education as a theoretical framework allows for the understanding that all classrooms are social and cultural spaces that can reproduce inequities or fight for social change (Baines, 2017; Freire, 1970; Freire \& Faundez, 1989; hooks, 1994; Kumashiro, 2000; McLaren, 2016; Swadener, AquinoSterling, Nagasawa, \& Bartlett, 2009). Through exploring the views of students in an inservice early childhood teacher education program and allowing them the space to share their own experiences and values, it is intended for this paper to offer ideas for teacher 
education programs about how to support new teachers in entering the teaching profession ready to challenge and even transform schools into being more inclusive and supportive educational environments for all learners (Dominelli, 2002; Larson, 2008; Novinger, O’Brien, \& Sweigman, 2005; Takacs, 2002, 2003).

Using this framework does not, however, come without some challenges. AOP and AOE are rooted in the belief that all voices should be valued and heard within the research process, and specifically the voices of the oppressed. However, this study, with its focus on the thoughts and experiences of students in an in-service teacher education program, does not include the voices of the young children with whom the research participants are working. Young children's voices and experiences, which are arguably undervalued in most contexts (Switaji, 2010), are not explicitly recognized in this study. This study focuses on the voices of adults as a first step to a fuller picture; more research needs to be conducted to get a richer understanding of the experiences of all those involved in classrooms and schools.

\section{Key Terms and Concepts}

As noted in the theoretical framework, all educational practices, including the writing of this research study, are situated within the dynamics of politically and socially contested spaces. It is my intention that this anti-oppressive lens, which recognizes and also attempts to combat social inequities, is used throughout this research study, continuing with the framing and defining of the key terms and concepts. The terms I am defining and using within this research study include: mental health, social-emotional skills, mental health conditions or mental health problems, challenging behavior, early childhood education program or school, in-service early childhood teacher education 
program, and lastly inclusion.

This paper attempts to challenge the dominant discourses of both the mental health and early education fields by beginning with a view of all people, including both children and educators, as capable, powerful, competent, and importantly, deeply connected to those around them (Edwards, Gandini, \& Forman, 1993; Joint Consortium for School Health [JCSH]; Malaguzzi, 1993). However, it is necessary to note that the medical model, which dominates the definitions and categorization of mental health issues, is just now beginning to define the causes and manifestations of early childhood mental health conditions (Egger \& Angold, 2006; Nash \& Schaefer, 2010). Therefore, in alignment with the anti-oppressive beliefs and values outlined above, I aim to question and subvert the traditional view of mental health issues as solely caused by individual pathology, the definitions that follow layer anti-oppressive viewpoints over more traditional definitions as a means of accurately representing where the field is. This integrative approach intends to support dialogue between those working within an antioppressive framework and those working within the medical model (Barnoff \& Coleman, 2017; Egger \& Angold, 2006).

The U.S. Department of Health and Human Services (1999) views children's mental health as, "the achievement of expected developmental cognitive, social, and emotional milestones and by secure attachments, satisfying social relationships, and effective coping skills" (p. 123). What are considered "expected" developmental milestones are left up to the interpretation of the reader or individual working with young children.

Because mental health and healthy social-emotional development are often 
considered synonymous when discussing young children, it is possible to define mental health further by understanding the social-emotional skills that encompass healthy socialemotional development (Zero to Three, 2004). The National Scientific Council on the Developing Child [NSCDC] (2004) defines social-emotional skills as "the ability to identify and understand one's own feelings, to accurately read and comprehend emotional states in others, to manage strong emotions and their expression in a constructive manner, to regulate one's own behavior, to develop empathy for others and to establish and sustain relationships" (pg.1). Together these definitions offer a broad view of mental health and healthy social-emotional development that can be interpreted and defined differently among and between differing cultural groups (Cowen, 1994; Head Start Bulletin, 2009).

Childhood mental health conditions or mental health problems (which, within the medical model are often termed mental disorders) are defined as, "serious deviations from expected cognitive, social, and emotional development" (NSCDC, 2004, p. 123). Because children's mental health conditions can be classified in a myriad of ways, it is beyond the scope of this paper to offer a list of the specific presentations seen by children with the vast range of mental health problems (for a review of the current early childhood mental health classification systems, please see: Egger \& Angold, 2006; Egger \& Emde, 2011). In this research study childhood mental health conditions will be offered as a broad umbrella for children's extreme developmental deviations that manifest as both externalizing problems (e.g. aggression, emotional outbursts, or hyper-activity) and internalizing problems (e.g. social phobias, withdrawal, obsessive-compulsive behaviors, depression, or anxiety), but will exclude neurological conditions such as Autism or 
physical tics that are not typically labeled as mental health issues, although they can cause mental health needs (Brennan, et al., 2003; Foster et al., 2005; Head Start Bulletin, 2009; Liu, 2004; Webster-Stratton, \& Reid, 2010). Although mental health conditions are defined using the individual child's development as the descriptor of the problem, it is not possible nor is it beneficial to view children's internal states in isolation without simultaneously looking at their social worlds; since it is the social conditions within which children live that greatly influence their mental health and its manifestations (Baines, 2017; Beresford, 2002; Bronfenbrenner, 1993; Shonkoff \& Phillips, 2000). The term challenging behavior has several different meanings within both early childhood education and the mental health field. Similar to mental health conditions, challenging behavior is often wrongly viewed as pathology within the individual child rather than as the result of the multifaceted interactions between biological factors and young children's surrounding contexts (McCabe \& Frede, 2007; Smith \& Fox, 2003). While some challenging behaviors are developmentally typical and subside with responsive guidance, some challenging behaviors persist across time and are in fact the externalizing and internalizing manifestations of mental health conditions. For the purposes of this paper challenging behavior is defined as any atypical repetitious behavior that hinders or has the potential to hinder young children's academic learning or prosocial interactions with other children and adults (Smith \& Fox, 2003). These behaviors include: persistent emotional outbursts, physical violence, verbal aggression, vocal outbursts (such as screaming), destruction of property, self-harming, consistently not adhering to requests made by adults, and social withdrawal (McCabe \& Frede, 2007; Smith \& Fox, 2003; Webster-Stratton, \& Reid, 2010). 
The term early childhood education program or school refers to educational environments that serve children between birth and six years of age.

In-service early childhood teacher education program refers to the education teachers, who have in-field experience, receive within a college or university. Teacher education typically involves coursework focused on child development, teaching academic concepts, equity and diversity, and classroom management.

Inclusion is defined as an educational environment where all young children and their families, regardless of abilities or needs, have access to and participate in the program; with adaptations to activities for children whose needs require them (see Kontos, Moore, \& Giorgetti, 1998).

\section{Purpose of the Study}

The purpose of this study is to illuminate how students in an in-service early childhood teacher education program think about, emotionally react to, and engage with students who express mental health issues and challenging behaviors in their classrooms. My intention is to contribute to the field of education by adding a discussion about the interplay between mental health and education. It is my hope that this study will inform how teacher education programs talk and teach about young children's mental health and challenging behaviors.

\section{Research Question}

This paper describes a research study that examines, through a case study methodology, the following research question: how do students in an in-service early childhood teacher education program think about, emotionally react to, and engage with children who express mental health issues and challenging behaviors in their classrooms? 
To fully understand this research question it is important to elucidate my understanding of the terms think about, emotionally react to, and engage with that are used in this research question. The term think about speaks to the students in an inservice early childhood teacher education program's beliefs about the reasons why children have and express their mental health and behavioral challenges as they do. Because teachers' beliefs often determine what and how they teach and what students learn in their classrooms, understanding their thought processes and beliefs is foundational to understanding how to best serve all children (Klehm, 2014).

In addition to understanding how these students think about the children they work with, it was my intention to understand how students in an in-service early childhood teacher education program emotionally react to the children in their classrooms. To truly comprehend why and how teachers respond to challenging behavior it is important to elucidate the feelings teachers experience (and their corresponding physiological responses, as they describe them) when their students express challenges to truly comprehend why and how they respond. Emotions are a significant aspect of teaching and are constructed through interactions with children as well as colleagues. Teachers' emotional responses have been found to influence burnout and the decision to drop out of the teaching field (Hong, 2010; Swartz \& McElwain, 2012). Therefore, understanding emotional responses is significant as a means of understanding the best ways to support teachers and the children in their care when challenges arise in the classroom.

Lastly, this research question had the goal of illuminating how students in an inservice early childhood teacher education program engage with the children who express 
mental health issues and challenging behaviors in their classrooms, which refers specifically to the ways in which they respond to and interact with the children who express mental health or behavioral challenges in their classrooms.

The decision to use both the terms mental health issues and behavioral challenges in the research question was based on the overlap and interplay between these two phrases in the contemporary research on young children. Often, the differences between the two cannot be distinguished, and they are used together or interchangeably in relation to young children's behaviors in the classroom. I believe that together they can offer a broad and comprehensive description of the students whose behaviors challenge teachers and hinder their success in the classroom.

\section{Research Methods and Procedures}

To explore this research question, I used a qualitative multiple-case design. Each student within the in-service early childhood teacher education program who participated in the study was a case, which allowed me to explore the individual perspectives of the participants while also exploring broad themes and subthemes across the participants (Creswell, 2009; Merriam, 2009; Yin, 2014). I used interviews, observations, artifacts, and email prompts to explore the research question. It was my hope that by using multiple data gathering procedures I would generate rich data that would highlight the thoughts and experiences of students within an in-service early childhood teacher education program as they work with children with mental health and behavioral challenges. The research methods and procedures completed are explained in depth in chapter three of this study. 


\section{Significance of the Study}

Research has noted the significant importance of healthy social-emotional development on young children's academic and life trajectories as well as the profound role early intervention and high skilled early childhood educators can play in supporting young children's mental health (Brennan, et al., 2003; Fox \& Hemmeter, 2009). However, little research had been done to understand what students in teacher education programs think about and how they respond to young children's mental health and behavioral challenges in their classrooms. It is important to the field of early childhood education to offer insight into the ways in which educators see and respond to young children's challenging behaviors and mental health needs, as well as offer ways to educate students in teacher education programs about mental health and challenging behaviors. Most importantly perhaps, this research can increase an awareness and understanding of the often-unrecognized existence and importance of children who experience mental health and challenging behaviors in the classroom, and the impact meeting their unique needs can have on their schooling and life successes (Blair, et al., 2010; NSCDC, 2008a; Shaw, Gilliom, Ingoldsby, 2003; Walker et al., 1998; Walker \& Golly, 1999).

\section{Summary}

Children with severe and complex social emotional needs are not being properly and successfully served within most early childhood programs. While many researchers have studied the importance of early mental health and behavioral regulation, few have studied the thoughts, feelings, and reactions to children's mental health needs of those studying in teacher education programs. Using an anti-oppressive framework and case 
study research design, this research describes how students in an in-service early childhood teacher education program think about, emotionally react to, and engage with children who express mental health issues and challenging behaviors in their classrooms. This research illuminates the needs of students in an in-service teacher education program so they can create supportive and responsive classroom communities that meet the needs of all learners. The following chapter reviews the literature relevant to this study and advocates for research that explores the thoughts, feelings, and actions of students in an in-service early childhood teacher education program as they relate to children's mental health and challenging behaviors. 
Chapter Two: Literature Review

\section{Introduction to the Literature}

Research demonstrates that supporting children academically is simply not as effective without concurrently attending to children's mental wellbeing (Kauffman, 2004; National Center for Mental Health Promotion and Youth Violence Prevention [NCMHPYV], 2009; Severson, et al., 2007; Shonkoff \& Phillips, 2000; Gresham, 2007). To understand the importance of exploring how teachers think about, emotionally react to, and engage with children with mental health and behavioral issues in the classroom, a review of the historical and contemporary literature is offered next. The review begins with an in-depth examination of what is known about early childhood mental health. The synthesis of the literature then explains the role school has played historically and currently in supporting children's acquisition of social-emotional skills. Next, contemporary research concerning teachers' dispositions and classroom management styles are analyzed as they connect to children's mental health outcomes. Following, the literature is synthesized to illuminate the gap in the current research and the importance of exploring how students in an in-service early childhood teacher education program think about, emotionally react to, and engage with children who express mental health issues and challenging behaviors in their classrooms as a means of ensuring that all children's needs are met in classrooms. Lastly, the methodological literature is reviewed.

\section{Early Childhood Mental Health}

The reported rate of mental health issues in young children is growing. Although research on young children's mental health is new, there have been some recent strides in understanding the influence of genetic and social experiences on young children's brain 
and mental health development, the risk factors that affect children, and the resiliency attributes that can safeguard many children against negative mental health outcomes.

Contemporary research shows that it is through the complex interactions between biological or genetic predispositions and socially bound, stressful experiences that mental health challenges arise (Larson, Russ, Crall, \& Halfon, 2008; McLeod, \& Kaiser, 2004; Shonkoff \& Phillips, 2000). Adverse experiences that influence the mental health of children can occur at home, school, or within the community (Felitti et al., 1998). To understand how and why these adverse experiences influence young children's development, it is imperative that the connections between the brain, early attachments, and societal influences are understood. This literature is significant since it demonstrates what is known about brain development and attachment experiences, which in turn highlights the vital role adults such as teachers can play in young children's developmental trajectories.

\section{Brain Development}

Children's brains develop within the context of their earliest experiences; neural development and social interactions are profoundly interwoven and cannot be separated (Badenoch, 2008; Center on the Developing Child at Harvard University, 2007; Shonkoff \& Phillips, 2000; van der Kolk, 2005; van der Kolk, 2014). While there are certainly genetically driven courses of development that guide the foundational organization of both body and brain, the primary expression of genes is influenced by children's experiences within their surrounding environments (Larson, Russ, Crall, \& Halfon, 2008; Shonkoff \& Phillips, 2000; van der Kolk, 2014). Current brain research demonstrates that the developing brain is exceptionally vulnerable to the impact of psychosocial risk factors 
because the brain's chemistry and formation change based on one's earliest experiences. There are specific areas of the brain that are particularly vulnerable to stress, these areas include: the prefrontal cortex (which supports complex cognitive behavior, decision making, personality expression and regulating social behavior), the hippocampus (which consolidates both short and long-term memory), and the corpus callosum (which enables interhemispheric communication) (Delima \& Vimpani, 2011; Siegel \& Payne Bryson 2012). All three of these functions are important elements for long-term healthy socialemotional development.

When children experience psychosocial stressors (such as domestic violence, sexual abuse, or neglect) that threaten their physical or mental safety, their brains trigger a set of chemical and neurological reactions known as the stress response, which activates their biological instinct to fight, freeze, or flee from the perceived danger (Delima \& Vimpani, 2011; Porges, 2004; van der Kolk, 2005). If this stress response happens over and over again it changes typical brain development. When children have not experienced significant stress, their brains respond to perceived stress or danger by placing the event memories into chronological order in their hippocampi before they consolidate as narrative memories in their left frontal cortices. However, when children have experienced serious social stressors, their brains often react differently. The emotional and physical responses to perceived threats do not go to the hippocampi but rather remain encoded in the amygdalae, the brain's regulator of emotions and emotional behaviors, as somatosensory memories; memories that present as visual images or physical sensations (Herman, 2015; van der Kolk, 2014). 
For children who live with recurring or constant stress or fear, the stress response can become their typical way of responding to the world (Wolpow, Johnson, Hertel, \& Kincaid, 2009). The areas of children's brains that become the most developed are the areas that are most frequently activated and used (Badenoch, 2008). Children who experience overwhelming stress or fear and are not supported in the regulation of their emotions may tend to overuse their amygdalae, which cause their amygdalae to overdevelop. Additionally, the hippocampi tend to be underdeveloped because they are underused in comparison to children who do not live in constant states of stress or fear. Therefore, even when danger is not present, children may respond as if there is danger because they are unable to regulate the arousal and emotional responses their extremely adaptive brains have created as a means for survival (Cole et al., 2013; Siegel \& Payne Bryson, 2012).

Due to the brain's ability to change based on its environments, many of the challenging behaviors displayed by children who have experienced prolonged stress or trauma can be understood as the reactions to sustained activation of the biological stress response system. These children's behaviors include poor self-regulation, increased impulsivity, anxiety, aggression, and even suicidality (Delima \& Vimpani, 2011; Siegel \& Payne Bryson, 2012). To truly understand the impact of environment and gene expression on brain development it is important to understand the attachment relationship and the impact of caring and attuned adults on young children's development. Attachment, and its connection to brain development, is discussed next. 


\section{Attachment}

Because young children's brains develop within the context of their earliest relationships and experiences, the quality of the relationship between young children and their primary caregivers is an extremely important factor in young children's mental health development. Children learn to regulate their emotions and behaviors by learning how to predict their caregivers' responses to them when they express different feelings. This interaction allows children to internalize the emotional and cognitive characteristics of their primary relationships (Bowlby, 1980). Children learn to trust their emotions and understand the world around them based on their earliest relationships (Stacks \& Oshio, 2009; Stubenbort, Cohen, \& Trybalski, 2010). Their experiences of feeling heard and understood help them to feel confident that they are able to make good things happen, such as make others smile or laugh. They also learn that if they do not know how to handle a difficult situation, they can locate individuals who can support them in finding a solution (Porges, 2004; van der Kolk, 2005).

Typically, when children experience distress or feel threatened, parents or other caregivers are able to support them in re-establishing a sense of safety and control within their lives. However, children who have difficult temperaments, caregivers with mental health issues, or who experience stress, early trauma, or maltreatment at the hands of trusted adults may not have the necessary experience for healthy attachment of being guided to regulate their emotions and successfully modulate their arousals (Head Start Bulletin, 2009; van der Kolk, 2005). When children cannot access this needed support during a stressful situation, it causes an arrest in their abilities to process, integrate, and categorize what happened. Without having the capacity to process their experiences, 
young children are at risk of potentially becoming overwhelmed by feelings of distress and unable to regulate their internal emotional and physical states, which can change their brain chemistry (van der Kolk, 2005).

Healthy and attached relationships between caregivers and children may look different across cultural and racial groups. Lansford et al. (2004) studied the relationship between physical parental control measures and children's externalizing behaviors (such as aggression and anger). They sought to understand if caregivers' use of physical discipline in the first five years of life was linked to children's aggression across cultural lines. Previous theories and empirical research had demonstrated a link, yet much of the research had been completed using middle-class European American families as participants. To expand the research and to understand attachment patterns across racial and cultural lines, Lansford et al. (2004) conducted a study following children from 5 to 16 , looking at the connection between parenting styles and children's externalizing behaviors in both European American and African American families. They found that physical discipline in the 'non-abusive range' by parents was associated with more externalizing behaviors for European American children, but not for African American children. Furthermore, they found that physical discipline by African American parents was associated with lower externalizing behaviors for their children, suggesting that children from different racial backgrounds, based on cultural norms, may interpret physical discipline by their parents differently. To African American children, physical discipline may not be seen as a lack of care or concern. As Lansford et al. (2004) explain: If physical punishment is administered in a context in which this form of discipline is normative or accompanied by parental warmth and a goal of 
helping the child grow into a responsible adult, then this caring message might be received by the child and could buffer any adverse effects of physical punishment on child outcomes. If physical punishment is administered in a context in which this parental behavior is less normative and more aberrant, then the message received by the child may be that the parent is out of control and rejecting of the child, and the child's reaction may be to escalate externalizing problems (p.802).

Thus, healthy attachment is not as simple as responding to children in the "right" way across racial and cultural groups, but rather it is context-based and culturally relative for the individual family and their background. The importance of context and culture becomes significant when looking at the relationship of teachers and students; attachment and attachment patterns influence children's relationships with the adults in their lives and impacts their learning and sense of self (van der Kolk, 2014).

\section{Social Risk Factors}

Children from all socioeconomic, cultural, religious, and familial backgrounds can experience stressors that may influence or exacerbate mental health problems. However, there are certain stressors that put children at a higher risk for negative mental and behavioral outcomes. Some of the primary risk factors found to influence mental health include: prenatal exposure to alcohol, drugs, and cigarette smoke; prenatal malnutrition; poor early nutrition; injury; infection; exposure to environmental toxins; low birth weight; experiencing trauma or family violence; living in households with substance abuse or mental illness; large family size; and poverty (Brennan, et al., 2003; Shonkoff \& Phillips, 2000). These stressors may affect children differently depending on 
the individual differences between children, their age when the exposure to the adverse experience occurs, and whether the experience was an isolated incident or occurred in conjunction with other risk factors. Risk factors threaten children in a cumulative manner; the more risk factors children experience the more likely it is they will experience long-term negative effects across the developmental domains (Felitti et al., 1998; Larson, et al., 2008).

\section{Resilience}

Although there is increased evidence that early childhood stressors and disrupted attachment can lead to changes in the brain and resulting behavioral changes, not all children who experience the aforementioned risk factors experience negative neural consequences. Resilience can be defined as the maintenance of healthy functioning when adversity occurs. If an individual lacks resiliency, a challenge or stressor may overwhelm his capacity to cope and move through the difficult experience. Resilience does not make the problems go away, but it can help an individual see beyond the current moment and still find pleasure in life (National Scientific Council on the Developing Child [NSCDC], 2008b). The research on resiliency notes that there are several resiliency measures that can defend against negative mental health outcomes (Moore, 2013; JCSH, 2010). Children are less likely to experience the adverse effects of stress and trauma if they believe they are worthy. This sense of worthiness in young children is more likely to occur for those who have certain characteristics, such as: high intelligence, strong familial attachments, an appealing appearance, and an easy, flexible, and social temperament. These factors influence how adults see and respond to children; children who are cute and easy going are much more likely to get positive attention and build a 
positive identity than children who are less attractive in appearance and more obstinate. These resiliency factors allow children to develop deep connections with the adults in their lives and have a sense of achievement and accomplishment across their environments (home, school and community) (Moore, 2013; JCSH, 2010; Larson, et al., 2008; NSCDC, 2008b; Streeck-Fischer \& van der Kolk, 2000).

Furthermore, part of this resilience can be attributed to the brain's neuroplasticity; the brain's ability to rewire, change, and re-organize in response to new experiences. Amazingly, just as young children's brains change based on traumatic or stressful environments, they are also able to change again when they are exposed to supportive environments (van der Kolk, 2005). Therefore, although a child may experience several risk factors, resiliency factors can counteract the effects on the brain. Neuroplasticity is especially prevalent in young children under the age of seven, which is why early childhood is such a critical period for appropriate access to mental health support (Siegel \& Payne Bryson, 2012).

\section{The Medical Model}

Although research on brain development, attachment, risk factors, and resiliency measures indicate that children's mental health is deeply connected to their early experiences, it is becoming more common within the medical field for young children displaying emotional distress, challenging behavior, and learning differences to be given psychiatric labels. These medical labels are meant to support the understanding of children's mental health, but often overlook the relationship between their personal experience and their environmental circumstances (Egger \& Emde, 2011). 
Over the past ten years there has been a significant increase in the prescription of psychoactive medications for young children with mental health or behavioral issues, even though the efficacy and safety of these drugs has not been studied in young children (NSCDC, 2008b). For example, Visser, Lesesne, and Perou (2007) reported in the National Survey of Children's Health that young children between 4-8 years old who have been diagnosed with attention deficit/hyperactivity disorder are more likely to be taking prescription drugs to combat their symptoms than their older peers. Furthermore, a recent report by the Centers for Disease Control and Prevention indicated that 15,000 children ages 2 and 3 years are being prescribed medications for ADHD, such as Ritalin or Adderall. It was found that it was much more likely for children living in poverty and receiving Medicaid to be prescribed drugs rather than alternative relationship-based treatments (such as parent-child interaction training or early intervention services) (Schwartz, 2014; Dell'Antonia, 2014). In most cases, the prescription of these stimulant medications and antidepressants for young children is considered "off label," which means they have not been studied on young children and there is no scientific data on the effects of these drugs on children's immediate or long-term behavioral and developmental outcomes (NSCDC, 2008b). Thus, until studies are conducted on the use and safety of these medications for young children, young children and their developing brains are at risk for unknown and unintended consequences (Schwartz, 2014).

To ensure young children get the support they need, it is imperative that their environmental contexts are considered when helping them through mental health issues. Offering young children a responsive and supportive environment is an important way to prevent mental health disorders and to promote healthy development. Many of the 
prevalent adult mental health disorders have origins in childhood; intervening in early childhood and creating environments that negate or counteract some of the risk factors experienced by children can change children's mental health trajectories (Campbell, 2014; Felliti et al., 1998; National Child Traumatic Stress Network, 2014). One important prevention method is to create schools that are aware and responsive to young children's mental health needs. The following section will discuss the role schools play in children's social-emotional development.

\section{Schools and Mental Health}

Teachers in early childhood education programs often do not have the skills or capacity to identify and handle children's mental health and behavioral challenges; which is indicated by the staggering rates of expulsion for young children attending early childhood education programs (NSCDC, 2008b; Hemmeter, et al., 2007; Gilliam, 2005). Nationally, 6.67 preschool aged children attending state-funded early childhood education programs are expelled per 1,000 enrolled; this rate is 3.2 times higher than the expulsion rate for students in public K-12 programs (Gilliam, 2005). In childcare programs, programs that are not state funded pre-kindergartens, the rate jumps to 27.4 expulsions per 1,000 enrolled (Gilliam, 2008). More than 10 percent of prekindergarten teachers expel at least one child per year, and of these teachers nearly 20 percent expel more than one child (Gilliam, 2005).

Furthermore, specific groups of children are being suspended or expelled, "pushed-out" of the early education environment, at higher rates than others. Black preschoolers are 3.6 times as likely to receive a suspension relative to their white peers. Black children make up only 19 percent of children enrolled in preschool, and yet they 
comprise 47 percent of children suspended one or more times (Gilliam, Maupin, Reyes, Accavitti, \& Shic, 2016b). Further, boys are expelled 4.5 times the rate of girls. These staggering disparities are in accordance with research connecting behavior to cultural norms, as well as research connecting boys' expression of mental health problems to externalizing behaviors and girls' expression of mental health problems to internalizing behaviors (Foster et al., 2005; Gilliam, 2005; National Alliance of Mental Illness [NAMI], 2007). Children are expelled at high rates due to schools' and educators' limited knowledge of how to work successfully with young children with challenging behaviors and their biased responses to culturally associated behaviors (Gilliam, 2005; Gilliam et al., 2016b; Walker-Dalhouse, 2005).

\section{Traditional Focus of Schools}

The research outlined above aligns with schools' traditional (and increasing) focus on academic preparedness (JCSH, 2010). Advancing children's social-emotional development has tended to be a secondary focus, if it is viewed as a focus at all (JCSH, 2010; Kauffman, 2004; Severson, et al., 2007). Schools typically screen students for academic difficulties to find them the appropriate resources to keep them enrolled in school, but screening for mental health issues is far less of a priority, is often not a common practice, and is often controversial (NAMI, 2007; Severson, et al., 2007). There seems to be a different threshold for when teachers view academic issues as severe enough to need intervention services and when social-emotional or behavioral issues are seen as needing intervention. This holds true even though seventy percent of children identified as having antisocial characteristics as teenagers were accurately classified by teacher and parent ratings of problem behaviors by age five (White, Moffitt, Earls, 
Robbins, \& Silva, 1990). Without a clear understanding of what constitutes typical and atypical behavior, and how children can be supported to learn new and different socialemotional skills, teachers are inadvertently missing opportunities to support young children's mental health.

However, figuring out how to successfully screen for mental health issues is a difficult task due to the bias that can and does occur when assessing for mental health issues (NAMI, 2007). The typical parameters used to identify current or potential mental health problems have been created and normed on dominant white culture, leaving people of color at a high risk of being misdiagnosed as having mental health issues or needing special education services (Skiba et al., 2006). Perceptions of which behaviors are developmentally appropriate, and which deserve intervention, are often based off of scientific research that uses a medical model of mental health that may not align with the worldviews or perspectives of differing racial, ethnic, and cultural groups. These differences in perceptions can create a mismatch between what teachers and other service providers expect from young children and what their families expect from their children, leading to young children receiving conflicting messages about what is acceptable and how they should behave (García Coll \& Magnuson, 2000). Teachers' misinterpretation of behaviors has led to the overrepresentation of children of color receiving special education services and mental health diagnoses. Rather than supporting young children, cultural misunderstandings and misinterpretations can exacerbate and fabricate mental health issues for specific groups of children (Skiba et al., 2006).

However, while some researchers (García Coll \& Magnuson, 2000; Skiba et al., 2006) argue that this mismatch between service providers and families can negatively 
influence the behavioral outcomes and mental health experiences of young children, there are other scholars (Kauffman, 1999; Merrell \& Walker, 2004) who insist that children are actually at a greater risk for mental health problems because prevention is impeded by service providers' and educators' fears of inadvertently discriminating against specific groups of children. According to these scholars, this fear of discrimination can in fact create bigger and more serious problems for children who need added support to be successful in school. As Kauffman explains (1999), "the gambits that stymie prevention are not mutually exclusive. In fact, they are often complementary. Like risk factors that are multiplicative rather than additive, they can become a witch's brew- individually not of great consequence, but combined a potent cocktail that easily wards off prevention" (p.452). Therefore, these scholars argue that all students should be screened for mental health issues so that they can receive the services they need. However, it is not simply mental health screening that can support the healthy development of children; it is also being involved with a supportive school environment with teachers and administrators who are highly trained and aware of the effects of mental health issues. Thus, it is imperative that we understand and know more about what teachers think, feel, and do when working with young children who experience mental health and challenging behaviors in the classroom as a means of learning how to best support them in teacher preparation programs.

\section{Inclusive Schools}

Although the rates of expulsion are high, and children are often not receiving the support they need, high-quality early childhood education can support children in overcoming their early mental health and behavioral challenges. Schools that support all 
children's needs can have a profound and positive influence on reducing emotional or behavioral problems as well as improving mental health and learning outcomes for children (NSCDC, 2008a; President's New Freedom Commission on Mental Health, 2003). In inclusive early childhood schools, children whose social-emotional development is behind their peers can have the opportunity to interact with their peers with the support of knowledgeable educators helping them learn to regulate their emotions and behaviors. In these inclusive programs, children who would qualify for early intervention can be identified and offered services (Brennan, et al., 2003).

Research has demonstrated that early identification and intervention can mitigate the negative effects of mental health problems and positively influence young children's learning and life success (NSCDC, 2008a; NCMHPYV, 2009; Severson, et al., 2007). Importantly, inclusion of children with mental health problems and challenging behavior is recognized as beneficial for all children, not just children experiencing difficulties. Children with social, emotional, and behavioral problems can learn from their typical peers, and children without these issues can learn the important skills necessary to be empathic as well as to value diversity and social differences (Brennan, et al., 2003; Odom, 2000; Shonkoff \& Phillips, 2000).

A defining characteristic of the programs that successfully support young children with mental health and behavioral challenges is that they see children within their social contexts and they work with their community resources. Teachers within these successfully inclusive programs understand children's social contexts; they are connected to the individual children, their families, and the community supports available to the families (Odom, \& Diamond, 1998; Odom, 2000). Further, the teachers are connected to 
each other and draw on each other for support (Brennan, et al., 2003). Rather than focusing on the individual pathology of the child, these programs consider and try to combat the role societal issues such as prejudice, stereotyping, familial socioeconomic resources, and employment or educational opportunities have on young children and their development (Swanson et al., 2003). They support the children through supporting the whole family. With this kind of inclusive model, children are less likely to be misdiagnosed as having a mental health problem due to cultural misunderstanding because teachers and families are working in partnership (Brennan, et al., 2003).

During a five-year research project, Models of Inclusion in Child Care, which was funded by the National Institute on Disability and Rehabilitation Research and the Center for Mental Health Services, Brennan, Ama, and Gordon (2002) found that teachers able to successfully support children with mental health and behavioral challenges in inclusive environments have four defining characteristics. First, teachers build strong relationships with individual children, giving them the ability to anticipate and support challenges. Second, teachers set up the environment and routines to encourage cooperation and selfregulation, creating an inclusive classroom space. Third, rather than solely focusing on the child experiencing challenges, inclusive teachers work to teach all children ways to respond to behaviors they do not like. This supports the children with challenging behaviors in stopping their behavior, and the typically developing children in learning how to advocate for their needs. Fourth, inclusive teachers offer mental health support (teaching children how to regulate, offering calming strategies, allowing space for all feelings) within their classrooms and curriculum. This study indicates that highly skilled inclusive teachers are able to support children with emotional and behavioral challenges. 
Although inclusive early childhood education programs can greatly improve the mental health and behavioral outcomes for the enrolled children, there are many barriers to truly inclusive programs. One of the primary barriers is the lack of training and knowledge of teachers working in early childhood education programs (Brennan, et al., 2003; Head Start Bulletin, 2009; Leatherman, 2007). Many teachers in early childhood programs do not have degrees in early childhood education or a related field (Bureau of Labor Statistics, 2018). The fact that teachers in the field do not have formal education or degrees is partially due to the fact that teachers working in early childhood education programs typically get paid less than those working in elementary, middle, or high schools, so those interested in teaching typically tend to work with older children. The training and qualifications required to be an early childhood education teacher are minimal, which leads to many educators being unqualified or under-qualified to work effectively with young children, let alone children who have mental health or behavioral challenges (Brennan, et al., 2003; Bureau of Labor Statistics, 2018). The majority of infant, toddler, and preschool programs in the United States do not require a teacher to hold a degree in early childhood education, and many States allow teachers to enter the profession with only a high school diploma. If teachers do have a degree in the field they are most likely to have an associate degree (Bureau of Labor Statistics, 2018). Further, the low pay and lack of training needed to work in early childhood education leads to high teacher turnover (Whitebook \& Sakai, 2003). It is estimated that 15-30 percent of those working in childcare leave the profession annually, which creates a new and unskilled workforce caring for society's youngest children every year (Brennan, et al., 2003; Whitebook \& Sakai, 2003; Whitebook, Phillips, \& Howes, 2014). 
Low pay, high teacher turnover, and inadequate training have critical implications for the inclusion of children with mental health and behavioral challenges. These barriers to consistency make it difficult for families and children to develop healthy attachments and relationships with early childhood educators, making the support of young children's mental health extremely difficult. For programs to be successfully inclusive, teachers must make a livable wage and also must see themselves as valuable educators who have the skills and knowledge to support all young children (Brennan, et al., 2003).

\section{Teacher Disposition}

Educators' dispositions must be considered when thinking about ways to create supportive classroom communities for children with mental health and behavioral challenges. While there are many different definitions of dispositions, and what constitutes important dispositions for teaching, there are some general commonalities found within different definitions of dispositions (Almerico, Johnston, Henriott \& Shapiro, 2011; Borko, Liston, \& Whitcomb, 2007; Schulte, Edwards, \& Edick, 2008; Schulte, Edick, Edwards, \& Mackiel, 2004; Taylor \& Wasicsko, 2000; The National Council for Accreditation of Teacher Education, 2001). According to Broadie, dispositions can be understood as "deeply rooted habits of thought and feelings" (as cited in Choi, Benson, and Shudak, 2016, p.73) or, as Choi, Benson, and Shudak (2016) explain, "dispositions are those internal conditions (attitudes, values, beliefs, thoughts, etc.) that influence our external behaviors (actions and interactions with students and others)" (p.72). Thus, for the purpose of this paper and research study, dispositions includes a person's internal states, such as thoughts, beliefs, values, feelings and emotions that go on to influence their behaviors. 
Research indicates that teachers' dispositions influence how they interact and relate to the children in their care, and ultimately what the children learn (Cummins \& Asempapa, 2013; Hong, 2010; National Council for Accreditation of Teacher Education, 2010; Stewart \& Davis, 2005). As Taylor and Wasicsko (2000) explain, "there is a significant body of research indicating that teachers' attitudes, values, and beliefs about students, about teaching, and about themselves, strongly influence the impact they will have on student learning and development" (p.2). Teachers' internal states influence their external behaviors. For example, it has been found that teachers' emotions, both their capacities to regulate their own emotional states as well as their emotional responses to the children in their classrooms, influence both children's learning and the teachers' efficacy and longevity in the educational field (Fried, 2011; Hong, 2007). As Jennings and Greenberg (2009) describe, "teachers influence their students not only by how and what they teach but also by how they relate, teach, and model social and emotional constructs, and manage the classroom" (p.499). Emotions are an important and continuous aspect of teaching and being a teacher and a significant piece of teacher dispositions. Teachers who have higher capacities to emotionally regulate are more likely to create environments that are conducive to learning (Fried, 2011; Jennings \& Greenberg, 2009).

Being emotionally regulated is just one piece of the pedagogical puzzle for effective teaching and more importantly one piece of effective dispositions for teaching. Research has found that educators must not only have the knowledge, but also believe they have the capacity to work with all learners in order to create fully inclusive and supportive early childhood education environments. Having the self-concept that they can 
work with all children and the value that they should work with all children is a predictor of program quality and student success. For example, a study analyzing 180 communitybased childcare centers in North Carolina found that a major predictor of overall program quality is teachers' beliefs that they have the knowledge and skills to handle any challenges that arise in their classrooms (Buysse, Wesley, Bryant, \& Gardner, 1999). Teachers' perceptions of their abilities to guide and influence their students' behavior directly influence children's classroom experiences. Teachers who believe they can positively influence children's behavior demonstrate more flexibility and use more creative guidance techniques than those who do not believe they can impact children's behaviors (Guzell-Roe \& Stringer, 2005).

However, although teacher disposition can positively influence students' behavior, the inverse is also true: teachers' personal dispositions can negatively influence their perceptions and relationships with children. Educators' negative and stereotypical views of children based on race, ethnicity, and socioeconomic status can hinder students' development and negatively affect the ways in which students see themselves as learners and as individuals (Delpit, 1995; Downey \& Pribesh, 2004; Gilliam, \& Shahar, 2006; Gilliam et al., 2016b; Hyland, 2010; Walker-Dalhouse, 2005). For example, even without notable differences in behavior, teachers often view children from families with lowincomes as having more disruptions and challenging behaviors than their peers and tend to discipline them more (Walker-Dalhouse, 2005). Furthermore, while poverty can be a risk factor for children of all ethnic and racial backgrounds, students of color also contend with racial stereotypes and negative beliefs held by teachers, particularly white teachers. A study by Walker-Dalhouse (2005) found that "teachers perceive that the 
behavior of African American males is more aggressive and severe than that of their white counterparts. African American males who misbehave in the same way as their white counterparts are more like to be punished" (p.24). Teachers' misperceptions of African American male students' behaviors leads to overrepresentation of African American students in the disciplinary system in schools and higher rates of suspension, expulsion, and special education referrals for students of color (Skiba et al., 2006).

Thus, due to the great influence teacher dispositions can have on young students, it is imperative that more is learned about teachers' dispositions and how teachers' internal conditions influence their views of their role and their students who express mental health and challenging behaviors in the classroom. A review of the literature surfaced limited research specifically addressing the dispositions of educators in an inservice early childhood teacher preparation program towards children with challenging behaviors and mental health issues. However, what has been elucidated in the literature is that often teachers feel unprepared and overwhelmed by the severe behavioral challenges they see in the classroom and do not see it as their role or responsibility to support children through extreme classroom behaviors. Teachers consistently state that receiving professional development around working successfully with children with challenging behaviors is of high priority (Hemmeter, et al., 2008). Thus, the literature is clear that more is needed to support educators in reaching and teaching all learners.

\section{Synthesis and Critique of the Research Literature}

The literature reviewed in this chapter offers an understanding of early childhood mental health, the historical and contemporary role of schools in supporting young children's social-emotional development, and the significance of teacher disposition on 
student outcomes. The review revealed that the importance of healthy early experiences has been widely recognized and accepted within the literature (Shonkoff \& Phillips, 2000). Furthermore, the literature indicates that the skills and dispositions of teachers in early childhood education programs can support or hinder young children's healthy social-emotional development (Cummins \& Asempapa, 2013). Yet, there is still very little research concerning early childhood mental health and challenging behaviors or about how teachers view young children experiencing challenges. Teacher preparation programs are designed to offer their students the professional knowledge, hands-on skills, and dispositions to support children's needs, and yet teachers are indicating that they do not have the necessary skills to meet all of their learners' needs (Hemmeter, et al., 2008). The literature reveals that schools and teachers lack the capacities to support all young children's healthy development, with little focus on the needs and questions of teachers themselves (Merrell \& Walker, 2004; Walker et al., 1998; Walker \& Golly, 1999).

With a subject as sensitive and misunderstood as mental health, it is imperative that we understand teachers' thinking about mental health and behaviors as a means of understanding what to teach. Thus, by exploring the knowledge and understanding of students in an in-service early childhood teacher preparation program the field can gain a better understanding of what teacher education students think and feel and do as a means of understanding what they want to - and need to - learn. It is my intention for this research to fill in part of this gap in contemporary research by describing how students in an in-service early childhood teacher education program think about, emotionally react to, and engage with children who express mental health issues and challenging behaviors 
in their classrooms as a way to understand how to better support both teachers and children.

Through observation, dialogue, artifacts, and written communication this study gathered rich data concerning what students in teacher education programs think, how they feel, and their methods of engagement with children who express mental health and behavioral challenges. Using a rigorous research design this study obtained data that can support teacher preparation programs in understanding how to better prepare their students in teacher preparation programs so that they are ready and able to support all learners (Blair, et al., 2010; NSCDC, 2008a; Shaw, Gilliom, Ingoldsby, 2003; Walker et

al., 1998; Walker \& Golly, 1999). The subsequent section of this chapter will describe the methodological literature that confirms the significance of using a qualitative case study design to explore this research question.

\section{Review of Methodological Literature}

Qualitative research is often used for discovery-oriented and rich descriptive studies focused on participant voice and experience (Maxwell, 2005). Given the study's exploration of how students in an in-service early childhood teacher education program think about, emotionally react to, and engage with children who express mental health issues and challenging behaviors in their classrooms, a qualitative approach was most fitting for my research. In this section I will briefly describe and defend the qualitative case-study design used in this study. Chapter three then offers a more detailed description of the specific methodology used throughout the study.

Qualitative research is preferred when a researcher both understands and values their role in both the collection and analysis of the data. As a researcher whose 
framework is rooted in $\mathrm{AOP}$ and $\mathrm{AOE}$, where acknowledging the positionality and influence of the researcher is key, the flexible nature of qualitative research worked well with the aforementioned research question. One of the strengths of qualitative research is the acknowledgement and transparency of the role and positionality of the researcher. Qualitative research allows for spontaneity and adaptation of questions and interactions between the researcher and the participants, leading to deep and rich understanding of both the individual and collective experiences of participants. At the end of this qualitative study I was left with powerful narratives to describe what I discovered rather than with numbers, as I would have with a quantitative study. Quantitative research, which typically involves predictions and the manipulation of different variables, did not seem appropriate for this study which sought to understand and know the individual people involved. Quantitative research, which certainly has an important role in research methodology, would not have captured the complexity of the participants' experiences and would not have allowed for the flexibility to gather the robust, descriptive data I needed to understand the phenomenon (Yin, 2014). The words of participants offer stories and images that give us a holistic view of the thoughts, feelings, and responses of the study's participants. For this study, that focused on the shaping of the relationships between teachers and children, a qualitative research design was able to share the authentic and meaningful words of the participants.

To gain a deeper understanding of students in an in-service teacher education program, I used a comparative or multiple-case design. Case study methodology focuses on a case or a "bounded system," that is "one among others" (Merriam, 2007, p.28). In this study, each case was defined as an individual student within the in-service teacher 
preparation program. Using a comparative case study design allowed me to study both the unique findings of individual cases, as well as compare themes and patterns among and between the cases.

Completing a qualitative case study enabled me to generate robust, descriptive data of the participants' experiences, within their real-world context (Yin, 2014). This rich data allowed me to focus my research on just a few participants, a small sample size, so the research could go deep and wide with each unit of analysis or in this case, each participating student in an in-service teacher education program. However, while this small sample size allowed for descriptive and rich understanding of each participant, it did not necessarily lend itself to wide concrete generalizations about the population of students in in-service teacher education programs as a whole. Yet, this does not mean the insights learned from this research cannot and will not be generalized in some ways. As Flyvberg (2006) explains,

Formal generalization is only one of many ways by which people gain and accumulate knowledge. That knowledge cannot be formally generalized does not mean that it cannot enter into the collective process of knowledge accumulation in a given field or in a society...formal generalization is overvalued as a source of scientific development, whereas 'the force of one example' is underestimated (p.228-230).

Thus, while there are some limitations surrounding the generalizability of my study, the benefits of "one example", and in this instance multiple examples compared to each other, outweighed this limitation (Flyvberg, 2006, p.230). 
All research has limitations. Along with the limitations around potential researcher bias and generalizability, comparative case study design can have other limitations as well, such as: 1) the time and money such in-depth descriptive data gathering can require; 2 ) the length of the rich narrative reports may be challenging to get stakeholders outside of academia (such as policy makers or educators) to read; and 3) the report may be perceived as lacking rigor because it does not involve large samples and numerical outcomes such as quantitative research (Flyvberg, 2006; Merriam, 2009; Yin, 2014). However, none of these possible limitations stop the case study design from being a valuable and necessary method of research for heuristic research questions such as the one used in this study. Chapter five goes into more detail about the limitations of qualitative design and my research design specifically, including the demographics of the participants and their self-selection process.

\section{Summary}

Chapter two offered a review of the literature describing the origins and expressions of young children's mental health, the position of schools to affect children's social-emotional development, how teacher disposition influences children's academic and life trajectories, as well as the methodological advantages of using a qualitative case study design. Based on this research, it can be presumed that the choices teachers make with their students can play an important factor in children's social-emotional development and academic outcomes over time. Yet, there is little research studying what teachers believe and how they emotionally respond to and engage with children in their classrooms who express mental health issues and challenging behaviors. 
Calling on the aforementioned literature to inform the development of the research question, the research methods used to conduct the study, as well as the analysis of the results, this research study looked at how students in an in-service early childhood teacher education program think about, emotionally react to, and engage with children who express mental health issues and challenging behaviors in their classrooms. Chapter three elucidates the details of the research design and methodology used to complete this study. 


\section{Chapter Three: Research Design and Methodology}

\section{Introduction to the Research Design and Methodology}

Research demonstrates that teachers can greatly influence children's mental health and behavioral outcomes, however educators often do not feel adequately prepared to handle the mental health and behavioral needs of the children in their classrooms (Hemmeter, et al., 2008; NSCDC, 2008a; President's New Freedom Commission on Mental Health, 2003). Therefore, I believe it is valuable to study teachers' thoughts, feelings, and responses to mental and behavioral health issues in their classrooms to work towards creating a teaching community full of competent and effective educators. The purpose of this study was to describe and explain how students in an in-service early childhood teacher education program think about, emotionally react to, and engage with children who express mental health issues and challenging behaviors in their classrooms. This chapter outlines the connection between the chosen anti-oppressive framework, the research question, and case study methodology. The research methods are discussed including the setting, research participants, and procedures for data collection and analysis.

\section{Researcher Position within the Anti-Oppressive Framework}

At its core the anti-oppressive framework is rooted in the belief that all interactions are subjective. What one knows and what one sees as reality are not objective or absolute; instead, they are varied based on individual experiences and social contexts (Guba \& Lincoln, 2005; Hofer, 2004; Strier, 2006). Worldviews are not shaped outside of social and cultural contexts, because it is the context that influences one's experience through both discourse and actions, changing the ways one knows and sees reality. The 
purpose of working within an anti-oppressive research framework is to address and illuminate the research participants' complicated and intersected experiences (Strier, 2006).

An anti-oppressive framework calls for qualitative, interpretive methods that allow for subjective voice and a deep understanding of both individualized and collective experiences (Strier, 2006). Butler and Drakeford (2000) explain that anti-oppressive researchers reject positivistic methodologies that "reduce research into mere technical evaluation and replaces intellectual and creative efforts with rules and regulations" (as cited in Strier, 2006, p. 5). Rather, they advocate for and use methodologies that call for the interpretation and reflection of the voices and experiences of those being studied.

Using an anti-oppressive lens, this research has the goal of reflecting and interpreting the experiences of the participants (Dominelli, 2002; Larson, 2008; Massaquoi, 2017; Strier, 2006; Takacs, 2002; Takacs, 2003). Teachers who are within an in-service early childhood teacher education program have unique perspectives on the origin and manifestations of early childhood mental health and challenging behaviors based on their personal and social experiences as well as what they have learned through formal education. By asking how teachers think about, emotionally react to, and engage with children who express mental health issues and challenging behaviors in their classrooms I sought to understand and share their beliefs, feelings, and responses to the world based on their lived experiences. To reach this goal I used a case study methodology, which is outlined below. 


\section{Research Question}

\section{Research Design}

To fully understand the thoughts, feelings, and actions of students within an inservice early childhood teacher education program concerning the different aspects of young children's mental health and behavioral challenges, I researched the following question: How do students in an in-service early childhood teacher education program think about, emotionally react to, and engage with children who express mental health issues and challenging behaviors in their classrooms?

\section{Case Study}

To answer my research question I completed a qualitative study. I used a comparative or multiple-case design (Creswell, 2009; Merriam, 2009; Yin, 2009). With a comparative case study my unit of analysis, or case, was defined as each individual student in the in-service early childhood teacher education program who participated in the study. Using an anti-oppressive framework with a multiple case design allowed for the illumination of the voices of the individual participants. The multiple-case research design shares the perspectives of the distinct cases while also allowing for a cross case analysis that highlights themes among and between cases (Creswell, 2009; Merriam, 2009; Yin, 2009). The multiple-case design produced rich data that I have used to describe the unique experiences and beliefs of the students within the in-service early childhood teacher education program as they work with children with mental health and behavioral challenges in their classrooms.

The purpose of using a case study design is to contribute to and expand the current research about early childhood mental health and teacher education by using a 
methodology that allows for participant voice and experience. The case study method allowed me to gather rich, descriptive data that was used to examine and reflect the ways in which students in an in-service early childhood teacher education program think about, emotionally react to, and engage with children who express mental health issues and challenging behaviors in their classrooms. Further, a case study was a reasonable method to use for my research question since the question itself asks "how;" which calls for an interpretive and reflective methodology that uncovers the beliefs and ways of knowing of the individual students.

This study relied on inductive reasoning; moving from a set of specific premises to general conclusions (Creswell, 2009). From the data I gathered about students' individual experiences and beliefs concerning young children's mental health and behavioral challenges I came to generalizations about their experiences and learning needs as students within an in-service early childhood teacher education program.

\section{Setting of the Study and Participants}

The setting for this proposed research was Tallsee University (TU) (a pseudonym), a large public university located in a midsized city in the Northwestern area of the United States. Specifically, the study took place within the university's Graduate School of Education, which offers master's degrees in both counseling education and teaching. The Graduate School of Education has several different counseling education and teacher education programs, with one master's degree that specifically focuses on inclusive early childhood education, which will be referred to as the M-ECE program throughout this paper. The M-ECE program is a fully online master's degree program, however many students live and work in the areas surrounding the university. 
This research focused on four participants who were enrolled and active in this master's degree program. To find the participants I sent emails with flyers attached to the M-ECE listserv as well as to the professors actively teaching courses to M-ECE students. I began distributing emails and flyers in September 2017 and sent my last request for participants in January 2018. In total I sent out 23 emails to professors and the listserv requesting participants. I also sent 16 individual emails with flyers attached to directors of mid- to large-sized early childhood education programs in the metro area surrounding Tallsee University. I asked the directors to post the flyers in their staff room and/or to allow me to come in to speak to their staff about my study. Of the 16 directors I sent emails to, I only received a response from one, the director of the early childhood education program attached to Tallsee University.

From the emails to the professors, listserv, and directors I received 14 inquiries from potential participants. However, of the 14 participants only 4 met the requirements of the study, including: being actively enrolled in the M-ECE master's program, currently teaching in a classroom with children between the ages of birth to six years old, having two or more years of teaching experience in the classroom, and working within driving distance of the researcher so that observations and interviews could be completed. The participants included in this study had varying backgrounds and experiences, to ensure I gathered enough data to generalize themes across cases, while also noting the individual experiences of participants. The participants themselves will be discussed in detail in chapter four, and in chapter five there is a discussion of how who they are, their positionalities, influence the research findings. 
To ensure each participant felt comfortable participating in the study I conducted a short phone or email conversation with each of them before beginning my data collection to explain the purpose of the study, to answer any questions they may have had, and to explain the letter of informed consent (see Appendix A) which described the purpose of the study, the potential risks, and the expectations of the participants. The letter confirmed that participation in the study was voluntary and that withdrawal could happen without repercussion. My contact information was present on the Letter of Informed Consent and all other materials about the study so that potential participants could ask follow-up questions. While the study was originally intended to have 5-7 participants, after beginning the data gathering process I deemed 4 cases sufficient based on the breadth and depth of data I was gathering.

\section{Data Collection Procedures}

To ensure I received a comprehensive picture of the thoughts and experiences of students in an in-service early childhood teacher education program, I selected several distinct data collection methods. These data collection strategies were each chosen because they offer opportunity for participant voice and experience, while simultaneously being effective ways to address my research question. The following data collection procedures were used: interviews, artifacts, observation, and email prompts.

Triangulating my data using a variety of data collection procedures improved credibility; and using multiple data collection methods offered rich and descriptive views of the cases while simultaneously reducing the possibility of bias within my research (Krathwohl, 2009; Maxwell, 2005). 
I completed the interviews, observations, artifact collection and email prompts within a strategic order so that they could build on each other, and so I could ask questions based on my observations and also frame my observations based on what I heard and read from participants (Krathwohl, 2009). The artifacts were given to me during the interviews so that they could be discussed face-to-face. The expected order of my interviews/artifact collection, observations, and email prompts is outlined in the following table:

\section{Data Collection Procedure(s) Completed:}

1) Observation \#1

2) Interview \#1

3) Artifact collection

4) Observation $\# 2$

5) Email prompt \#1

6) Interview \#2

7) Artifact collection

8) Observation \#3

9) Email prompt $\# 2$

Table 1: Order of Data Collection

Although this was the expected order, there were a few participants who took longer to respond to the email prompts; the specific data collection timeline for each participant is outlined in Appendix B. I collected data between March 2017 to February 2018.

Completing the data collection took a varying length for each participant ranging from 6 weeks to 11 months. The length of time it took to complete the data collection for each participant was influenced by participant and researcher availability and the participants' proximity to Tallsee University. The data collection procedures as well as the instruments and measures used are described in detail below. 


\section{Interviews}

To understand how teachers in an in-service early childhood teacher education program experience and think about the expression of young children's mental health issues and challenging behaviors in the classroom I completed two one-on-one interviews with each participant during the study. The intention of the interviews was to create a space for participants to take a deeper look at their thoughts and feelings about their experiences with young children and to begin to articulate their underlying belief structure about early childhood mental health and behavioral challenges (Kvale, 1996). As Kvale (2006) describes, "in qualitative interviews, social scientists investigate varieties of human experience. They attempt to understand the world from the subjects' point of view and to unfold the meaning of their lived world" (p. 481). Rubin and Rubin (1995) describe the interview process as "the art of hearing data" (p.1). Qualitative interviewing becomes "a way of finding out what others feel and think about their worlds" (Rubin \& Rubin, 1995, p. 1). The interviews offered time and space for participants to articulate their beliefs and thoughts about where mental health and behavioral challenges come from and how they should best be handled in the early childhood education classroom.

The interviews used an Interview Protocol (see Appendix C) that asked general questions about participants' thoughts and feelings about young children's mental health and behavioral experiences. Further, within the interviews I asked questions based on what I saw and experienced during my observations and from what participants wrote in the email prompts; I asked participants to clarify or explain why or how they reacted to 
specific incidents in their classroom, and to articulate triumphs or challenges they were having with the children in their care.

The first interview primarily focused on the participants' thoughts about children who express mental health issues and challenging behaviors in their classrooms. Questions such as, where do you think young children's mental health issues come from? And how do you think teachers should respond to children's challenging behaviors?, were asked.

The second interview built off what was said in the first interview by asking participants to articulate their emotional reactions to young children's expression of mental health and behavioral challenges. I asked participants to describe how they felt when a student displayed specific behaviors during my observations and/or to articulate their typical emotional reactions to children's behaviors. During this second interview I also asked participants to describe how they usually engage with children when they have challenging behaviors. Further, because teachers work within the context of a school environment with families, students, administrators, and often co-teachers, I asked questions to understand whether participants engaged in similar or dissimilar ways to their colleagues and the families they were working with. I asked questions such as: does your co-teacher respond to his/her behavior in the same way? Do the values of your administration align with yours in terms of how you believe these children's behaviors should be handled? Do the families you work with handle guidance issues in the same ways that you do? By asking these questions I intended to reach a deeper understanding of the individual's experience within the larger context of their school and work community. 
Interviews were done in a location and at a time chosen by participants to ensure they felt safe, comfortable, and could manage the time commitment within their schedules. One interview was conducted via Skype, because of distance and time constraints, however because there was face to face video I do not believe this compromised the quality of the interview at all. Each interview lasted between 45-65 minutes. All interviews were voice-recorded so that I could fully engage with the participant rather than needing to focus on taking notes throughout the interview. After each interview I created an Interview Cover Sheet (see Appendix D), listing pertinent information such as the: date, time, and location of the interview as well as the interviewee's pseudonym. I then wrote down my initial thoughts and questions about the interview so that I could have a record of my thinking throughout the interview process. An electronic copy of the Interview Cover Sheet was stored with the interview transcription once it was finished. I transcribed the interviews verbatim for my use. I was the only one with access to the voice-recordings. Each voice-recording, along with the Interview Cover Sheet and transcription were saved as individual electronic files on my locked computer as well as uploaded and automatically backed-up to the secure cloud. Each document was given a coded name to help with organization and to ensure the confidentiality of my participants. The interviews will remain on my locked computer and in the secure cloud until the appropriate wait time has passed (three years) and then they will be destroyed.

\section{Artifacts}

Participants were asked to bring relevant artifacts to the interviews, such as classroom or school policies, classroom curricula, email exchanges with administrators or 
families, photographs or videos. What was deemed relevant was determined by each participant; they each brought artifacts that represented some aspect of their classroom that connected to the ways they approached and dealt with mental health and challenging behaviors. These artifacts offered interviewees another way to assess their beliefs and values and reactions to young children's mental health issues and challenging behaviors in the classroom. The process also intended to initiate very relevant and genuine conversations about specific issues from their current classroom experiences.

These artifacts were also used as sources of data for my research. To ensure I was promptly and systematically recording the artifacts I completed an Artifact Cover Sheet the day I received the artifact (see appendix E) and then promptly filed the artifact and cover sheet into a locked filing cabinet. The Artifact Cover Sheet allowed for significant information about the artifact to be recorded right away, including: the date and time it was received, the participant (pseudonym) who shared it with me, a description of the artifact, and the significance of the artifact for the participant as well as any significance I noted for my research.

\section{Nonparticipant Observations}

I also completed three nonparticipant observations, each two hours in length, of the participants in their classrooms and schools. Nonparticipant observation is a data collection method in which I, the researcher, observes within a natural setting (Maxwell, 2005). Because a case study design is intended to happen within an authentic context, these direct observations gave me an opportunity to gather data within a social system: the participants' work environments (Krathwohl, 2009; Maxwell, 2005). These observations gave me a chance to compare what they did to what they said in the 
interviews, and then to dig deeper in subsequent interviews and email prompts to ask them questions about what I noticed. Having this added data increased my understanding of the participants' thoughts and feelings concerning young children's mental health and behavioral challenges.

The purpose of the observations was to gather data about how participants emotionally reacted to and engaged with students who expressed mental health issues or challenging behaviors in their classrooms. As Phillippi \& Lauderdale (2018) explain, "Prior to beginning the study, the researcher should plan an approach to field note collection that is congruent with the theoretical framework and the methodological approach. The theoretical framework and methodological approach help to define the nature of knowledge, which directs the line of inquiry and the value placed on different sources of information" (p.383). Thus, as I conducted my observations and completed my fieldnotes my theoretical framework rooted in AOP and AOE was at the forefront of my mind. To create consistency across cases, I completed my observations using an Observation Procedure Sheet (see Appendix F), which was a template for my field notes, this template offered space for direct observation as well as space for my interpretations and personal reflections. Because when using an $\mathrm{AOP}$ and $\mathrm{AOE}$ framework no observations are viewed as neutral, of course, all of my fieldnotes were in some ways influenced by who I am and my positionality.

On the Observation Procedure Sheet I recorded the participant I observed, the time and place of the observation, and the activities I watched. During my observations I took descriptive field notes, focusing on the participants' interactions (or lack of interactions) with their students and colleagues, as well as the interactions between the 
students. I also noted the teachers' pedagogical choices and the guidance techniques used. I took particular care to notice participants' body language, tone of voice, and general demeanor as they worked with their students (Phillippi \& Lauderdale, 2018).

To ensure that I was not interrupting the classroom's day I tried to remain as unobtrusive as possible. I asked each participant beforehand how and when they would like to introduce me to the families and children. One teacher chose to send out an email to the families explaining that I was coming to complete observations for my doctoral research, and the other participants chose to explain my presence to the families only if they asked, which they did not. To the children participants described me as a "friend coming to observe" or someone "coming to learn about our classroom." In whatever way I was introduced in the space, I tried to reflect back the language that was used to show my respect for the classroom teacher. I had anticipated that while observing the children would want to speak to me and ask me questions, and that was true. To try not to intrude or interrupt the classroom's flow, I tried to remain as quiet as possible without interrupting their work. I smiled at the children when they showed me toys or drawing, and minimally responding to the children's requests for conversation while trying to be respectful. My hope was for the children to recognize that I was friendly and not a scary person, but also not that interesting so that they could return to their typical classroom activities. However, I of course cannot assess what true impact my very presence had on the children, or the participants.

Through these nonparticipant observations I was able to witness how participants responded to their students' behaviors. I was able to note situations, such as moments when a student spoke out during a read-aloud or hit a peer that elicited, or did not elicit, 
responses from the participants. I took descriptive observational notes of their responses that demonstrated both positive feelings (such as smiling, laughing, or nodding) and responses that demonstrated negative feelings (such as heavy sighing, brow furrowing, or yelling,). For example, if a child repeatedly hit another child and the participant raised her voice, I would note the louder voice in my description of the observation and would write my interpretation of the moment in my notes. As I observed, I also noted times when participants did not seem to have an emotional response and rather appeared to respond without feeling or ignored the issue. For example, if a child was playing alone during a group time and a teacher continued his or her current activity without getting involved, I noted this instance. Situations such as this were then used to determine some of the questions I asked during the interviews and the email prompts. For example, I asked questions such as: do you remember what you were feeling during that moment? Why do you think the child was not joining the group activity? Can you describe to me why you chose to respond the way you did?

In almost all of the observations, at least some form of behavior that could be deemed challenging was noticed, however, during the observations where very few big behaviors occurred, this too was noted. During the interview I was able to ask if the challenges I saw in the classroom were typical, or if there were usually more or less challenging behaviors, and if there were more challenging behaviors than what I witnessed what they looked like. Through these observations and this line of questioning during the interviews I was able to gather more information about the teacher and their work environment. For example, I was able to ask questions to learn whether participants had ever worked with children whose behaviors they could not successfully handle in 
their classroom and what they did. I also was able to learn if children with challenges were typically expelled from their school when challenges happened or if there was a heavy interview process before admission, which filtered out children who may have needed more specialized support. Asking questions about their past experiences allowed me to explore the participants' beliefs and reactions to mental health issues and challenging behaviors even when they did not happen often during my observations.

The observations, coupled with the follow up interviews and email prompts, offered some understanding of the participants' emotional reactions and explained why they engaged with their students in the ways that they did. After each observation I catalogued the field notes and kept them under lock and key except for the time when they were in immediate use as I coded and analyzed my data.

\section{Email Prompts}

To gain a deeper understanding of how participants think about, emotionally react to, and engage with children who express mental health issues and challenging behaviors in their classrooms I used email prompts as a data collection strategy. Using both interviews and email prompts as data collection procedures was intended to accommodate the diverse communication styles of the participants. People often feel they communicate better when either speaking or writing, and by conducting both interviews and email prompts I hoped participants felt they were able to express their thoughts and feelings effectively.

Participants were asked to respond to two email prompts throughout the study. The participants were reminded that the email prompts were voluntary and were asked to spend 10 to 20 minutes on each one. The email prompts each had two baseline questions 
(see Appendix G) that I asked of all participants. During the first email prompt I asked: 1) What does "challenging behavior" mean to you? And 2) What are the most important social-emotional skills for young children to learn? These questions intended to gain a deeper understanding of participants' beliefs concerning behavior and mental health. During the second email prompt, which came at the very end of the study, participants were asked to reflect back on their experience thinking and talking about young children's needs throughout the study. This second email prompt asked: 1) We have now had many different conversations (through interview, artifact description, and email) about young children's behavioral and mental health needs, is there anything else you would like me to know about your thoughts or feelings related to this issue? And 2) After thinking so deeply about young children's mental health and behavioral challenges, are you left with any big questions about young children's behavioral and mental health issues?

Along with these questions I asked all participants, I also asked one or two questions that I wrote specifically for each participant based on their individual observations and interviews. This ensured that I received responses that directly related to my research question and the individual experiences of participants.

Because the participants were all active students in an online master's program, they all had access to an email account and computer, however, in case participants found email to be a difficult way of communicating, I also offered them the opportunity to handwrite their responses to the prompts; all participants chose to use the computer to respond to the prompts. Once I receive their responses I read and filed them into individual electronic files on my locked computer and backed-up the files to the secure 
cloud.

\section{Data Analysis Procedures}

This study intended to illuminate how students in an in-service early childhood teacher education program think about, emotionally react to, and engage with young children experiencing mental health and behavioral challenges in their classrooms. To reach this goal I collected and analyzed my data simultaneously so that my data collection procedures (the questions I ask during interviews; email prompts; etc.) were informed by the data and my interpretations as they were gathered (Krathwohl, 2009; Saldaña, 2009).

\section{Analytic Memos}

Throughout my analysis and the coding process, which is outlined below, I completed analytic memos, which are similar to research journal entries, where I wrote down my thoughts and ideas about my data (Saldaña, 2009). The purpose of completing analytic memos during my data analysis was to ensure that I was reflecting on the research process. This gave me space to think critically about my role as a researcher and how my assumptions, thoughts, and beliefs influenced my research techniques and focus (Merriam, 2009; Saldaña, 2009). This helped me continually think about and recognize that all analysis is subjective and that I was bring my personal experience and theoretical lens to the coding and analyzing processes.

Throughout the data analysis I used the margins of transcripts, observational field notes, and artifacts to record my own thoughts, reflections, and notes about the data. This allowed me to be actively thinking about and engaging with the data throughout the study (Merriam, 2009). 


\section{First Cycle Coding}

I grounded my analysis of my findings in my anti-oppressive framework; my goal was to bring the voices and experiences of participants alive as a means of creating rich descriptive data that can be used to instigate change. To analyze my findings I used specific coding methods which were rooted in uncovering and illuminating the voices of my participants. My coding scheme was directly connected to my research; how and what I coded was dependent on my research question and the participants themselves. While my primary goal was to highlight the participants themselves, the act of coding is in and of itself an interpretive task, where I, as the researcher determined what and how to code the data I had. Using an anti-oppressive framework calls on me as the research to acknowledge the influence I have on the research itself and the findings of the study. As Saldaña (2009) explains, "the act of coding requires that you wear your researcher's analytic lens. But how you perceive and interpret what is happening in the data depends on what type of filter covers that lens" (p. 6). My positionality and the influence of who I am on my research design and execution is outlined in detail in chapter five.

To explore my research question I chose coding methods that intended to uncover and share the thoughts and feelings of the participants. I used three primary coding methods during my first cycle of coding, all of which were intended to share who my participants are and allow their voices to be at the forefront of the research findings. I used the following coding methods: Values Coding, In Vivo Coding, and Emotion Coding. Values coding allows a researcher to look for and create codes that capture the values, attitudes, and beliefs of the research participants. In Vivo Coding captures the actual words and language used by participants. And Emotion Coding creates codes that 
capture the participants' feelings and views of the world. These coding methods, and how I used them in my research, are described below (Saldaña, 2009).

Values coding. I used Values Coding to elucidate the values, attitudes, and beliefs of the research participants. Values Coding was particularly useful for my research since I conducted both interviews and observations of participants. Using Values Coding I was able to compare and contrast what a participant stated her values, attitudes, and beliefs were during interviews with what I saw through her actions or interactions during the observations (Saldaña, 2009). Saldaña (2009) asserts that Values Coding requires that a researcher have a clear "paradigm, perspective, and positionality" since the research data can be coded "any number of ways depending on the researcher's own systems of values, attitudes, and beliefs" (p.93). My anti-oppressive theoretical lens and my personal values and beliefs about children with challenging behaviors and mental health issues of course influenced the codes I chose. For example, using values coding I coded the following interview statement as follows:

\begin{tabular}{|l|l|}
\hline Statement & Code \\
\hline $\begin{array}{l}\text { Example 1: } \\
\text { Most of the kids that were frustrating } \\
\text { me were the good kids you know, who } \\
\text { always follow directions and did what } \\
\text { they were supposed to do and had a } \\
\text { good time at school }\end{array}$ & ONLY SOME ARE GOOD \\
\hline $\begin{array}{l}\text { Example 2: } \\
\text { Because the children I know that really } \\
\text { struggle with mental health issues, their } \\
\text { parents clearly struggle with that as } \\
\text { well, just in the way that they come in } \\
\text { each night to pick them up can be so } \\
\text { different, their energy and their mood } \\
\text { and the way that they interact with their } \\
\text { child in that first moment can be so } \\
\text { different. }\end{array}$ & \\
\hline
\end{tabular}




\begin{tabular}{|l|l|}
\hline Example 3: & CHILDREN ARE IMPORTANT \\
And that because every young child & CHI \\
needs to know their important and some & \\
people and some parents aren't able to & \\
do that, and I know about that and so I & \\
think that that's a really important role & \\
of an early childhood educator. & \\
\hline
\end{tabular}

Table 2: Values Coding

While my intent within an anti-oppressive framework is always to elucidate who my participants are, it is impossible to ignore how my positionality and personal beliefs influence which sections of the research I coded, the ways I viewed the statements I chose to code, and the codes themselves I used in my research.

In Vivo Coding. During the coding process I also used In Vivo Coding. In Vivo Coding uses participants' words to create codes to keep the data rooted in the participants' language and experiences (Saldaña, 2009). This brings who the participants are to the forefront of the coding process, allowing their lived experiences to dominate the codes. For example, here are the codes using In Vivo coding for the same interview statement from above:

\begin{tabular}{|c|c|}
\hline Statement & Code \\
\hline $\begin{array}{l}\text { Example 1: } \\
\text { Most of the kids that were frustrating } \\
\text { me were the good kids you know, who } \\
\text { always follow directions and did what } \\
\text { they were supposed to do and had a } \\
\text { good time at school }\end{array}$ & $\begin{array}{l}\text { GOOD KIDS } \\
\text { SUPPOSED TO DO }\end{array}$ \\
\hline $\begin{array}{l}\text { Example 2: } \\
\text { Because the children I know that really } \\
\text { struggle with mental health issues, their } \\
\text { parents clearly struggle with that as } \\
\text { well, just in the way that they come in } \\
\text { each night to pick them up can be so } \\
\text { different, their energy and their mood } \\
\text { and the way that they interact with their } \\
\text { child in that first moment can be so }\end{array}$ & $\begin{array}{l}\text { PARENTS CLEARLY } \\
\text { STRUGGLE }\end{array}$ \\
\hline
\end{tabular}




\begin{tabular}{|l|l|}
\hline different. & \\
\hline Example 3: & \\
And that because every young child & \\
needs to know their important and some & SOME PARENTS AREN'T \\
people and some parents aren't able to \\
do that, and I know about that and so I \\
think that that's a really important role \\
of an early childhood educator.
\end{tabular}

Table 3: In Vivo Coding

I then used the code good kids whenever the participant discussed children who were able to meet the expected or desired behaviors in the classroom.

Emotion Coding. After I completed my initial round of coding I went back to complete Emotion Coding. As Saldaña (2009) explains, Emotion Coding is appropriate for those studies that "explore intrapersonal and interpersonal participant experiences and actions" (p.86). I used emotion coding to allow me to delve deeper into the participants' feelings, perspectives and worldviews. My intention was to capture a more vulnerable aspect of who they are as people, and as teachers. Here are the emotion codes on the same statement as above:

\begin{tabular}{|l|l|}
\hline Statement & Code \\
\hline Example 1: & FRUSTRATION \\
Most of the kids that were frustrating \\
me were the good kids you know, who \\
always follow directions and did what \\
they were supposed to do and had a \\
good time at school
\end{tabular}




\begin{tabular}{|l|l|}
\hline different. & \\
\hline $\begin{array}{l}\text { Example 3: } \\
\text { And that because every young child } \\
\text { needs to know their important and some } \\
\text { people and some parents aren't able to } \\
\text { do that, and I know about that and so I } \\
\text { think that that's a really important role } \\
\text { of an early childhood educator. }\end{array}$ & DISAPPOINTMENT \\
\hline
\end{tabular}

Table 4: Emotion Coding

Using emotions coding allowed me to look for the feelings in participants' statements to get a better understanding of how their emotions impact their actions and their worldviews.

\section{Second Cycle Coding}

After this process of values, in vivo, and emotion coding, I completed a second cycle coding to reorganize and reanalyze my data as well as to analyze the relationship between the codes I had developed. This second-cycle coding pushed me deeper into my analytic work with the data. In this second cycle coding process I used what Saldaña (2009) calls Focused Coding. Focused Coding required that as the researcher I looked for the codes that seemed most important, or those that appeared most often, to create categories. This second cycle coding gave me the reflection time to ensure that my codes were using the most accurate words or phrases, it also allowed me time to combine codes where needed and assess the utility of some of my infrequent codes. From this second cycle coding process I evaluated my codes, made appropriate adjustments, and combined codes into categories (Krathwohl, 2009; Merriam, 2009; Saldaña, 2009). For example, from the codes: "home life," "parenting," and "early experiences" as well as others I 
created the category "home environment." Through the multiple codes I gathered I was able to create categories that defined the overarching ideas that appeared in the codes.

\section{Data Analysis}

My qualitative multiple-case design allowed me to analyze my cases both individually and collectively. First, I was able to look at each case as a single unit, looking at the ways each participant thinks about, emotionally reacts to, and engages with children who experience mental health issues and challenging behaviors in their classrooms. Second, I was able to look across and between cases to explore broad themes that emerged (Creswell, 2009; Merriam, 2009; Yin, 2009).

To attempt to ensure I received authentic data, I used several data collection methods. By triangulating my data collection methods and offering numerous ways for participants to share their thoughts, beliefs, and experiences I tried to get to know each participant individually and thus hopefully build an authentic relationship with each person. Additionally, using multiple data collection methods allowed me to compare and contrast participants' responses across data gathering instruments in order to view the findings from multiple angles. I reviewed the data as it was collected and transcribed the interviews right after they happened. This constant and consistent connection to the data allowed me the chance to reflect on the data collection process as it happened and guided my choices as I approached subsequent interviews and observations.

By using the different data collection and coding methods outlined above, I was able to look at the cases on their own and as a whole to create a descriptive and detailed report that offers a unique look at individuals in an in-service teacher education program 
working with children who express mental health issues and challenging behaviors in the classroom.

\section{Summary}

This use of qualitative comparative case study methodology for this research was most fitting because my research question was attempting to capture the voices and experiences of students in an in-service early childhood teacher education program. Using interviews, artifacts, observation, and email prompts this study generated rich data that was then coded using multiple coding methods to capture the thoughts, feelings, and responses of the research participants. The comparative case study design allowed for holistic descriptions of the individual participants as well as cross-case synthesis. The findings, including the themes and subthemes that emerged from the research, are outlined in the following chapter. Chapter five then synthesizes the findings before offering implications for practice, discussing in detail the limitations of the study, and making suggestions for future research. 


\section{Chapter Four: Findings}

\section{Introduction to the Findings}

This qualitative study examined how students in an in-service early childhood teacher education program think about, emotionally react to, and engage with children who express mental health issues and challenging behaviors in their classrooms. To complete this research multiple data collection procedures were used, including: interviews, artifacts, observation, and email prompts. The results were produced using multiple coding methods to capture the beliefs, feelings, and actions of the research participants.

\section{Analysis of Findings}

I solicited the participation of four early childhood education teachers who were actively pursuing a master's degree in early childhood education. I conducted in-depth interviews, artifact collections, observations, and email prompts with each of them. Each participant was on her own timeline based on individual scheduling and needs; however, my data collection as a whole took thirteen months. Based on the logistics and experiences with each participant, the length of time it took to complete the different research tasks varied greatly between participants (please see Appendix B for the timeline of data collection for each participant).

As noted in chapter three, using multiple data collection methods allowed me to triangulate my data and offer a rich and descriptive view of the phenomenon (Krathwohl, 2009; Maxwell, 2005). Each data collection method was completed in a specific order and I collected and analyzed my data simultaneously so that the experiences from each could inform what came next. By framing my interviews based on what I observed, and 
observing based on what I saw and read from participants, I was able to reflect and inform my data collection as the process unfolded (Krathwohl, 2009).

In addition to the data collection methods mentioned above, I also completed analytic memos where I reflected on my thoughts and ideas about the data being collected (Saldaña, 2009). This ensured that I was actively reflecting on the research process as it occurred. Further, I transcribed each interview myself, which proved to be a wonderful way to gain deeper awareness and familiarity with the data.

Throughout the data analysis process I read the interviews, observations, and email prompts multiple times, while also writing and reviewing my notes and analytic memos. The coding process was completed by assigning codes to phrases and paragraphs in the data. Rooted in my anti-oppressive framework, I used coding methods that revealed the thoughts, feelings, and responses of participants. To get to the heart of my research question I used first and second cycle coding methods that allowed for and celebrated the voices and experiences of participants. During my first cycle coding I used three different coding methods: Values Coding, In Vivo Coding, and Emotion Coding. After this process, I completed Focused coding as a second cycle coding method, which pushed me farther into my analytic work with the data and required me to find the codes that seemed most important, or those that appeared most often. My codes were refined and reorganized multiple times as I continuously engaged with the data; some codes were collapsed together throughout this process, which helped me determine that I had exhausted the possibilities and confirmed that my data was coded appropriately. Once this was completed, I searched for strong patterns or themes among and between the cases. During this process I closely examined similarities in thinking, emotions, and 
engagement with children in the classroom who express mental health or behavioral issues between participants. The following sections of this chapter explore the cases in two distinct ways, first through looking at the individual cases and their specific experiences and second, through discussing the themes that emerged.

\section{Findings}

The findings reported in in this chapter are organized in two ways: first, in section one individual cases are explored, and second, themes across cases are elucidated. In Section One, individual case descriptions and contextual information are offered to understand the thoughts, feelings, and responses of each of the four participants. I worked to present my participants honestly and candidly by using their words as much as possible throughout the case descriptions. My intention is to allow the participants to speak for themselves as much as possible; their thoughts, feelings, and actions are dependent on and determined by who they are and their positionalities. As the researcher, it is my role to elucidate who they are. In section two, broad themes among the participants are highlighted to synthesize the data and create generalities about their specific experiences. While the purpose of qualitative research is not to generalize to the population as a whole, the data gathered in this research is able to offer a clear understanding of the participants' voices and experiences as they relate to in-service teacher preparation programming. Both sections of this chapter have the purpose of sharing and understanding the experiences of the participants and their stories, and to offer a new perspective of the phenomenon. 


\section{Section One: Individual Cases}

There are four participants in this study: Roxanne, Sophia, Livia, and Mary. While discussing the findings, it is important to acknowledge who the participants are and how they came to be a part of this study. All four participants are white, cisgender women who have been working in the early childhood education field for between 2.5-15 years. Three of the four participants work in laboratory schools on college campuses, which means they often have observers and student teachers in their spaces. Most importantly, each participant volunteered to be a part of the study and indicated that mental health and challenging behaviors are issues they think about a lot and care deeply about. Chapter five will go into the limitations of my study based on the demographics and self-selection of the participants.

Roxanne. "I hope that being calm in the face of challenging behaviors teaches children that no matter what, I still love them" (Roxanne, Email Exchange, January 9, 2018).

Roxanne teaches kindergarten and first grade students in an after-school program within an early childhood education center named the Willow Center. The Willow Center is connected to a large university situated within a small city. Roxanne works with two other lead teachers spread over two classrooms, the rest of the staff are student teachers who rotate in and out of the space based on their class schedules. Roxanne joined the MECE master's program to further her learning. Roxanne took an online course from the researcher called "Curriculum and Culture" in the summer of 2016. This course focused on issues of equity related to culture, race, and ethnicity, but did not delve into issues of mental health, challenging behavior, or inclusion. 
Roxanne completed her bachelor's degree at the same university where Willow Center is located. As an undergraduate student she knew she wanted to work with children and "called [Willow Center] every week until there was an opening" (Roxanne, Interview, March 12, 2017). Roxanne started working as a student teacher in the center in 2003. She happened to land in the 5-6-year-old classroom with her current boss and mentor, Evelyn. "I got in with Evelyn and it was just similar, it was just the way we were so similar, and it was super easy to learn from her and start to develop more of my own thoughts around how kids grow and develop" (Roxanne, Interview, March 12, 2017). Roxanne's philosophy easily aligned with Evelyn's and the other teachers' in the Kindergarten and first grade classrooms.

Throughout my interviews with Roxanne she discussed her shared philosophy with Evelyn and the program, she often used the word "we" to describe their collective philosophy and thoughts on how to work with young children; for example, "we all share with each other how our beliefs in working with children completely align, and we take very similar approaches in, you know, asking questions about what's going on with them, trying to get them to tell us how they're feeling" or "I don't really know how you would call the philosophy that we have" (Roxanne, Interview, March 12, 2017). It is clear Roxanne sees herself within a collective community of likeminded individuals. However, Roxanne's alliance with the school and with the program's philosophy seems to be specific to the classrooms under the direct supervision of Evelyn. For a brief period of time, after 5 years working under Evelyn, Roxanne became a substitute and worked in other parts of Willow Center. As Roxanne described: 
I worked in the other classrooms, the majority of the preschool and toddler classrooms for a year pretty much full time, and I saw how things were very different at the younger age groups, specifically in the preschool. The toddler room seemed really natural for me in how I kind of viewed how to work with kids, but the preschool age was very different, there was just, and I don't know if it's just how the philosophy was for that program, or it was that the age group is so challenging [laughter], but I've since worked plenty with the preschool and my way of doing things works fabulous, I think. And I have lots of success working with them, so I feel comfortable in knowing you can work this way, I think, through the ages (Interview, March 12, 2017).

Roxanne and her team have strong values of inclusion and working with all children, and yet Willow Center as a whole, and specifically the preschool classrooms, have not been successful in supporting all children in their classrooms. As Roxanne described, "they know that when they come to us [the classrooms Evelyn supervises] they know that they are going to be given that chance to be heard and that's almost the biggest thing that we've found because they'll come in, from even our preschool program, and be labeled a bad kid who's violent, and we don't have any problems with them" (Roxanne, Interview, March 12, 2017).

Roxanne's philosophy is very flexible and responsive to the children. She knows the children in her care well, and sets high, but also attainable, expectations for each of them. During my first observation on March 10, 2017, there was a large group discussion facilitated by Evelyn outside, but three children did not join. Instead, they played off to 
the sidelines while Roxanne stayed close, prompting them to join by saying things such as: "It's kind of hard to hear from over here," but seeming calm and unconcerned that none of the three children chose to join the discussion (Observation, March 10, 2017). When I asked Roxanne to explain why she chose the approach she did, quiet, undemanding, and ultimately futile, since they all remained off to the sidelines, Roxanne explained:

Well they definitely have challenging behaviors and some other diagnosed special needs, there's definitely autism working, and then there's the other two with challenging behaviors. I mean that's what it is, and mental health issues, huge struggles with mental health. And so, they just can't do what other kids can do in those moments. So they're not able to go and stop what they're doing and change location and have a conversation about something abstract... we don't expect them to ever join. It's awesome if they do and they'll probably sit down for maybe five minutes at the most and then they're off doing their own thing... we know that that's them, and they need something different and that they're not trying to be rude or they're not trying to be ignoring us or anything... and you know, we try to talk to them about how even though you do need something different right now, you know you still need to respect what's happening for the other children and we try to teach them that recognition of what the people around you are doing and that it's working for them as well (Interview, March 12, 2017). 
For Roxanne, it was not about getting the children to conform to the group, rather it was about meeting their individual needs. This is a theme that was found throughout my observations and interviews with Roxanne; she values listening to the children and responding to who they are.

Roxanne's thinking about challenging behavior centers around recognition of who the child is and what they need from the adults around them. As Roxanne explained in an email correspondence:

For me, challenging behavior means a child's actions that elicit specific thinking and reflection on the teacher's part to understand what could be happening for the child. For example, asking myself, is the child trying to get their needs met from some experience? Are certain behaviors occurring more regularly or infrequently? What is happening around these behaviors? What actions from the teacher/s does the child respond to in these situations? For after-school times, what is happening for the child during their in-school time? Are these behaviors also seen by the family? For me, challenging behaviors are behaviors beyond what teachers might typically expect, negative or positive, in response to something. The behaviors take the child away from their typical activities for extended periods of time, and they call on me to think more critically about very different ways to navigate the behaviors with the child (January 9, 2017). Roxanne's beliefs and thinking about children who express mental health issues and challenging behaviors in the classroom put a lot of the responsibility to make it work in the classroom on the adults. She believes in personal reflection and discussion with 
coworkers to find ways to change the emotional and physical environment to meet the children where they are (Interview, September 20, 2017).

In the classroom Roxanne is steady and calm. Her presence is known, and yet never appears overpowering. Her calm demeanor and desire to connect to each child is purposeful, she wants the children who experience mental health issues or challenging behaviors to know that they can count on her. As Roxanne described, "[I] am willing to hear them out in any way they need to express themselves" (Email Exchange, January 9, 2018). Roxanne believes part of her reaction to the children is simply part of her “temperament," and something she has always had (Interview, September 20, 2017). Roxanne's emotional reaction to the children seems to have changed over her 15 years of teaching, "I had to do my own growing" (Interview, March 12, 2017) she explained, and her growing has landed her in a place where she does sometimes feel frustration, but where she can also "take a breath" and re-center (Interview, September 20, 2017).

When engaging with children with mental health and behavioral issues in the classroom, Roxanne tries to build her relationship and trust with each child. "[I] try to really build that trust with them so they know what I expect" (Roxanne, Interview, September 20,2017). She tries to see each situation for what it is, rather than using her experiences from the last situation with that child as an indication of how this one will go; she tries not to prejudge what is occurring, even if it is an incident with a child who has had many incidents before.

One of the artifacts Roxanne shared with me from her school was a problemsolving guide named "The 5 C's of Conflict Resolution," Figure 1, which describes how to engage in problem solving with children in the classroom. As she explained: 
This is something that Evelyn and I developed to help coach our student teachers on how to work through problems with kids that come up. It's mainly just about slowing them down, stopping and having them hear each other. And not necessarily us telling them what we think they need to think or feel, but hearing what they have to say and allowing them to have the conversation however it goes. And that just kind of follows through with our philosophy on how we handle you know, how you should act while you're here.

Roxanne stated the document fits her values for working with children and it is the way she tries to approach conflict resolution.

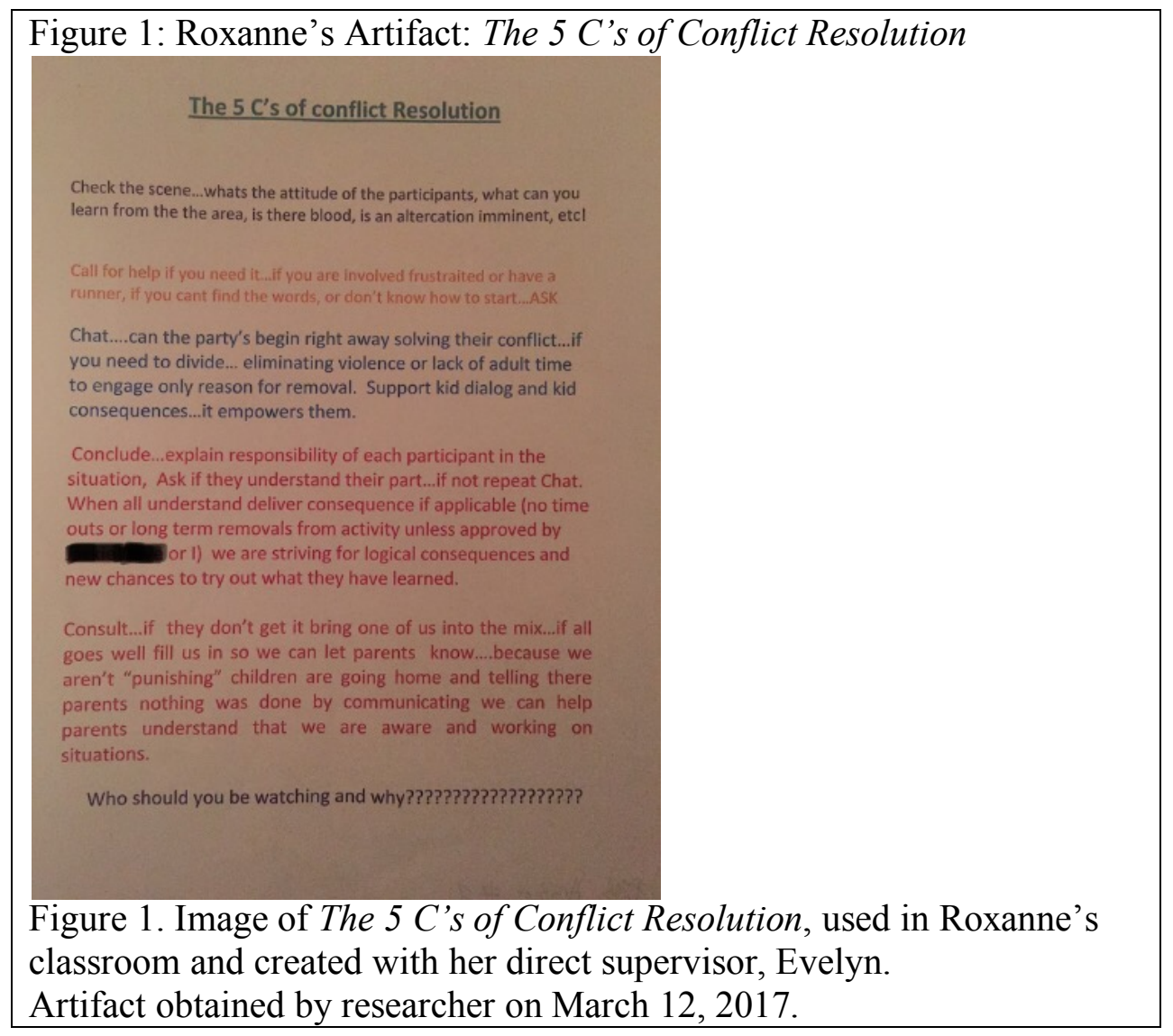


Offering "new chances" to try out new behaviors aligns with what I observed in the classroom (Artifact, March 12, 2017). Roxanne's approach to classroom guidance values teaching children how to be in the classroom, rather than simply attempting to control their behavior. To do this well, Roxanne believes the adults need to be able to manage their emotional reactions to the children's behaviors. As Roxanne explained, I found that was really important for me to learn... that you can't go in with your reaction, that's not going to help the kids learn. And I mean, they're only six years old and when you really think about it, it's like that's really young [laughter]. You know, they've hardly had these experiences, and then also knowing that they're learning this, and they need to learn these sorts of responsibilities, and it can be expected that you can learn it if it's something we know you can learn. We've seen your other development, I think that leads into it, but yeah, I think that I definitely think it's important to manage that response (Interview, September 20, 2017).

Roxanne's approach to teaching, and beliefs about working with children with mental health issues and behavioral challenges, have certainly been shaped by the strong team she has around her. She believes part of what keeps her mostly inwardly and certainly outwardly calm during conflict is her temperament and the work she has put into learning how to remain calm. She wants the children in her care to trust her and to rely on her, and so she takes a methodical and consistent approach to engaging with the children in her classroom. 
Sophia. "The teacher is the guide, or example, of appropriate responses to stressors and stimuli" (Sophia, Email Exchange, June 5, 2017).

Sophia works in a rural public charter school two hours away from Tallsee University. The charter school includes Kindergarten through twelfth grade, with 208 students. The charter school also has a private-pay one classroom preschool attached, which is where Sophia works as the lead teacher. Sophia has a maximum of 10 children per day in her class. There is a high level of poverty at the school (40 percent) and based on the anecdotal evidence shared with Sophia via the families, many of Sophia's students have experienced some sort of trauma.

Sophia worked for one year as the teacher's assistant in her son's preschool classroom before she was promoted to lead preschool teacher. As Sophia described, "my school hired me with no education" (Interview, March 24, 2017). Sophia is currently in her second year as the lead preschool teacher. Within the past two years she has rotated through four different assistant teachers; two of whom had different values than her concerning how to be with and teach young children, and one who quickly learned from the experience that she did not want to work with children in group care. As Sophia explained:

I started the [last] year with one aide, the aide situation at the school was a problem we did always have two adults but they weren't always comfortable with that age. So the first one left in November... The first one had been taking classes to be an elementary teacher, but hadn't had experience working with this age, and had worked with middle school students, and she was just like, I can't deal I can't stand this, I cannot 
stand that they won't stand in a line. Blech, so she left. And then the next one I had, she was fantastic, she had a great rapport with little kids, she loved them. And the kids loved her, and I loved her. And we really could talk about anything, but the level of stress that it put on us made her decide to never do it again. She will not take care of other peoples' kids again. Because she couldn't stand little kids hurting that much and you know having parenting that you can't control that could be so harmful, and you can see it, and you can watch them interact with their children when they come pick up and you know something's gone on when you see their behavior, and you can't do anything about it, and she couldn't take it. But she stayed through the year out of commitment to me and because that's the kind of person she is you know. And then this year... I told them we need to hire outside, we need to hire somebody who wants to be with little kids. But we had this budget problem and we couldn't justify hiring someone new...so the [aide] they gave to me had done preschool in the past and she liked it then but she did realize after leaving preschool, because she left for a couple of years after working in preschool, that she no longer liked working with that age group, she liked kindergarten, but not preschool because they weren't ready to listen [laughs]. And so that's who I got, and she spent the first six months until after Christmas furious that she was there. Barely interacting with the kids, barely interacting with them, and grumpy - short tempered. When I tried to talk about, guide her into what I was wanting to do with the kids, when I tried to talk to her 
about what I was learning [at Tallsee University and in community trainings]... she just wouldn't have it. She ended up complaining to a board member, who's a friend of hers... about me having a change in philosophy and how I had no discipline and I was letting the kids run wild, so I got some conversations from the director, and just, I haven't felt really supported, at all (Interview, March 24, 2017).

Working with aides with different values and approaches to working with young children made it difficult for Sophia to create the consistency she wanted to have in her classroom. As a new teacher, it also caused Sophia to second-guess her decisions and her approach. Sophia has a good relationship with her current aide, however the new aide had just started within a week of our second interview.

Sophia had a very difficult first year as lead teacher; as she described, "last year I felt most behaviors were, ended up being beyond what I could handle" (Interview, March 24, 2017). She had very little support from her different classroom aides and the school administration in general, "the hardest part was that I did not feel supported, very supported, I did struggle with feeling supported with you know, my organization. Because they just, they didn't know what to do, because it was preschool... and lucky for me, it was my first year [laughs]" (Interview, March 24, 2017).

Sophia was overwhelmed by the behaviors she saw from many children, and knew she needed more support and training if she was going to remain in the field and successfully support the children in her care, which was her goal. As Sophia wrote in an email correspondence, “The more I think about it the more I want to say that it's not really the behavior that's challenging, just my comfort and ability to manage it...I guess 
it means behavior that presents me with a management challenge that persists after I've attempted to empathize or redirect. I've noticed myself feeling challenged when a child overreacts to a simple act or direction, like me opening the door (when he wanted to) and he lays on the floor and screams" (Email Exchange, June 5, 2017). Feeling like there were behaviors she could not understand or handle and believing that there were ways to successfully support children with challenging behaviors in the classroom, pushed Sophia to apply to the M-ECE master's program and to attend community trainings.

Between January of her first year as lead teacher to July, Sophia took 118 hours of community trainings to gather knowledge and skills to work with children with mental health needs and challenging behaviors. As she explained, "I took a lot of trainings and read a lot of stuff, a lot of books and articles and then taking classes to learn better strategies" (Interview, May 5, 2017). From all of her learning and trainings, Sophia's general beliefs about how to be and interact with children who express challenges in the classroom were solidified, "I believe in cooperation, I believe in sharing, I believe in working together, and I believe those are important skills for humans to have in the world and I think empathy is extremely important” (Sophia, Interview, May 5, 2017).

While Sophia definitely expresses that she wants to remain calm and support her students in expressing their feelings, learning empathy, and problem solving, she also finds herself getting triggered by the behaviors she sees:

There are some times that I get triggered and I know I'm triggered. When I say [an expectation] almost in a huff, you know? Where it's hard for me to control. Well when you're ready to do this [laughs], you know there's a little attitude in my voice too, and you can tell that I'm attached to the 
outcome and then I feel, I feel it in my body my muscles feel rigid when, when it's a situation where I'm worried about where the rest of the class is, we need to move out of the room into another space, like when we're in the gym and we need to leave the gym because the next class is coming, that really matters and then I get more tense about those situations, I'm a little more insistent I'm a little less patient (Interview, May 5, 2017).

Although Sophia describes her relationships with coworkers and administrators as shaky, her connection to her students is clear. Sophia cares deeply about who her students are as individuals and seeks connection with them in the classroom. During observations it was noted that Sophia plays with her students throughout the majority of the open play time during the day; she enters their games and their imaginative play. When asked about where she likes to be in the classroom she said, "I'm often moving around the floor or the tables, making sure that everyone is engaged and just kinda checking in with their various activities" (Sophia, Interview, May 5, 2017). However, she described how this level of engagement interfered with her organization and the rhythm of her day, "I'm usually near a child, and this year, well no even last year too, sometimes to the detriment of my organization" (Interview, May 5, 2017). As an observer, it seemed like Sophia was immersing herself in the children's play as a way to manage the big behaviors; by joining them, rather than sitting back and watching, it seemed like she hoped to stop the challenging behaviors from happening (Sophia, Observation, March 16, 2017). 
Livia. "It's a really hard balance to try to really speak to them and feed them where they need to be fed" (Livia, Interview, June 16, 2017)

Livia works in an on-site preschool at a private Christian liberal arts college in the same mid-sized city as Tallsee University. She is the only lead teacher, with her support staff consisting of student teachers from the college. Livia's one classroom school also has a director, but her director has never worked as a preschool teacher, so while supportive of Livia's choices, cannot offer knowledge from direct experience. Livia taught in preschool and family support programs between 1994-1998, and then stopped teaching while raising her children who are all now teens or adults. This time around, she has been teaching for three years, and all three years have been at this current school. She began the M-ECE master's program soon after beginning to teach again. Getting her master's in early childhood education was "a bucket list thing," and something she had wanted to do many years earlier, "I had started the process actually before I had kids, and it just didn't go the way I wanted to, so I didn't complete it then, so it was something I always wanted to do" (Livia, Interview, June 16, 2017). Livia took the master's program slowly, taking just one or two classes a term as she continued to work and parent. Livia had been a student of mine in a class entitled Equity and Cultural Diversity in Early Childhood Education during the winter of 2016. This course explored issues related to mental health, challenging behavior, and inclusion. During the year Livia took the class, inclusion was heatedly but respectfully debated multiple times, so she came into the study knowing the researcher's values and passion for the subject.

When Livia initially approached me with her interest in being a part of my study, she sent me an email that stated, "I had basically a behavior classroom last year with 
multiple challenges. I'm happy to chat." (Email Exchange, September 23, 2016).

Throughout this study Livia expressed her wish that more people stepped up to care for children with mental health and behavioral challenges in school. She also shared that working with children with challenges was something she believed she was good at. When asked where she thinks mental health issues come from, Livia explained: I think, I think there's a lot of different factors I think there are some environment factors and genetic factors... I don't know, I mean some of it, I wonder about just for lack of a better term, breeding, how, how their DNA is formed, how kids come into the world, how much of that is affected by mom's lifestyle. I mean, I think there's a lot I don't know, it's just guessing, again based on conversations and reading that I've done. I think that there's a lot, a lot of different places that it can come from for a specific child (Interview, June 16, 2017).

Her response relayed the belief that both environmental and genetic factors play into mental health and behavioral issues. When discussing the environmental factors that influence young children, she shared some of the traumas that some of her students have experienced:

[A] little boy... did have some trauma in his life, in his early life, and I don't know if it was directly at him, but it was between mom and dad. I think mom had been physically abused in front of the children, and so he had a lot, a lot of trouble being in our classroom and being with other kids. And he also had some speech delays, and some other things that were hard for him to express himself, so there was a lot, I think there was a lot going 
on for that little boy. But I think a lot of it stemmed from [that]. His little sister displayed some of the same characteristics, and I think it was from that trauma that he experienced early in life. One of the cool things about those, I still have that little girl this year and she's doing so much better and her brother is doing a lot better. I don't have him anymore, but just because their family life changed and, they're doing a lot, they're dealing with those issues and they're doing so much better than they were (Interview, June 16, 2017).

Livia sees mental health issues as a societal problem, which we all are responsible for solving. When pressed to explain how her values around inclusion and working with children with challenging behaviors became so clear, and how this became such an important issue for her, she said in an email exchange on August 17, 2017, "I am loyal to a fault which does not always serve me well in my personal life! But, I am passionate about children having a space in society that honors who they are and all that they bring with them." During her next interview, Livia expanded on her beliefs concerning inclusion and said:

Honestly Katie, I have to say, that I think a lot of this came from your class when, when I started thinking about not kicking kids out of preschool and some of the stuff I was hearing about high school drop outs and how they were, you know [more likely to drop out after expulsions], there was a lot of stuff that I was reading and what not. A lot of discussions from your class, feeling like they deserve to be you know, in a 
space... a lot of that stuff came from your class (Interview, August 18, 2017).

Livia also explained in an email how over her last three years teaching, she has "gained enormous compassion for children and families with behavioral and mental health needs" (Email Exchange, August 17, 2017). She believes she has grown personally and professionally because of them, and this has informed her way of being with children in the classroom.

Livia's demeanor during observations can be described as quietly joyful; she exudes a sense of confidence and true delight at being in the space with the children. During an observation on August 3,2017, where Livia was outside with a group of children on the playground, her patience and enjoyment of the children really showed. On this particular day she had given the children a ten-minute warning before it was time to go inside. When it was time, one child, Rick, who I had been told had some of the more significant behavioral challenges, refused to go inside. Rick was engrossed in playing a Star Wars game and did not want to transition to snack indoors. At one point, Livia walked over to him and said, "Where is Luke Skywalker? Luke, it's time to go, the ship is leaving, we can't get stuck here." Livia joined his play to prompt him inside, but it did not work. Rick continued to refuse to go inside. At one point, during the 20-minute exchange, Rick turned to Livia and told her he cut her arm off. Livia looked at him with a genuine smile and said, “my left or right arm?" I wrote in my notes after watching this, "this situation just isn't about her;" meaning, she was not ruffled, she was not upset by Rick's behavior, because she saw, and she knew, that this experience was not about her. Interrupting by engaging him in a conversation about why he should not tell people he is 
cutting their arms off, would not have been helpful in reaching her goal of having him join his peers inside.

Twenty minutes after the initial call to go inside, Rick walked into the classroom and announced to his classmates, "sorry I was late!" and sat down to eat snack. When asked later in an interview to describe what his statement "sorry I was late" indicated to Livia, she smiled and said,

I hadn't thought about that, to me it's just his sense of humor - I mean he cracks me up all the time, even though I can be so angry with him or what he's doing, and then he can turn around and do something like that. I think it shows he feels pretty comfortable in that group of kids and that he belongs, which is really important to me that he feels like he belongs. And I don't know about what that says about what went on outside [laughs]. Livia's ability to find humor and interest in all of her students, no matter how challenging, seems to fuel her joy in the classroom.

While Livia exudes a sense of calm, understanding, and overall patience, she explained how she does not always feel calm, and it took a lot of work to get to the point where she could show a calm exterior. During one interview she was describing her emotional reaction when a child threw a chair at her:

One of the things I have learned, that honestly I did not do well early on, but one of the things I have learned, [is] I have to separate my emotions from what's happening. Whether to me or to other children...that was a tough day when he threw that chair. I remember thinking, I want to get in my car and drive away now [laughs]. I kinda do what you have to do, it's 
EARLY CHILDHOOD EDUCATION AND MENTAL HEALTH

not an option at that point. I mean, if I explode what good does that do to anybody else. I mean my heart was racing a little bit... I was working really hard to keep my cool because yeah, I just wanted to like, [laughs] get out of my space! You know, but I don't know, I feel like he was one that sometimes I could turn him around with a hug. I'd say, you're looking really angry right now, would you like to have a hug? And he did, he liked to be hugged tight and so that would sometimes help. But yeah, I just had to really remove my own stuff from that (June 16, 2017).

Livia explains how she used to be "pretty black and white" in her thinking; she had an idea of what the right way to do something would be, and she wanted it to be done that way (Livia, Interview, June 16, 2017). But over time, she learned to remove herself from the situation, she came to see that the children's conflicts or behaviors were theirs alone, and not something she needed to get emotionally triggered by. She also came to see that her ideas of fairness, justice, or right and wrong were not always the same as the children's, and as she put it, she became "a lot more gray" (Livia, Interview, June 16, 2017). With age and perspective, the way she engaged with the children began to change. She began to feel more relaxed and learned to not "sweat the small stuff," which resulted in a teaching style that is warm, engaging, and slow; nothing is a race, because there is nowhere to really be, besides where she already is (Livia, Interview, June 16, 2017). 
Mary. "I constantly wonder about the feedback and input a child receives about behavior, conflict, problem-solving and discipline across environments." (Mary, Email Exchange, March 30, 2018).

Mary is a lead toddler teacher at the onsite early childhood education program located at Tallsee University. Mary has been working with her current cohort of children since they were infants and older babies. The children are now 18-28 months, and she will continue to be their lead teacher for one more year until they enter a preschool classroom. Before becoming a toddler teacher Mary worked as a kindergarten teacher for two years, but is happy she made the switch to working with younger children and feels like her current position is her "dream job" (Conversation, February 2, 2018). Mary's classroom is unique in her school in that she has the only classroom where there are not two fulltime co-lead teachers. Mary's co-lead from last year went on family leave for the year, leaving Mary to lead the classroom by herself. She has a part-time lead teacher who works with her three mornings a week, and an assistant who is in her classroom 30 hours a week, but as she explained she is "by far the most consistent face they see" (Interview, January 26, 2018). Because her school is a laboratory school situated on a public university, the classroom has many student teachers and practicum students. The teaching schedule posted in the classroom noted eleven different adults working with this group of children throughout the week.

One of the first things that became clear about Mary was that she thinks deeply about her work with young children. Her work stems from an intellectual interest in how to best care for young children, as well as a love for the connection and interactions with the children themselves. Mary has a sense of what she wants to teach the children in her 
classroom, "It is really important to me that the children develop a sense of community as well as independence, that the children learn to be thoughtful, kind and compassionate while also knowing how to advocate for themselves, and that they build resilience to the trials of negotiation and compromising" (Email Exchange, February 8, 2018). Mary has a sense of how she wants the children to be individually and together, but does not always know how to help them get there. Mary's strengths, she says, lie in working with infants and toddlers. However, she has concerns about her capacity to handle the needs of the children as they continue to develop and is "always seeking out new materials" to help her learn (Interview, January 26, 2018).

Mary spends a lot of time thinking about the words she uses with the children. Language is very important to her:

I sometimes get caught in the loop of using the same language over and over and over again and I know I sound like a broken record. Sometimes I'm like okay, I need to think of a new way to get through to them or I need to think of new language to break that loop so they stop and think about it and go "oh this is what sharing means" or "this is what passing back and forth or sharing means." So I think it's definitely helpful to hear different language. I'll just watch other teachers and I'll be like oh that's a great idea and then I'll try it in the classroom (Interview, January 26, 2018).

In an analytic memo I wrote February 9, 2018, reflecting on Mary's interview and first email exchange, I wrote, "Mary told me that the children in her care are "going to be good people.' She seems to have a vision for how the language she uses with them now, 
will help the children to be a certain way, she is imagining them into the future and has a vision for the ways they will impact the world."

While Mary seems to intellectually have a vision for what she wants for the children in her care, she feels she struggles more with the day to day implementation of effective language to reach that vision; "I feel like I'm flying by the seat of my pants a lot, like, I don't know what to say to you, [laughs] please don't throw that" (Mary, Interview, January 26, 2018). She described what happens for her when the language she is using is not working:

I think I would feel a little bit refreshed to have new language to use, a different approach. I think that they can keep saying no and I can keep giving them two options, and I can keep giving them two options, and then you feel like you're in this power struggle and I'm like okay, I don't feel like I'm getting somewhere. I know I'm frustrating this child, I'm feeling frustrated...yeah, I think my own frustration definitely builds when I feel like I can't get out of my own loop and I think that sometimes I need to support the children in getting out of their own loop (interview, January 26, 2018).

When discussing Mary's emotional reaction to some of the more challenging behaviors she sees in the classroom, she explained how authenticity is very important to her and how her frustration can build if she feels like she is not seeing a change in behavior: My external response is to respond authentically, if it hurts I will say ouch, that really hurt. One time I took a Lego to the forehead and I was like, 'I would like ice for this' and I brought the child with me to model that, 
'help me take care of myself' to me too. And I'll be totally genuine with them, I'll be very serious, I'm not going to laugh about it even if it didn't hurt that much, but like 'ow, I would not want you to do that to somebody, that hurt me,' My internal reaction, and I'm a little embarrassed to admit this, but like with [one] particular child, because it happens so consistently, my frustration level does go up a little more, like uh this keeps happening, and it physically hurts me and it's emotionally challenging because I don’t always know how to respond (Interview, March 2, 2018).

In an email prompt, I asked Mary to describe what challenging behavior means to her, her response demonstrates that to her behaviors become challenging when they do not change:

I think about challenging behavior in terms of the behaviors that are hurting other children (physically, emotionally) or our space. These behaviors interfere with children's safety and learning; these are behaviors that have been addressed consistently and we continue to see very frequently... I consider them to be especially challenging when I find myself stuck using the same language over and over again, or offering the same redirection in different ways and not seeing much change or internalization of the problem from the child" (Email Exchange, February $8,2018)$.

For Mary, challenges come from behavior not changing after repeated discussion to initiate change. 
Mary's worries about whether she is good enough in the classroom are clear through her interviews and email prompts. However, in the classroom Mary's language appears precise and purposeful; she offers the children choices and ownership over how and when activities will occur in the classroom. For example, when preparing a resistant child for a diaper change she stated, "Do you need two minutes? Okay, in two minutes we will go to change your diaper." After reading a book to a few children, Mary came back over to the child, "It's been two minutes, I gave a two-minute warning, do you want to pick a toy? Pick a toy to save and we'll put it on the counter. Why don't you drive it over and we'll see where it wants to land. Do you want to put it on the counter or in the bucket?" During observations she used language to create connection with the children and to share power with the children.

While language was clearly a valued manner of connection, Mary also uses touch and closeness to build relationships with the children. She described one child in particular, Laura, who experienced some anxiety in the classroom environment and needed to be physically close to Mary to feel okay. "Something I've seen since day one in the infant room is she has attached herself to me wholeheartedly. She is attached at my hip and she's very, very sensitive of new people in the classroom" (Mary, Interview, March 2, 2018). Laura's need for closeness seems to be understood by Mary, but not always welcomed. During my observation on March 16, 2018 I watched Mary work with a group of children in a gross motor space within the center. At one point a student teacher brought Laura to the gross motor space after she woke from her nap and Laura ran into Mary's open arms as Mary said "Laura's here! Long time no see, it's been about 40 minutes" (Mary, Observation, March 16, 2018). 
Throughout my observation in the gross motor space on March 16, 2018, I observed multiple transitions of both children and adults in and out of the room. During my two-hours in the space, I observed 8 different adults who either entered the room or came to the door of the movement space, none of whom said hello or goodbye to the children as they came or left. There seemed to be little acknowledgement of how the staffing transitions affected the children's feelings or behaviors.

\section{Section Two: Cross-Case Synthesis}

The individual cases explored above highlight the unique experiences of participants in relation to their thoughts, emotions, and responses. Taking a more holistic view of the participants now, this section explores the themes and subthemes found among participants' thoughts about, emotional reactions to, and engagement with children who express mental health issues and challenging behaviors in the classroom. The cross-case synthesis is broken into three broad themes that are directly pulled from the research question. These themes include:

- Thoughts about children who experience mental health and behavioral challenges;

- Emotional reactions to children who experience mental health and behavioral challenges; and

- Engagement with children who experience mental health and behavioral challenges.

Each of these themes have 3-6 subthemes that fit under the broader theme; I created these subthemes directly from the data analysis. 
Throughout most of Section Two the participants' pseudonyms are used so that their thoughts and ideas that were elucidated in Section One can be used as the backdrop for the explanation of the themes and subthemes in Section Two. However, I have consciously hidden the identities of participants when I am identifying what could be perceived as more negative themes and subthemes. Obscuring the identities of participants in some instances is twofold. First, I want to respect the vulnerability it took for the participants to share their thoughts and feelings with me and allow observations of their most challenging moments with children. Second, I want to remind the reader that the examples I am using to convey the themes and subthemes are simply that, examples of what has been found across the cases.

\section{Thoughts about children who experience mental health and behavioral}

challenges. The self-selection into the study drew a participant pool that was invested in supporting children's behavioral and mental health challenges in the classroom. As Mary explained, "when I got your email about your study I was like, oh my gosh, oh my gosh I deal with this so much can I do any more of it? And then I was like, well of course, I think about it all the time" (January 26, 2018). The descriptions of individual cases demonstrated that each participant had thoughts and ideas about where mental health issues and challenging behaviors come from, and how to handle them in the classroom. While each participant had a unique perspective and lens, through my analysis of the data I created a few overarching subthemes when looking at how the participants think about children who express mental health issues and challenging behaviors in the classroom. From the most frequent codes connected to participants' thoughts about children who 
experienced mental health and behavioral challenges in the classroom the following categories were created:

- Home environment;

- Classroom environment;

- Children need connection;

- Stick-to-itiveness;

- Outside resources are necessary; and

- Want to know more.

Home Environment. Each participant discussed the impact that children's earliest experiences and home-life have on their development and their presentation of behaviors in the classroom. Participants talked about the ways in which parenting style, diet, and trauma all factored into children's wellbeing and sense of self. As Roxanne explained in an email prompt, "I think that young children's behavior and mental health are extremely related to their environments. Whether it's a reaction or cause from life inutero, infancy, or other events in their young years" (Email Exchange, Roxanne, February 11, 2018). Roxanne continued to describe her thinking during an interview on March 12, 2017:

The children I know that really struggle with mental health issues, their parents clearly struggle with that as well, just in the way that they come in each night to pick them up can be so different. Their energy and their mood and the way that they interact with their child in that first moment can be so different. Positive or negative, up one day or down the next, and also knowing that maybe somebody was adopted and came from a very 
horrible, awful, you know first three years of their life, and just knowing that background, and how much that family experience has affected them is very clear.

For all of the participants, it was clear that early experiences influence who children are and how they express themselves in the classroom.

Participants described how some of the children they have encountered with the most challenging behaviors, lived in homes where the parents expected the child or children to spend a lot of time alone. For example, Roxanne, when asked if she had ever worked with a child whose mental health issues she couldn't handle, described a child whose mental health needs had been beyond what she understood, "the child sort of shared a lot about their family with us... there was a lot of pressure put on the kids to, to just kinda be on their own. So that's kinda the information that we got" (Roxanne, Interview, March 12, 2017). Sophia described a similar experience with a child whose behavior has been both puzzling and challenging; she had been stealing toys and putting them down her pants. One morning, Sophia saw flubber squished onto her stomach, and after looking more closely, saw that the child had pushed the flubber down inside of her underwear. Sophia had several ideas of where this behavior was coming from: her parents were young (21 years old), her dad had just recently spent some time in prison, her parents had four children, and the parents were overwhelmed by their children and so they left them alone and without rules. As Sophia described:

"I think [challenging behaviors] come from their environment at home... in this one family there's so much, they're so, the parents have a hard time managing them so they are left, they are unable to interact to set 
boundaries, so those kids are in charge of their world, so what they do is make a space where they can do that, like downstairs... you stay downstairs, so the children are downstairs doing anything they choose and they're mostly fine, but they're not guided much, so then they get guided and that's really frustrating because nobody, 'I don't have to do that,' you know, and that's the way their environment is set up (Sophia, Interview, March 24, 2017).

Both situations described parents who were expecting their young children to care for themselves. Leaving young children alone for long stretches of time could potentially be deemed neglectful, a term that was noticeably absent from both Roxanne and Sophia's descriptions of what occurred. Neglect is the most common form of child maltreatment and can have serious and devastating developmental repercussions for young children across the lifespan, however it is often difficult for both professionals and lay people to pinpoint or define (Whalley, 2015). The line between neglect and individual parenting style can be blurry as an outsider, and this blurriness was evident in the ways in which both Roxanne and Sophia discussed these parents.

Mary also described how children's home lives and family dynamics played into the children's mental health issues and behavioral challenges. Mary discussed one child in particular, Tom, who was expressing challenging behaviors in the classroom. Mary explained, "I think there is a family dynamic that they haven't shared with us that is kind of creating a lot of these behaviors" (Mary, Interview, March 2, 2018). As evidence of the ways in which this family's home life was influencing their child's behavior, Mary brought an email exchange between Mary, her co-lead teacher, their direct supervisor, 
and Tom's father and mother. Mary very directly in the first email asked if there had been changes in Tom's home life that could have caused his behaviors, she wrote to Tom's parents in an email entitled "a note about today:"

I am writing to check in with you both about Tom's weekend and any possible changes in his routine. We have seen several incidents of hitting today in which Tom has found a hard toy and used it to hit another classmate or teacher. He consistently laughed each time a teacher intervened or someone said 'stop!' ... If these behaviors do continue, we will begin tracking them in order to document possible patterns and what might provoke these incidents. We are curious if you have any insight as well (Mary, Artifact, March 2, 2018).

The initial email was not received well. Tom's parents seemed to feel attacked and were resistant to meeting and tried to defend their son's behavior by pointing out that "while of course this is alarming, it does fall into developmentally appropriate behavior for a young child to explore and work through" (Artifact, March 2, 2018). Mary described the fallout from the initial email,

It feels like it's just a really hard conversation for them to have... and because it's been so challenging for them it's kind of built itself up, this meeting, this impending meeting has been built up into such a big thing that it hasn't happened. And we continue to see these behaviors and we continue to touch base here and there, 'well this is what happened yesterday this is how we handled it have you seen these behaviors at home?' And like sometimes you get like half a conversation out of that 
EARLY CHILDHOOD EDUCATION AND MENTAL HEALTH

and sometimes you feel like you're talking into the air (Interview, March 2, 2018).

Mary was able to describe some of the behaviors she sees in Tom's father, that she thinks influences Tom's behavior in the classroom:

I think some of the behaviors that I see from the father is distrust of female professionalism. I see a lot of white male privilege. I also see a lot of leniency in any responsibilities or when the child is asked to do something it's like 'oh well we'll skip it this time' kind of like, 'I'm the fun parent' or 'I'm just going to let you get by with it because we have a great relationship.' And I see the child now will just scream 'no' in my face (Interview, March 2, 2018).

Mary connects Tom's dad's view of professional women, privilege, and parental leniency to Tom's behavioral challenges in the classroom.

Whatever was happening at home, Tom's parents did not want to discuss it, but that did not stop Mary from wondering how Tom's experiences at home were influencing his behavior in the classroom, and also her reactions to him. "I see a lot of the behaviors, the way that the father treats me, I see it reflected in his child's behavior. Sometimes I stop myself and I question myself, is this just toddler behavior? Am I putting that lens on it, like father like son? Or is it more than that? Like is this really a bigger behavioral challenge that I'm facing? And I try to check myself on that" (Mary, Interview, March 2, 2018).

Livia also described how one child who was having a lot of challenges in the classroom and was struggling to use respectful language with his peers, as being 
influenced by his father's behavior at home. The child was saying things like "'Oh I can't believe you are here today' or 'I don't like you' or even to the parents 'do you know that your son is a jerk"' (Livia, Interview, August 18, 2017). And Livia explained:

It took the whole year to figure out that his language, some of his really awful language and the things he would say to people came from his dad, but his dad didn't see that, you know, where you're driving in a car and he's in the back seat, you're not thinking about that you're cussing out the other driver that your two- or three-year-old is hearing you, and that becomes a thing that you say, so that was an interesting thing I think for the dad to realize 'I need to change some of my behavior,' which was great that he could get to a place of acknowledging, 'I think I have a hand in this' [laughed] (Interview, August 18, 2017).

While Livia and the other participants each noted ways in which early experiences influenced children's mental health and behavior. Livia also noted how parenting could help overcome some of the challenging behaviors. In an email exchange Livia wrote, While there may be many reasons for behavior and mental health circumstances, I do believe parenting has a great deal to do with helping these kids become better self-managers. How they respond to their child, how much energy they have to advocate for them and work with many other professionals to create the best possible space for them to learn. I often wish there was some mandate for parent ed!!! For all parents!!! (Email Exchange, September 27, 2017). 
Classroom Environment. The participants all noted their beliefs that the home environment and parenting style influence children's mental health and challenging behaviors and this same belief extended to the classroom environment as well. All participants noted the importance of educator consistency in the classroom. Further, the impact of the physical environment on behavior was noted across cases.

All the participants noted the physical classroom environment as an important factor influencing young children's behavior. While the participants' classrooms were very different from each other, ranging from extremely small to large and expansive, the physical space was noted by each as having an impact on children's behavior. During an observation, Mary turned to me with a smile and said, "It's chaos all the time!" and then turned to her colleague and said, "It just got really extreme in here, so I decided we should go outside" (Observation, March 16, 2018). Mary addressed her thinking about how the environment and group size can affect behavior several times throughout our interviews and emails; here she describes in detail how the dynamics of the group and the space can influence the children's behavior:

Right before I came to meet you today I had that moment where the energy went from here to here to here to here and the students were overflowing, and I picked a couple of kids and I just dropped them outside with another teacher. And just splitting the group for a little bit kind of took that energy level down and we were able to regroup a little bit and we all ended up on the playground and it was this beautiful play moment together. So sometimes I need to, my best strategy is to split the group, because I can work a lot better with that small - with a fewer number of 
children to kind of tune into them for a minute and then see the bigger picture again (Mary, March 2, 2018).

This idea that group size and physical space influence the children's challenging behavior was reiterated by Sophia as well, "With the same kids, plus a couple of others, and there doesn't have to be any challenging kids coming in, but eight in the room compared to five makes a difference, and they're just on top of each other more so there are more conflicts, because there's not enough room for them to have space" (Interview, March 24, 2017).

Sophia also noted how sometimes it was not the number of children that influenced their behavior, but the number of children with behavioral challenges coupled with the guidance strategies used by the educator:

I had one day where I had four kids and I couldn't, I couldn't [manage them] by myself, and I couldn't handle the kinds of conflicts because three of them were having them at the same time and my style does take a lot of... my style is that I feel like it's important to walk with them through the process to help them learn. I think it's not really fair to expect children to figure it out on their own so much because they're still learning to figure it out (Sophia, Interview, May 5, 2017).

So while the physical space influences behavior, the number of children with behavioral challenges in the environment and the ways in which educators respond to the behaviors also influence how children behave.

Children Need Connection. The importance of connection and focusing on emotions and relationships before attempting to modify behavior was a sentiment that 
was echoed by all the participants. As stated by Sophia, "I think it's critical that we care first for a child's emotional state with empathy and love" (Email Exchange, June 5, 2017).

The participants agreed that relationships are at the heart of their teaching and learning alongside children. And when connection does not come easily or readily, it can be challenging. "I think that's what's most challenging for me is when I'm having a hard time connecting with a child, for whatever reason, and usually I don't, but occasionally I do... usually I can find a way in with something that I know we have in common that I'm noticing, and find that connection and start to build a relationship" (Livia, Interview, August 18, 2017). Livia explained in an email exchange why this connection, this relationship building, is so important, "Building relationships with children individually I believe is at the heart of a lot of this [working with children with mental health and challenging behaviors]. When you enter into their world, and they see their own value through your eyes, they usually want to be the best version of themselves" (Livia, Email Exchange, August 17, 2017).

This importance of connection is a value that is disseminated to the children as well. Connection is modeled and expected from the children who are not expressing mental health and behavioral challenges in the classroom. When asked to explain how she thinks the children feel, when they see children not joining the group or following the classroom's expectations in the same way, Roxanne said,

Well, we talk honestly about it you know, 'that person isn't able to sit like you are and wait. They can for a little bit and then they can't. And there are other things they can do, really well'. We try to just have that 
conversation with them because we include so many kids with all different behaviors that's just kind of the kind of community we have there, and the kids really understand that. And they actually help those three [with mental health and behavioral challenges] especially well. I mean there are kids that will tell them, 'hey you know, we're going to go do this right now so why don't you come and sit next to me.' And the one other kid will say 'hmm no no' and the kid will say 'alright well I'm going to go ahead and go over here.' And you know, our kids will say that and they kind of take on the role of nurturing those three especially because they do see that they need something different and we do allow that. And all the kids know that if they need something different that day that they need to talk about, that we're going to listen to them, do something for them just as much as we would do for any other kids. So if they're really struggling with something that may have happened right before a big group time, they know that they can come and sit away and work through that with one of us if that's what they need to do. We've done that before with them and they know that about our routine there at Willow Center (Roxanne, Interview, March 12, 2017).

Fostering connection was paramount to each participant's teaching philosophy. Mary shared as her first artifact (January 26, 2018) a packet of information that she hands out to student teachers as well as interested parents that outlines her guidance philosophy for working with young children. In this packet there is a page entitled "Connection before Correction," a concept Mary discussed in both of her interviews 
(Interviews, January 26, 2018 and March 2, 2018). This artifact asserts that children need connection with adults through love, support, and acknowledgement, before the adults seek to change or modify behavior. As Mary explained, "we try really hard to lean into it and be like 'hey it looks like you're having a hard time with this', and really support that connection. But it takes a long time and you still see so many of those behaviors" (Mary, Interview, January 26, 2018). This assertion that, while connection is important, it can be time consuming and not always immediately effective, was reiterated in Mary's next interview as well when she was talking about a specific child who was struggling to keep his peers safe in the classroom:

I try to include him as much as I can in the group dynamic like hey 'I' $m$ glad we're all together. I'm glad we're all able to walk back to school' and trying not to isolate his behaviors... I try to include him in that connection, like 'we are all doing this'... I've also tried really hard to have that moment of one on one connection with him and then follow through with whatever the responsibility is, it's like 'I'm going to give you a really big hug right now and then I'm going to ask you to stand back up on your feet so we can walk back to school' and that moment of connection will often change the mood for a minute so it doesn't feel like that power struggle it can also, not do anything, I'm definitely looking for more strategies because it remains challenging (Mary, Interview, March 2, 2018). Connection seems to also buffer the effects of challenging behavior in the classroom, As Livia described when talking about one of her most challenging students, "He and I have 
developed a great relationship. I'm really going to miss him, as challenging as he's been this year I'm really going to miss him (Livia, Interview, August 18, 2017).

Stick-to-itiveness. The participants all shared a desire to include and meet the needs of children with mental health and behavioral issues. Livia described this as "stick-to-itiveness" in her first interview when she was describing the challenging behaviors of one of her students (June 16, 2017). "I just felt like the stick-to-itiveness for lack of better words, that was really important for him to know, that he was ok, he was different than the other kids and he dealt with things differently, but he was ok and he had a right to be here and to participate with us" (Livia, Interview, June 16, 2017).

Roxanne described a similar determination to support all children. In an email exchange Roxanne (February 11, 2018) explained that her center's values around inclusion were different than hers,

I've recently found out that the center in which I work does not support my feelings on this topic and has actually been a part of the 'preschoolexpulsion epidemic'... I want to know more about how to train or provide resources about how else children with behavioral or mental health needs can be supported in group care. Information I can train and share with my colleagues and director. I think it might be more information on how to combat ECE expulsions. Also what has come up in conversations about inclusion, is the idea of a "therapy placement"? And that this "placement" is the only place to access support for children with behavioral or mental health needs? That ECE support from other EC professionals is not accessible unless the child is in a therapy placement?? I have a lot of 
emotions about this and disagree that children only belong in certain settings to receive the support they need. Inclusion to me means children can access the support they need in any [early childhood] setting. Am I wrong to disagree with this?

The participants believed in finding ways to support all children. However, this did not stop several of the participants from sharing that they did encounter children whose behaviors were beyond their capacity to handle. The experience of not having the tools or capacity to support a child's mental health or behavioral challenges in the classroom is discussed in more detail below in the section entitled 'overwhelmed.'

Outside Resources are Necessary. All the participants discussed the importance of utilizing outside resources to better their understanding of the children in their classrooms and the children's experiences, which in turn helped them engage in more effective ways with their students. While the participants used different resources to support their classroom work (early intervention programming, inclusion advocates, expertise of supervisors, etc.) they all found highly skilled individuals to support their classroom work.

As mentioned in Sophia's case description above, she took multiple trainings to improve her practice. She also found and utilized a statewide program that supports teachers in creating inclusive classrooms. Through this program specialists came to observe and offer suggestions to support her growth as a teacher and her students' experiences. Sophia explained:

I called them about the behavior of my new kids this year, and these two kids, these two who I am most concerned about going to kindergarten, I 
feel like they both - they're, they have no developmental delays besides the social emotional, but they have a really hard time adapting to being instructed by an adult, you know, they really need to do things in their own way, or else they lose it completely, in their own ways, in different ways... And then I have another kid who is younger who is really, he has communication delays and he has high frustration, or a low threshold, he has a low tolerance for working with other people or um not getting his way, not getting what he wants right now, and so I asked them to come... Their role is to observe how I handle a situation and how the classroom is set up and how the routines are and [tell me] if those are helping or hurting (Sophia, Interview, March 24, 2017).

Sophia took the suggestions she received to heart and implemented them immediately. Because Sophia's school did not know much about early childhood education and she had a tenuous relationship with her administration, these outside resources were invaluable in carrying her through her moments with her students who challenged her the most.

Livia also found outside resources necessary to support her work in the classroom. Livia developed an important relationship with her county's early intervention program, which allowed her to deepen her understanding of mental health and behavioral issues and find new ways to engage with her students. Through this program the children who qualified as having special needs would receive free physical therapy, occupational therapy, speech therapy, and/or general teacher support services within the classroom. These specialists would not only work with the children, but they would work with Livia 
as well, offering resources, ideas, and suggested materials to improve her teaching and to lessen the mental health and behavioral challenges in her classroom. These specialists are what carried her through her very challenging second year teaching in her current school, "People from [the county's early intervention program] were supportive and even though they weren't there very much, they would give me resources and that helped me kind of build my understanding of what needed to happen" (Livia, Interview, August 18, 2017).

One of her favorite ideas she got from the county's early intervention program was to include visuals in her repertoire of methods to work with young children:

It's amazing to me... because I always felt like the visuals for me personally were like, that's just too much work, you know, just listen to my words and do what I say [laughed] you know, but I am amazed at how many times it works, when they just want to shut out all of the stimulation and the noise and they don't respond, but if you show them a picture they're like oh ok, and they're into it so I would, I started using them more (Livia, Interview, June 16, 2017).

One of the artifacts Livia shared with me from her school was a photo of her Classroom Agreements, Figure 2. Her Classroom Agreements, which she created with the children and posted in the classroom for them to see, offered visuals to go along with the individual agreements. As Livia explained,

You can see in the picture that there are picture cards, a lot of them go along with the picture cards and it didn't really, it wasn't really planned that way, it just worked out that some of the people from [the county's early intervention program] had these cards and a lot of them worked; the 
sign for listening and speaking and taking turns and being respectful and sharing, those kind of things, so you'll see at the bottom the visuals that we put on there, so some of the kids will see to remember (Interview, August 18, 2017).

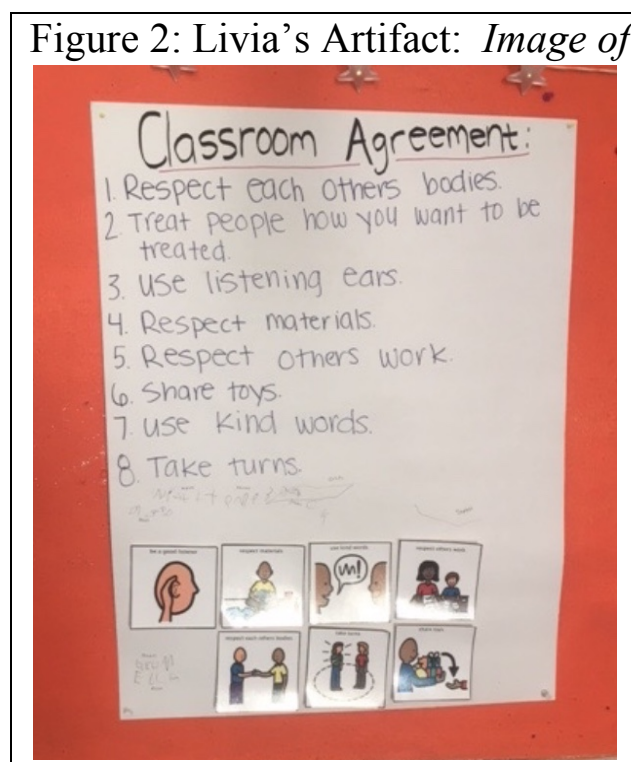

Figure 2. Image of Classroom Agreements, used in Livia's classroom and created with the support of the county's early intervention team. Artifact obtained by researcher on August 18, 2017.

While not every participant had a close relationship with formal inclusion programs, all the participants did reach out to others for support. Mary described how her direct supervisor, the school's infant/toddler coordinator, was a great support and resource for her when she had questions or concerns about things that were happening in her classroom:

I feel like I do have the opportunity to talk to my co-teacher and other teachers and my coordinator about the philosophy and how to handle those situations. And my coordinator has come in and kind of seen how these particular moments in the day unfold when we struggle to have children 
clear their dishes or there's a lot of defiance in a particular situation sometimes having that new face who knows the philosophy really well but may be not as familiar to the child, just having that new face in there changes the mood a little bit and changes the tone in the room and it unfolds a little bit differently so I do feel supported by them most of the time (Mary, Interview, March 18, 2018).

By utilizing the expertise of outside resources participants were expanding their understanding of children's mental health and behavioral needs as well as their toolbox of skills to use in the classroom with all children.

Want to Know More. While each of the participants self-selected into the study because of their interest in mental health and challenging behaviors, believed in stick-to-itiveness, and were in touch with outside resources, they all felt they had a lot more to learn. There was a sense among the participants that they were not doing enough, and that if they improved, they could have a greater impact on the children they worked with. This drive to want to know more came through during the interviews, email prompts, and artifact collection.

In general, participants found that the early childhood education field is not putting enough emphasis on understanding mental health and challenging behaviors. As Sophia explained, "I think a child's mental health is extremely important and it's the area where teachers have the least amount of training. Teachers and child care workers need help" (Email Exchange June 20, 2017). Further, Roxanne, who appeared very selfassured throughout the research process, made it clear during her last email exchange that she was still wanting and needing to grow as a teacher, "I just want to know more. This 
theme is definitely where my passion with children lies. There haven't been a lot of opportunities to learn about behavioral or mental health needs for children K-3" (Email Exchange, February 11, 2018). Lack of training and lack of opportunities for trainings were issues that came up throughout the study.

While all participants felt like they wanted to know more about mental health and challenging behaviors, some participants had specific goals they wanted to work on; things they noticed in their practice where they felt like they needed more support. As Sophia explained:

Right now I'm trying to learn the difference between being a friend, being friendly, and being a resource, and being a something else- that I'm not yet. Because I haven't been able to... put on the teacher hat. I had someone say to me last year, 'you know, you have to put on the teacher hat and say to the parent, you can't talk this way'.... Not that way of course, there's a way to talk to your kids and you don't call your kid an idiot. I haven't gotten that yet. So I'd really like to, I'd really like to, I don't know what class that is [laughed] (Sophia, Interview, March 24, 2017).

Other participants just wanted to learn more in a general sense; they understood they were missing some of the information and tools that could be helpful, but they were not sure exactly where or how to get that information. As Livia explained, Mental health issues have always been around but it seems as though they have become more prevalent in the last several years, and maybe more so for children? Violence? Food Additives? No attachment parenting? 
EARLY CHILDHOOD EDUCATION AND MENTAL HEALTH

Technology? Some may seem silly but I think there are a lot of correlations that could be made to any number of things. Where to start and how to weigh what is more important remains the question (Livia, Email Exchange, September 27, 2017).

Interestingly, while Livia had many questions about where mental health issues came from, and how to most effectively deal with them, she had already grown a lot through the trial and error of the past three years as a classroom teacher:

I started getting these kids [with behavioral issues], I was like "how did this happen?'... I just did what I needed to do... I think I just stumbled upon it because it was handed to me and I, I don't feel like, I mean yeah it's always an option to leave the job and find something different but that's not what I wanted either. So I just figured out ways to deal with it (Livia, Interview, August 18, 2017).

This growth is what inspired Livia to apply for the director position at her school, which she got and was intending to begin the following fall, specifically so she could offer more support and training to her teaching team, "I mean my heart is, still is really in the classroom, but I was frustrated with the lack of support that I had from my supervisor and really the only way that I knew that that might change is if I was in that position to offer that to my teachers" (Livia, Interview, August 18, 2017).

The participants all greatly wanted to know more so they could offer the best environment to the children as possible. Their not knowing did lead to some doubts, as Sophia explained, "Learning what I have about child development makes me feel very responsible for molding these young minds... So when I get a lot of behaviors at once, I 
wonder whether we do more harm than good" (Email Exchange, June 20, 2017). This fear of not knowing or doing the wrong thing, seemed to be a driving force for the participants to want to learn more. As I wrote in an analytic memo on March 7, 2018, I'm surprised by the self-doubt participants seem to all share. It seems like when they think about mental health and challenging behaviors they do seem to realize where they come from, but then they completely doubt their methods for dealing with these issues, even though, from where I'm standing (or observing as it may be) they seem to understand a lot of what to do already! It seems like confirmation from an outside source, perhaps a community training or a course within the university would give them the seal of approval they need to feel like they know what they are doing?

While I stand behind my memo, and believe all of the participants were attempting to create connected, nurturing, and caring environments for the children, I did notice throughout the interviews that several participants talked about serious issues that can negatively influence mental health and behavior, such as trauma and attachment issues, without truly understanding their impact on young children's brains and development. For example, Sophia shared her struggles with a few children, all of whom had experienced early loss or abuse:

They're also not getting involved with their work, they're not reaching that deeper level of learning, of making sense of the world, because they're skittering from one thing to another. And I know for my one girl, that she is so distracted... she just bounces from one thing to the other and then she can't, she'll have three things in front of her, and then I'll try to 
help her choose just one of them. But then the kids that I have that are really - well, that are kind of healthier seeming emotionally, don't seem to have as much trouble with, in guiding them. They want my attention, but they don't need to be reminded or redirected (Sophia, Interview, March 24, 2017).

In this description Sophia did a fantastic job outlining what occurs when children have experienced early trauma. Preschoolers who have lived or live in unpredictable and stressful environments may have a hard time calming themselves and focusing because they are constantly scanning the environment for threats to their physical and emotional safety. This can be called hypervigilance, which can make preschoolers seem inattentive, impulsive, and hyperactive (van der Kolk, 2014). However, Sophia did not have this language, which left her to describe what she was seeing without any confirmation that her experiences with the children are valid and true from a research standpoint.

\section{Emotional reactions to children who experience mental health and}

behavioral challenges. Throughout this study the participants shared, and I observed, the ways in which they emotionally responded to the children's mental health and behavioral issues that surfaced in the classroom. When analyzing the data I constructed specific subthemes that highlighted the ways in which participants emotionally reacted to the children who expressed mental health issues or challenging behaviors. The emotional responses that were shared across cases most frequently include: 
- Try to stay calm;

- Frustration happens; and

- Overwhelmed.

Try to Stay Calm. The participants spoke about their intentions to stay calm in the classroom. "I try really hard to keep a calm voice around the classroom, whether I'm just having a conversation or asking the child to do something" (Mary, Interview, March 18, 2018). By staying calm the participants hope to build strong relationships with their students, as Livia explained, "I feel like it's really important for [children] to feel accepted right where they're at. And to be given some tools to use to be successful... and a lot of that just takes some repetition and a lot of unconditional love I think (Livia, Interview, June 16, 2017). By staying calm the participants were able to build their connection with children, and in turn, the children's capacity to handle their emotions.

During the observations, there were many examples of the participants engaging in calm, quiet, and engaging ways with the children. For example, during one observation of Roxanne I wrote the following observation and fieldnotes:

Roxanne rings gong, everyone is quiet.

Roxanne: 'I'd like to tell everyone that in about 5 minutes we're going to clean up because I realized snack time is in about 12 minutes, so it's sneaking up on us.' The children resumed talking. Rozanne starts helping children clean up their clay project.

Child to Roxanne: 'why can't we go outside?' 
Roxanne: 'well we were doing a bunch of stuff inside and time flashed by.' Roxanne rang the gong again.

Roxanne: 'Did you hear that gong? That's to get your attention because it's time to clean up for snack.'

The kids began talking again, some are cleaning up. Roxanne starts calling out individual names to direct them to put stuff away.

Roxanne: 'Katarina can you come help me find 5 pieces to put into the Polly Pocket box?'

At this moment another child comes up to her to tell her another child threw something at him.

Roxanne: 'I saw that, do you want to ask him about it?'

The child turned to the one who had thrown the object and says: 'Why did you throw that thing? Because it hit me in the head'

The child who threw the object says: 'I was throwing it in the bucket' (Roxanne, Observation, November 10, 2017).

This exchange continued on for quite a while, with Roxanne simultaneously directing children to put toys away while engaging in the facilitation of problem-solving between the two students, where one accidentally threw something at the other. There was a lot going on in the room, and Roxanne seemed aware of all of it. When the child came up to Roxanne to tell her that he'd had something thrown at his head, and Roxanne responded with "I saw that," it caused me to take note. In the margins of my observation (November $10,2017)$ I wrote, "Roxanne seemed aware of conflicts before they were brought to her attention, but she monitored with a watchful eye, rather than swooping in to fix the 
problem. This seemed to allow her to stay calm, rather than get flustered by the children's behaviors before the children themselves decided they didn't like what was happening."

This capacity to see a room full of children, with the energy, noise, and movement that comes with them, and still remain calm was shared by other participants as well. Livia explained how she remains calm, even in the face of chaos:

You know, in my classroom sometimes it feels really chaotic, it can be loud, but when you stop and kind of remove yourself and look around there's so much going on there, the engagement with each other, the intensity of a puzzle or the block area is really fun to watch if you can separate yourself from the noise level, there's a lot of really great stuff happening so you know sometimes I think it feels chaotic but it's just the noise level (Livia, Interview, June 16, 2017).

Remaining calm to see the beauty and engagement of the children's learning within the noise and chaos seemed to be temperamental for many participants, "I've learned also it is just in my temperament, being I think a little bit more patient in my responses" (Roxanne, Interview, September 20, 2017). However, even Roxanne who sees herself as temperamentally calm and patient, was sometimes able to display a calm exterior, but not a calm emotional interior. When I said to her during an interview, "something I noticed was that nothing seemed to really ruffle your feathers, you were calm and even about everything" she responded, "good, because it doesn't always feel that way" (Interview, March 12, 2017).

For participants, staying calm seems to have two purposes: first, to build stronger connections to and relationships with the children as discussed above and second, to 
leave room to communicate when things were serious. As Mary described, "I try really hard not to raise my voice and I rarely do, but I think those really authentic reactions, I want the children to notice them from everyone in the classroom... I think that's why my tone changes [when one child is hurting another] because that's one of my biggest priorities in the classroom, especially with this age group (Mary, Interview, January 26, 2018). Danger seemed to bring about a tone change faster than anything else, participants seemed to want to communicate swiftly and clearly that there was a problem.

Frustration Happens. While participants clearly wanted to communicate a calm exterior and often felt calm inside as well, there were moments where they each felt frustrated as well. This frustration seemed most prominent when (a) the participants felt like the children were engaging in repetitive behavior or (b) not complying with requests or following classroom expectations that they had the capacity to follow. As Livia explained, "Power struggles are WAY too easy but never very helpful" (Email Exchange, August 17, 2017).

Dealing with the same behaviors over and over seemed to cause an emotional reaction of frustration for the participants. Roxanne explained, "In my head it's like, you know a huge sigh, like 'uh come on'... a little frustration that they're going at this again, whatever it is" (Roxanne, Interview, September 20, 2017). Mary described how her body changes when the children are engaging in challenging behaviors over and over again, "I do feel it in my body because I do feel such a close connection to these children... the behaviors can be more repetitive, you know, you see the same situation over and over again; two children pulling on the spatula, two children pulling on the car, two children pulling on the firetruck" (Mary, Interview, January 26, 2018). 
This frustration was also visible in the classroom during some of the more tense moments where children displayed bigger behaviors during daily routines. For example, during an observation of Sophia on April 7, 2017 I wrote in my notes that Sophia seemed frustrated by the behavior of one child, Sam, in particular. Sophia had previously mentioned that she believed there was emotional abuse, if not physical abuse, happening between Sam's parents, and that she was not sure if that abuse extended to Sam as well. In this particular moment, it was cleanup time and Sam was not participating in cleanup, he was continuing to play. Sophia's tone changed from her initial request for participation once she realized Sam was not listening, she said in what I noted as a 'rough voice,' "Sam, Sam, I need you to look at me. I'm covering the puzzle because I know you want to do it, but I need you to look at me." Sophia then took the puzzle away, and Sam screamed, "hey!" As the observer, it seemed clear that Sophia was annoyed by Sam's refusal to participate, and her frustration was palpable the longer the power struggle continued.

The participants felt frustrated by repetitive behaviors as well as behaviors they believed the children knew how to handle. Mary described her emotional reaction to the specific behaviors of one of the children in her classroom, "It gets frustrating because I know what he's capable of" (Mary, Interview, March 18, 2018). This feeling of frustration when it was believed the children knew what to do, but simply were not doing it, was reiterated by the other participants as well. Livia explained her frustration dealing with one child who expressed challenges in the classroom, "I think it is because it's been a whole year and I, I know he has the skills and I know sometimes he's just doing it because he wants to push buttons" (Livia, Interview, August 18, 2017). In another 
instance Livia described again how her frustration was amplified when she felt like the children's behavior was something they could control or change:

I certainly, have my days of frustration, I mean even this year, I had a great group of kids and there was one day this spring when I told them, I was like, I was so frustrated and we'd had this conversation and I said, 'I am frustrated enough that I feel like not even being your teacher any more' [laughs]. And a couple of them go 'huhhhhhh!' And I was like, I was just being real because that's how I was, so frustrated, and most of the kids that were frustrating me were the good kids, you know, who always follow directions and did what they were supposed to do and had a good time at school... but I just was honest with them about how I was feeling, that I still loved them, but I was just really frustrated (Livia, Interview, August 18, 2017).

To override the expression of these feelings and remain calm as they hoped for, participants used reflection and self-talk. As Livia described, it would sometimes help to remind "myself to be patient or in some cases to acknowledge out loud that I'm not feeling very patient today” (Livia, Email Exchange, August 17, 2017).

Overwhelmed. Along with describing feelings of frustration, participants described feeling overwhelmed by the more challenging behaviors and mental health needs they encountered in the classroom when they did not believe they had the knowledge or tools to handle situations that arose in the classroom. As Sophia described in an email, "When I have one child not wanting to clean up while another runs out [of the room] to the bathroom to wash hands for snack, I tend to get flustered. Even harder is 
the scenario where I have a child with big feelings and everyone else wants to eat or go outside" (Sophia, email, June 5, 2017). The pull of multiple needs seemed to leave participants emotionally overwhelmed and unsure of how to respond to the behavior.

Each participant was asked if they had every had a child whose mental health or behavioral needs they felt like they couldn't meet, and Sophia, Roxanne, and Livia all agreed they had. Sophia had expeled a child for behavioral reasons, and Roxanne and Livia had essentially counseled the children out of their programs by sharing the difficulties they were having with the children's families. Mary had never gotten to that point with a child, but also seemed to believe it was possible to get to that point, as she explained:

I've definitely had some behaviors that I don't know how to support myself and I've definitely reached out and asked for some support, but I don't think I've ever... I haven't, I haven't gotten, I mean I'm a pretty young teacher and I haven't gotten to the point of like, I just don't know what to do with this kid, I think the closest I've gotten is with Tom [a current child in the class] (Mary, Interview, January 26, 2018).

All participants, whether they had gotten to the point of deciding they could not handle a child's needs or not, described feeling overwhelmed by certain behaviors. Roxanne described feeling uncertain about how to handle some of the bigger mental health and behavioral needs of some children. She described her experience with one child who eventually left Willow Center, a decision, that while initiated by the child's parents, seemed to come as a relief to Roxanne: 
EARLY CHILDHOOD EDUCATION AND MENTAL HEALTH

[He] definitely didn't have any diagnoses for any sort of special needs or anything, it was definitely some mental health challenges... There were times, there were only a couple of times where it got to the point where we've done all that we can do at this moment for this person, well we didn't know, I mean I didn't know how else to help them in that moment (Interview, March 12, 2017).

Livia also described her experience with a child whose behaviors overwhelmed her. Like Roxanne above, the child's parents eventually unenrolled him from the preschool:

So although it wasn't our choice necessarily for him to leave, it was, we really didn't have the skills or the staff to meet his needs. He was delightful when he was on, but in a split second he would turn, and he was big, he was a big kid. It was difficult to anticipate what was going to happen... he would, he threw chairs at me, he would just pick up chairs and throw chairs at me. He was really angry and a big kid (Livia, interview, June 16, 2017).

So while only one of the participants had actively expelled a student, two other participants had been in conversation with the children's parents who ultimately made the decision to pull their children from the schools.

\section{Engagement with children who experience mental health and behavioral}

challenges. Participants shared that how they engaged with children in the classroom was greatly informed by the ways that they thought about and emotionally reacted to the children who expressed mental health issues and challenging behaviors. Their beliefs about how they wanted to be with children, and their emotional reactions to the children, 
determined in many ways their moment-to-moment engagement with their students. My data collection methods allowed multiple observations of each participant where I was able to notice how teachers interacted with and responded to the children in their classrooms. Through the observations as well as the other data, the following subthemes were created to describe participants' engagement with the children:

- Flexibility and boundaries;

- Warmth; and

- Different.

Flexibility and Boundaries. The participants all demonstrated a high level of flexibility in their engagement with the children in their classrooms. However, this flexibility seemed to have differing results, depending on whether it was coupled with clear and consistent boundaries. This section will detail the ways in which flexibility and boundary setting was demonstrated in the classroom.

Livia, Sophia, and Roxanne all co-created classroom agreements with the children in their classrooms and referred to these agreements when engaging with the children during some of the more challenging moments. Rather than relying on their adult sense of fairness, these classroom agreements supported the children in determining what felt good and fair. While Mary did not have set classroom agreements like the other three participants (the children in her classroom were not yet speaking in sentences) she engaged the children in conversations that allowed for flexibility and for the children's voices and needs to shine through. For example, during observations Mary was heard using language such as, "are you both okay with that?" to engage the children in the discussion of what was and was not okay in the classroom (Observation, June 2, 2018). 
As Mary explained during an interview, "We try our best to talk [through conflict] and if the children don't react to something I try and not to react to it, which can be really challenging because as an adult I have a very different sense of fairness than a toddler does [laughed], I'm like no they were using that! But she didn't react to it, so I'm not going to make a big deal about it” (January 26, 2018).

Roxanne's second observation (May 12, 2017) highlighted her flexibility with the children. During the children's daily afternoon snack Roxanne sat down with one table to eat the offered chips, guacamole, and cheese. At this table there was some discussion, and raised voices, among the children about how many chips the children should take for their first scoop and how much was available for seconds. There were children standing and one child was reaching across the table to take the bowl and serving tongs out of a peer's hand. Roxanne sat calmly and watched as the children attempted to problem-solve. Luckily, it seemed as the observer, Roxanne was asked by the children how much they should take for seconds and she said, "It looks like if you take the same amount for seconds, there will be enough for everyone" (Observation, May 12, 2017). While this language is flexible- it offers a suggestion but no prescribed command - what seemed most interesting to me as the observer was what came next. A few minutes later, Roxanne walked over to the second table of children and asked them, "What are you doing for seconds?" (Observation, May 12, 2017). By posing a question to the children, she was allowing them to come up with their own plan and their own sense of fairness, rather than simply imposing her own ideas on to them. Roxanne's flexible approach allowed the children to feel ownership over their activities and seemed to foster a community of capable learners. 
During my first observation of Livia (May 31,2017) I watched as she helped the children create what she called "Jackson Pollocks;" these were pendulum paintings that were made by placing paper on the floor, filling a plastic soda bottle with paint, and hanging it from a string attached to a tripod above the paper. Each child would then get a turn to swing the paint filled bottle and watch the paint drip down onto the paper. As I watched the children take their turns, it became evident that they all had different swinging patterns. While yes, most ensured the paint landed only on the paper, for some the paint splattered off the walls. One child in particular had a lot of energy and a loud voice during this exercise, he seemed a bit escalated and very excited to participate in the project, he enthusiastically swung his paint filled soda bottle, and the paint went flying everywhere; the walls, the floor, and the chairs around them. Livia turned to the swinger and with a large and genuine seeming smile on her face said, "are you getting paint all over?" Livia engaged with this child in a playful manner. She allowed all of the children to explore the materials in different ways, but also set firm boundaries around cleanup time. When it was time to clean before their daily circle, she ensured that all the children who had painted cleaned up their messes, including the child who had swung his paint around the room. In my observation notes I wrote that Livia did not "seem bothered" by the different ways the children engaged with the materials (Researcher Notes, May 31, 2017). Rather, she seemed to delight in their engagement.

When asked about her thinking during the Jackson Pollock activity, Livia described why she tries to have a high level of flexibility in her engagement with children, but also, why children need boundaries: 
EARLY CHILDHOOD EDUCATION AND MENTAL HEALTH

There's just so much beautiful stuff going on that that I think we try to control too much, and kids definitely need boundaries and they need routines and they need structure... but at the same time there's a lot of, there's so much speaking to coloring outside the lines and making exceptions at certain points and so the paint gets on the floor - well, you know where the rags are you can go clean it up, and they do, and it gives them a sense of they're capable. It's also if, if they look at it as a mistake or something, that it's ok, it's not the end of the world. [Becoming flexible] was definitely a process, I think just, part of getting older and seeing my own kids, not wanting to micromanage because it was exhausting [laughs] (Livia, Interview, June 16, 2017).

Livia's flexibility determined how she engaged with the children and how her individual activities played out, and also determined the curriculum she offered the entire class. When discussing her second-year teaching in her current school, a year when she had several students with behavioral challenges, she describes how her teaching style changed to meet the needs of the children:

There's a lot of things I let go of that year, in terms of what I wanted to bring to the classroom or teach, you know, because so many of these kids had behavior stuff they needed to work on, and so that's what we spent our time on. How do we get along with other people? And how do we approach other people? And just those kind of basic life skills, so I did let go of a lot and that's just sort of what we focused on (Livia, Interview, June 16, 2017). 
Mary's flexibility was demonstrated in the classroom through her consistent use of choices and her flexibility to change spaces or rooms based on the energy and needs of the students (Observations, February 2, 2018 and March 16, 2018). Figure 3 offers a page from Mary's packet outlining her guidance philosophy. This page, entitled Adult-Child Power Relationships, reiterates the importance of flexibility with strong boundaries that was seen from Mary in the classroom. The document describes how power can be used in multiple ways with children; there are times when the adult must be in charge and hold all the power; there are times when the adult's role is one of holding the boundaries for the child's exploration; and there are times when the child and adult share power and explore as learners together. Mary's engagement with the children matched the beliefs found in this document; she was consistently flexible within her boundaried classroom.

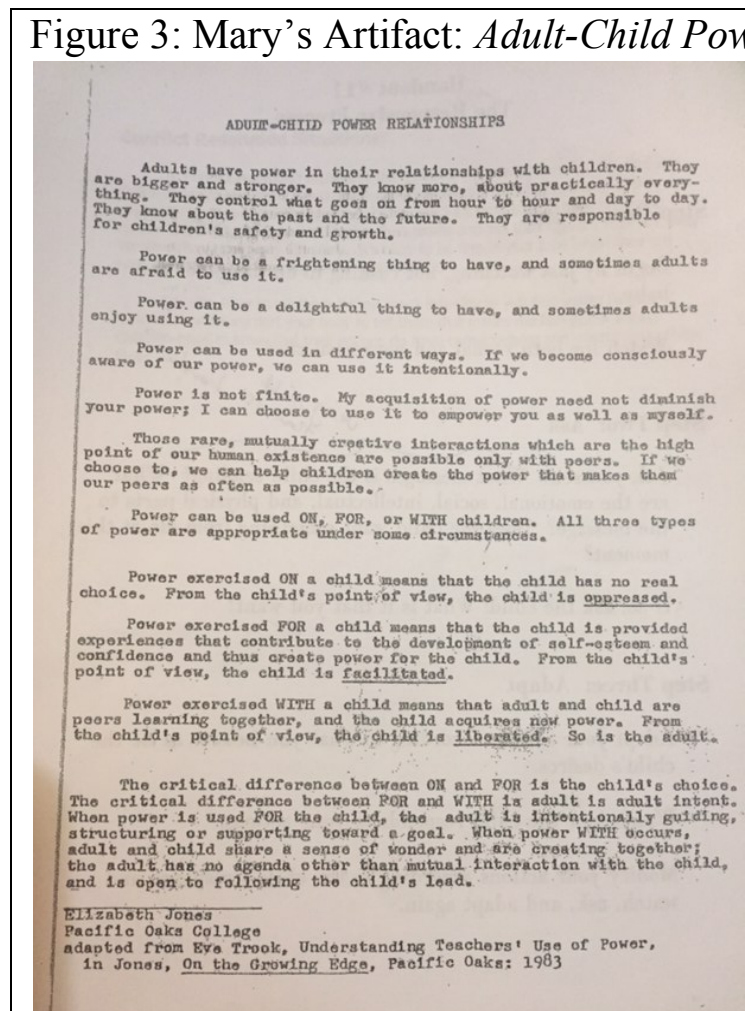

Figure 3. Image of Adult-Child Power Relationships. Given to student teachers in 
Mary's classroom as an example of how to interact with the children. Artifact obtained by researcher on January 26, 2018.

While all the participants attempted to engage with the children in a flexible manner while also holding boundaries, the line between the two was not always clear. Livia, for example, described an instance with a child who wanted to wear a particular piece of clothing that was not at school:

He is so defiant about what he's going to do and what he's not going to do and the challenge for me was just being able to be flexible with those periods and realize that, and kinda embrace that he's a nonconformist and that's okay, but then I had to ask myself, how do I do this as a classroom teacher? Because I don't want all kids to become nonconformists because that would make it really difficult to do what we do, but also be able to honor that that's kinda who he is (Livia, Interview, August 18, 2017). Being flexible while also holding boundaries seemed to be a challenge that other participants experienced as well. Participants sometimes seemed to find themselves lost in the dance between flexibility and boundary holding. Sometimes, flexibility left the children without a sense of where their role ended, and their teacher's role began. For example, during an observation on April 7, 2017, I watched as one of the participants read a book to the children in her classroom as they ate snack. During her reading there were several different interruptions: children needing water cups, children getting up from the table, and children talking to her about other things besides the book. To each interruption she responded immediately, which made the book hard to follow and caused 
more and more children to lose interest in listening; I wrote in my observation notes, “there were lots of distractions during the book; responding to the kids' different needs throughout the process and interrupting the flow - the entire thing felt disjointed and hard to track" (Researcher, Observation Notes, April 7, 2017).

In another instance I watched as a participant transitioned the children from playing outside on the play structure to inside for circle. I observed as a five-minute warning was given to the children, however, when the five minutes were up several children still had one last thing they wanted to complete, and rather than holding the boundary of the limit, the participant attempted to accommodate the different children's needs, which caused all of the children to lose focus and slowed the transition inside. I wrote in my observation notes, "She tries to accommodate the needs/requests of the students to the point of loss of control/not holding boundaries" (Researcher, Observation Notes, May 29, 2017).

While the participants' flexibility worked to build connection with the children, when lacking boundaries it seemed to cause tension and leave the children without a clear sense of who was supposed to be setting the limits around what could and could not happen within the school environment.

Warmth. Throughout the twelve observations I completed, each participant exuded warmth for the children. The warmth displayed by the participants toward the children was demonstrated in multiple ways; they showed they liked them, enjoyed being with them, and had fun with them through facial expressions, laughter, nurturing touch, and tone of voice. During the interviews, the participants all shared the deep love and positive regard they had for the children; Mary described her feelings for 
the children in her first interview, "I'm so emotionally connected to these children, I love them all so much and I am so attached" (January 26, 2018). The way the participants engaged with the children during the observations corroborated the feelings they shared during the interviews.

As I discussed in the individual case descriptions, during my first observation of Roxanne on March 10, 2017 I observed as most of the children attended a meeting facilitated by Roxanne's supervisor Evelyn on the playground while three children continued to play. Roxanne had prompted the three children to join the discussion, but when they refused, she moved off to the sidelines. At this point, another teacher came over and also attempted to engage them in the meeting. I wrote in my observation notes that his voice seemed "rough and annoyed" (March 10, 2017). When he realized they would not be listening to him, he retreated to the meeting and Roxanne remained by the children. Throughout all of this, one of the children was playing with a bat, swinging at imaginary balls and celebrating imaginary home runs. At one point Roxanne turned to him and with a wide and genuine smile said, "if you want to practice those moves will you do that away from where we are?" (Observation, March 10, 2017). I noticed during this interaction how she was both calm and flexible, but most significantly, she was warm; her eyes were soft and her smile was genuine. She seemed to find real joy in this child, even when he was not listening and participating in potentially distracting behavior.

This same warmth was seen from the other participants in the classroom as well. Livia too had a genuine smile that she shared with the children during moments when her teaching team seemed overwhelmed or annoyed by the children's behavior. During 
Livia's third observation I wrote in my observation notes, "joy- she has joy on her face when other teachers have anger and frustration" (Livia, Observation, September 8, 2017).

Mary was observed hugging and holding the children in her classroom. During an observation, I watched Mary interact with Tom, a child whose behaviors seemed to sometimes overwhelm Mary, as she woke him from his nap. Mary sat next to Tom and said, "it's time to wake up, I'm going to lift you up and snuggle you" before she took him off his mat and put him on her lap (January 16, 2018). Later in the observation Mary was talking to another child who had just come back into the room after a diaper change and was trying to push another child, Laura, off Mary's lap so he could sit with her; Mary said to him, "Are you wanting a hug? Laura is sitting in my lap, I'm not going to let you push Laura out of my lap, but I have a hug for you" (Observation, January 26, 2018). The participants consistently engaged in warm ways with the children because as Sophia explained during her last interview, "It's just so important, no matter what, and no matter how you feel about their behaviors or their actions, to care for them and love them and show them that they matter" (May 5, 2017).

Different. While it is true that the participants were warm and loving with the children, it was also noted that throughout the observations all four of the participants focused more of their attention and their time guiding the behavior of boys and used different tones of voice to communicate when they wanted behaviors to stop for boys and girls. For boys I noted participants using a stronger and coarser voice, and with girls I noted participants using a softer more relaxed tone, even while repeating the same request. This focus on the behavior of the boys in the classrooms was corroborated during the interviews; throughout the interviews the participants spoke of multiple boys with 
mental health needs they were concerned with or big behaviors they did not know how to resolve, but each only noted one girl with comparable issues.

Research demonstrates that boys are more likely to have externalizing behaviors (hitting, kicking), while girls are more likely to have internalizing behaviors (anxiety, fears). However, this does not mean that boys' behaviors are more problematic or concerning (Foster et al., 2005; Gilliam, 2005; National Alliance of Mental Illness [NAMI], 2007). This focus on the externalizing behaviors in the classroom demonstrates participants' focus on the immediate highly visible needs of the classroom environment. For example, Livia spoke about how her classroom was "basically a behavior classroom last year" (Email Exchange, September 23, 2016) in her initial email to me; six out of her thirteen students expressed mental health or behavior challenges in the classroom. When pressed to share more about that experience, she spoke about several boys with mental health needs and challenging behaviors. Of all the children she mentioned, she only spoke of one girl, the sister in a boy/girl sibling set who had experienced early trauma. The participant explained how although she recognized they both had behaviors, their behaviors were different; "she had a lot of behaviors, not as severe as her brother" (Interview, June 16, 2017).

This focus on boys' behaviors being bigger than girls' behaviors was seen during the classroom observations. In fact, outside of one child who missed the group meeting on the playground during Roxanne's first observation (March 10,2017) and Laura's behavior in Mary's classroom (January 26, 2018; March 16, 2018), there were no other notable guidance moments during the observations of big behaviors between the four participants and the girls in the classrooms. 
Further, while there were very few black children in any of the classrooms, I also noted in one of the classrooms that the only black presenting child, named Jax, seemed to receive an inordinate amount of guidance, although his behavior appeared to the researcher to be on par with his peers. In the analytic memo I composed directly after my first observation of this participant, I wrote, “I'm wondering if Jax's behavior will come up during the interview? To me it seemed like [she] was using a harsher tone with him and was micromanaging his behavior more than the other children" (Analytic Memo, January 26, 2018). Later, during my second observation in the same classroom after watching and recording another incident with Jax, I wrote in my observational notes, "Jax [is] the only black child in class - I was surprised during the interview that she didn't mention him as a hard kid because she corrects him a lot, although his behavior seems typical and equal to others" (February 2,2018). While one teacher and one participant cannot justify a subtheme on its own, it is mentioned here because it seems important to acknowledge and note as an area of possible difference. More research must be done to make formal conclusions or even suggestions about the interplay of race and guidance strategies as it relates to mental health and behavioral issues. However, since previous research has demonstrated that teachers' perceptions of students differs based on the children's race, it seemed significant to explicitly acknowledge and address my observations here (Gilliam, 2016b).

\section{Summary}

Chapter four reported the findings in two ways: first, in Section One individual case descriptions were offered to get a clear picture of who each participant is as an 
individual and to analyze their unique experiences. As the individual cases evinced, each participant had unique thoughts, emotions, and reactions to children with mental health issues and challenging behaviors in the classroom. Along with describing the individual participants, a cross case synthesis was conducted to look for themes among the cases. Section Two identified overarching patterns found among the data by explaining the themes and subthemes developed that elucidated how participants think about, emotionally react to, and engage with children with mental health issues and challenging behaviors. In the next and final chapter, chapter five, I offer a discussion of the findings and outline the implications for practice and possible avenues for future research. 


\section{Chapter Five: Discussion}

\section{Introduction to the Discussion}

Chapter five begins with a synthesis of the study's findings, which answers the research question: How do students in an in-service early childhood teacher education program think about, emotionally react to, and engage with children who express mental health issues and challenging behaviors in their classrooms? Using my anti-oppressive lens, I continue the discussion by sharing the implications of the study, as well as suggesting ways to include issues pertaining to mental health and challenging behaviors in both in-service teacher preparation programs and professional development within early childhood settings. Next, I reflect on my own biases and positionality within the research context and discuss how who I am may have affected the study. I then acknowledge and discuss the limitations of the study. Lastly before concluding, I offer suggestions for future research.

\section{Synthesis of Findings}

I used a comparative or multiple-case design to collect data on four students in an in-service teacher education program to understand how they think about, emotionally react to, and engage with children who express mental health issues and challenging behaviors in their classrooms. Using observations, interviews, artifacts, and email prompts, I collected data over a thirteen-month period. I used three primary first cycle coding methods: Values Coding, In Vivo Coding, and Emotion Coding before using Focused Coding as a second cycle coding method to reorganize and reanalyze my data to develop themes and subthemes. 
Using a multiple-case design allowed me to hone in on the experiences of the individual cases to look at the unique ways each participant thinks about, emotionally reacts to, and engages with children who experience mental health issues and challenging behaviors in their classrooms while also completing a broader cross-case synthesis, which enabled me to look across the cases. Through this process specific themes and subthemes were created, including:

- Thoughts about children who experience mental health and behavioral challenges: home environment; classroom environment; children need connection; stick-toitiveness; outside resources are necessary; and want to know more;

- Emotional reactions to children who experience mental health and behavioral challenges: try to stay calm, frustration happens, and overwhelmed; and

- Engagement with children who experience mental health and behavioral challenges: flexibility and boundaries; warmth, and different.

The findings of this study are unique because of the self-selection process of the participants. Roxanne, Sophia, Livia, and Mary joined this study because of their individual interest in supporting children who experience mental health and challenging behaviors. They made statements such as, "I think about this stuff all the time" and this is "where my passion with children lies." Because this was a topic of interest for all four participants, their thoughts on the subject were vast and deep; the findings covered both the factors that influence children's mental health and behavior as well as thoughts about what to do in the classroom to support children. Through the data collection process the participants' emotional responses to children who experience mental health and challenging behaviors were explored and elucidated as well as the ways in which 
participants engaged with children who expressed challenges. While each of the themes were parceled out in chapter four to describe in detail the findings of this study, this section offers a synthesis of the findings to explain how the three themes and their subthemes are connected and influence each other. Through this process I will connect the themes to the contemporary literature, noting similarities as well as differences. Next, I will use these findings to assert implications for practice.

As the literature review demonstrates, relationships and early experiences shape brain development and behavior throughout children's lives (Delima \& Vimpani, 2011; Herman, 2015; Siegel \& Payne Bryson 2012; van der Kolk, 2014). The data indicate that the participants have a general understanding of this current research and actively think about the effects of the home environment and the classroom environment on young children's mental and behavioral health. Throughout the data collection period the participants shared their beliefs that young children's environments greatly impact their development. They consistently noted that the children's behaviors can often be traced to their early experiences; domestic violence, history of adoption, and parental divorce were just a few of the incidents the participants shared as influencers of children's behavior. However, interestingly, systemic issues of inequity and injustice affecting children's home environments and school experiences were not discussed by the participants. Participants shared the issues families faced, without acknowledging how these issues were connected to the larger societal context. Further, research indicates that genes matter; children's genes are expressed based on their early experiences (Larson, Russ, Crall, \& Halfon, 2008; Shonkoff \& Phillips, 2000; van der Kolk, 2014). And while two participants, Livia and Roxanne, briefly mentioned that mental health and behavioral 
challenges can also be genetic, the four participants primarily focused their attention on the environmental factors that influence children's behavior.

Participants described how children need adults who believe in stick-to-itiveness to overcome their challenges; stick-to-itiveness being defined as the belief that educators should include and meet the needs of children with mental health and behavioral issues in the classroom. "Not all the kids in one space can be all alike, we can honor their differences, and teach nonchallenging kids how to understand challenging kids, they can be in the same space with them" (Livia, Interview, August 18, 2017). The participants believe in classrooms that offer children the "tools to use to be successful... and a lot of that just takes some repetition and a lot of unconditional love" (Livia, Interview, June 16, 2017).

This belief in stick-to-itiveness aligns with the current research on the benefits of inclusion. Inclusive programs allow both typically developing and nontypically developing children to learn from each other and grow their capacities to have patience, understanding, and empathy while also stopping children's behavioral issues from worsening throughout the elementary and adolescent years (Carlson et al., 2012; Brennan, et al., 2003; Odom, 2000; Shonkoff \& Phillips, 2000). However, while the participants' beliefs are broadly in line with the contemporary research on the importance of inclusion, these findings counter the research concerning educator beliefs about their role in the classroom. Research has indicated that often teachers do not see supporting young children's mental and behavioral health as within their purview, and yet the data in this study indicate that participants all shared a disposition towards inclusion; they saw it as the educators' role to support young children's mental and behavioral health in the 
classroom (Hemmeter, et al., 2008; Kauffman, 2004; Severson, Walker, Hope-Doolittle, Kratochwill, Gresham, 2007).

The participants' focus on the impact of environmental factors on young children's behavior and their belief in stick-to-itiveness informed their understanding of the best ways to support children with mental health and behavioral challenges in the classroom. Participants believe that to overcome challenges children need connection with safe and consistent adults. As participants shared, "I think the bottom line isrelationships are everything" and "I know my relationship with the kids and their families matters a lot" (Mary, Interview, January 26, 2018; Sophia, Email Exchange, June 20, 2018). This claim is supported by current literature on the importance of connection to change problem behaviors (Badenoch, 2008; van der Kolk, 2014).

This focus on the importance of connection and relationship building informed participants' emotional reactions in the classroom. Throughout the data collection period, it was noted that participants try to stay calm when working with children with mental health issues and challenging behaviors. Roxanne explained she tries to stay calm "in hopes that they can rely on me to hear them before heading into challenging behaviors, or that when they are in that spot, they can rely on my consistent response to eventually feel more at easy" (Email Exchange, January 9, 2018). As the literature review described, children learn to regulate their feelings and behaviors through their interactions with their significant caregivers. The capacity of educators to stay emotionally regulated and the relationships educators form with the children influence how the children see themselves and see the world (Bowlby, 1980; Stacks \& Oshio, 2009; Stubenbort, Cohen, \& Trybalski, 2010; Swartz \& McElwain, 2012). Thus, by staying calm the participants 
hoped to build strong relationships with the children that could help alleviate and lessen some of their challenging behaviors.

Further, along with their calm emotional response, participants engaged the children with warmth; they offered smiles, nurturing touch, supportive words, and more to engage the children and demonstrate their availability for connection and relationship. The way the participants engaged with the children during the observations corroborated the feelings they shared during the interviews, as well as the research on the importance of connection and physical touch for young children (Dombro, Jablon, \& Stetson, 2011; Ho \& Funk, 2018).

However, even while understanding the importance of their relationships with the children and their belief in stick-to-itiveness, participants all stated that they did not believe they have the knowledge or tools to successfully work with some of the biggest problem behaviors in their classrooms and they want to know more about how to work with and help the children with the biggest challenges. The participants shared statements such as, "teachers and child care workers need help," and "I need a lot more mentoring" (Sophia, Email Exchange, June 20, 2017; Mary, Interview, January 26, 2018). As the literature review in chapter two explained, this desire for more support and professional development has been found to be a high priority for educators in other studies as well; teachers believe they need more knowledge and tools to offer adequate guidance strategies to support all learners (Hemmeter, et al., 2007; Hemmeter, et al., 2008; NSCDC, 2008b).

Although the participants shared that their beliefs concerning the importance of sticking by children and connecting to them influence their desire and attempts to stay 
calm in the classroom, the interviews, email prompts, and observations found that

frustration happens. When frustrated participants shared that their bodies felt tense with an "inside feeling" (Roxanne, Interview, September 20, 2017) and they experienced "feeling impatient" (Livia, Interview, August 18, 2017). This frustration was noted during observations as well, through participants' tone of voice changing as behaviors escalated and specific comments such as "that was a bit frustrating" (Mary, Observation, February 2, 2018).

Further, participants felt overwhelmed when they did not know how to handle children's mental health and behavioral needs. Three of the four participants shared that not knowing how to handle a child's needs and feeling overwhelmed by a child's behaviors led to the child either being expelled from the program, "we removed her... we had to ask her not to come back," or counseled out of the program "it was his mom's choice, it wasn't our choice but it was, we had a lot of conversations" (Sophia, March 24, 2017). This inability to meet the needs of children with big behavioral challenges is noted in the current research as well; expulsion rates are higher in the preschool years than any other time, specifically because teachers in early childhood settings do not have the tools to handle these early problem behaviors (Gilliam, Maupin, \& Reyes, 2016a). Interestingly, the experience of 'counseling out' specific students is not mentioned in the contemporary literature, and may be skewing the current data on expulsions, making the rates of children with mental health and behavioral issues leaving programs seem lower than they actually are.

Because they wanted to know more and felt frustrated and overwhelmed by some behaviors, the participants believe outside resources are necessary to successfully meet 
children's needs. Whether they reached out to supervisors, early interventionists, or State trainers, all participants found others to help them in the classroom. They found these resources to be influential in their handling of challenging issues, "I've really enjoyed working with [the early interventionists]... I feel like they have been very responsive" (Livia, Interview, June 16, 2017). The value participants received from working with organizations and individuals outside of their classroom is reiterated in the contemporary research; teachers who are supported by outside resources are more likely to see positive behavioral changes from the children in their classrooms (Gilliam, 2008; Gilliam et al., 2016a). By utilizing the expertise of others, participants were expanding their understanding of children's mental health and behavioral needs, as well as their toolbox of skills to use in the classroom with all children. However, as noted above, although the outside resources were useful, they were not enough to make the participants feel confident in their capacities to handle the big mental health and behavioral challenges they encountered in the classroom, nor were they enough to keep all of the children successfully enrolled in the early childhood settings.

Research demonstrates that teachers' perceptions of their abilities to guide and influence their students' behavior directly influences children's classroom experiences. Teachers who believe they can have a positive impact on children's behavior engage with children in more flexible ways and use more creative guidance techniques than those who do not believe they can impact children's behaviors (Guzell-Roe \& Stringer, 2005). In alignment with this research, the findings of this study demonstrate that these participants, who all believed in stick-to-itiveness, engaged with the children in highly flexible and responsive ways. However, this study indicated an interplay between 
flexibility and boundaries; meaning, while participants all engaged in a flexible manner, they did not always hold clear boundaries for the children. It was found that the efficacy of participants' flexibility was interwoven with their capacity to set boundaries. For some, their flexibility seemed to be a helpful way to ensure the children were all getting what they needed. For others, where flexibility appeared to be without boundaries, children's behaviors escalated, and in turn, participants felt frustrated or overwhelmed. These findings align with current research that indicates young children do best in environments that are both flexible and boundaried; environments that give them the freedom to explore within the safety of predictability and structure (Siegel \& Bryson, 2012). Further, it affirms the research demonstrating that the ways in which educators engage in the classroom influences their emotional reactions to the children in their care (Hagenauer, Hascher, \& Volet, 2015).

While my data revealed that the participants were actively and intentionally thinking about how to best meet the needs of all children in their classrooms, the data also showed that the participants engaged with the children in different ways based on sex and perceived gender expression. In the classroom the participants focused their attention and time on boys' behavior and throughout the interviews and email prompts discussed their concerns about boys' behavior more than girls'. The participant response to behavior based on sex and perceived gender expression is corroborated in the research that shows that boys are more like to be viewed as having negative behaviors and are more likely to have attention focused on their behaviors in early education classrooms (Gilliam, 2005; Gilliam, 2016b). The findings of this study demonstrate that some children's needs may be overlooked; while boys are more likely to demonstrate 
externalizing behaviors that let their mental health and behavioral needs known, girls are more likely to display internalizing behaviors, which, while not as prominent and obtrusive, are still significant predictors of academic trajectories (Head Start Bulletin, 2009).

While the classrooms were predominantly white and the participants were all white (both limitations of the study discussed below), which left little data to gather based on the racial dynamics of the classroom, it was noted that the only black presenting child in one classroom seemed to receive an inordinate amount of focus, although a difference in his behavior in comparison to his peers was not noted. While these few observations are not enough to draw meaningful conclusions, it should be noted that these observations are in alignment with current research that demonstrates that black boys, even more so than white boys, are perceived negatively by their teachers (Gilliam, 2016b). The serious and significant implications of this finding of difference, as well as the other findings outlined in this synthesis, are discussed in detail below.

\section{Implications for Practice}

A synthesis of literature examined in chapter two concerning teacher disposition demonstrated that teachers' values, beliefs, and attitudes greatly influence how they engage with children in the classroom and ultimately, what children learn (Cummins \& Asempapa, 2013; Guzell-Roe \& Stringer, 2005; Hagenauer, Hascher, \& Volet, 2015; Hong, 2010; National Council for Accreditation of Teacher Education, 2010; Stewart \& Davis, 2005). This research revealed that the participants came into the study with strong values and beliefs, dispositions, toward inclusion and meeting the needs of all children. However, while they were able to meet the needs of most children, having a disposition 
toward inclusion was ultimately not enough to create classroom environments that could meet the needs of all children with mental health and behavioral issues. Through this study highlighting how students in an in-service teacher education program think about, emotionally react to, and engage with children who experience mental health and behavioral challenges in the classroom specific implications for practice were revealed. Using my anti-oppressive framework I present a discussion of and recommendations for addressing the needs of students enrolled in an in-service teacher education program, with the ultimate goal being of course to create a teaching force that has the capacity to meet the needs of all young children.

\section{Research Based Knowledge}

While the participants demonstrated professional dispositions that valued and believed in inclusive classrooms, I found that they wanted to know more. Thus, I argue that teacher preparation programs, as well as ongoing in-house trainings within early childhood schools, and community-based professional development opportunities must offer the necessary research-based knowledge, statistics, terms, and applicable laws and regulations, to deepen teachers' awareness of mental health and behavioral issues in the early childhood setting. While participants showed a basic understanding of the origins of mental health and behavioral challenges, they all felt they needed more to successfully handle the behaviors they saw in their classrooms. This gap in their understanding of mental health and behavioral issues was not for a lack of trying on their part; all participants shared they wanted to know more and were actively searching for the knowledge that could deepen their thinking and practice. 
The participants talked about the ways in which early experiences of trauma and maltreatment influenced young children's development, without having the research or terminology to affirm their statements or experiences. In chapter four it was noted that participants described the impact of early traumas without the proper terminology; they made statements such as "he was left alone" rather than "he experienced neglect" or "she has a hard time focusing" rather than "she is hypervigilant." Lacking this understanding of the relevant literature and language seemed to leave the participants with doubts about the behaviors they saw in the classroom as well as their capacities to handle the issues that arose.

It is imperative that teachers have access to research-based knowledge concerning young children who express mental health or challenging behaviors in the classroom. I believe this training must be a foundational piece of teacher preparation programs, since these programs are intended to prepare teachers to meet the needs of all students. However, this learning can and should happen within professional development days in early childhood education schools themselves, as well as via community-based learning. While teachers' needs for professional development change throughout their years in the classroom, this research has demonstrated that teachers at several different stages in their careers want more information. Offering different avenues for direct knowledge about where mental health issues and challenging behaviors come from and how they are expressed in the classroom, can create a teaching force at every career stage that feels knowledgeable and ready to tackle the challenges they see in the field. 


\section{Hands-On Tools}

Participants shared their desires for more skills and techniques to use within the classroom. They each discussed the benefits of outside resources and shared valuable skills they had gained from these professionals; and yet, participants expressed feeling frustrated and overwhelmed by the behaviors they saw in the classroom. Three of the four participants discussed expelling or counseling out children with mental health and behavioral challenges when children's behaviors were bigger than they felt they could handle. No matter teachers' dispositions towards inclusivity, lacking the necessary knowledge and skills to recognize and respond to children's behaviors leaves certain children vulnerable to not having their needs met in the classroom.

Believing in and valuing inclusivity coupled with research-based knowledge is not enough for educators to feel capable of handling the mental health and behavioral challenges of all children. Teacher education programs, as well as school and community-based professional development, must also offer teachers opportunities to learn hands-on techniques that can be used in the classroom when directly working with children with mental health issues and challenging behaviors. Teacher education programs are an important place to offer this sort of learning since it is often at this time when teachers are forming or transforming their professional identities as teachers. As Hong (2007) explains, "professional identity not only answers the question, 'Who am I at this moment?', but also, 'Who do I want to become?'” (p.12). By ensuring students value and learn how to meet the needs of children with mental health issues and challenging behaviors in the teacher education environment, we can encourage teachers to form 
teacher identities that view themselves as capable of meeting the needs of children who experience mental health and challenging behaviors.

As the literature review indicated, teachers are more successful at handling mental health needs and big behaviors in their classrooms when they believe they have both the knowledge and the skills to handle challenges that arise (Buysse, Wesley, Bryant, \& Gardner, 1999; Gilliam, 2008; Gilliam, 2016a). Thus, offering participants the hands-on skills they are wanting and attempting to seek out, can lessen the burden on teachers to fend for themselves, and increase the value and benefit of teacher education programming.

\section{Reflection}

Finally, teachers-in-training as well as practicing teachers must be offered opportunities to engage in consistent critical reflection as they acquire the knowledge and skills that will improve their abilities to work with children with mental health and behavioral challenges. Because mental health issues and challenging behaviors have a myriad of origins and ways of being expressed in the classroom, working with children with these issues cannot be a one-size-fits-all approach. Responding to their unique needs is a complex process that involves deep knowledge, a high level of skill, and the capacity to self-reflect and change based on child response. Thus, teacher educators as well as program administrators must offer teachers-in-training and practicing educators the time and space to process their experiences related to mental health and challenging behaviors in the classroom; questioning, analyzing their practices, and even acknowledging mistakes, is paramount for creating a teacher workforce that feels ready and able to tackle 
the complexities of actively including and supporting children with mental health and behavioral issues.

Further, offering and teaching reflective practices will not only allow students to reflect on all that they need to know, but also all that they do know, which can help them build teacher identities as confident and capable practitioners. This study demonstrated that the participants had an outstanding number of strengths and skills, and yet they all shared doubts about their capacities and their abilities to meet the needs of all learners. While these doubts may actually be a reason why they are such wonderful teachers; they are constantly striving to be better and never feel like they can plateau at 'good enough,' their doubts can also hinder their confidence in the classroom and ultimately influence children's learning (Cummins \& Asempapa, 2013; Hong, 2010). Through reflective practices teacher educators and school administrators can help teachers-in-training and those actively teaching see their strengths, even while asking them to learn and grow.

The participants were primarily calm, warm, and flexible in their emotional reactions and engagement with children in their classrooms. They valued relationships and were intentional about building authentic and meaningful connections with each of the children. However, the findings of this study suggest that despite these practices, and their coursework on equity and cultural diversity, participants' responses to children differed based on sex and (perhaps) race. While it is true that boys are more likely to have externalizing behaviors that may be more readily seen in the classroom, the literature review has established that internalizing behaviors, most likely displayed by girls, can be just as significant and harmful long-term (Head Start Bulletin, 2009; Liu, 2004). Critical reflection will allow students to look inward, process, and interrupt implicit biases and 
oppressive ways of being. Through reflection students will be able to question their priorities in the classroom and wonder whose behaviors need immediate attention and why. When discussing the high rates of expulsion for black boys, Gilliam et al. (2016b) offers several possible reasons for the high exclusionary rates, including "inadequate education and training for teachers, especially in self-reflective strategies to identify and correct potential biases in perceptions and practice" (p.2). By offering reflective practices specifically focused on mental health and behavioral issues, students in teacher preparation programs can gain insight into how their positionality and unique experiences can influence and even distort their understanding of classroom occurrences. Because we know from the literature that who teachers are influences how they see the world and how they see the children in their care, we must offer them the tools to reflect on their personal experiences (Gilliam et al., 2016b).

\section{Credibility and Limitations of the Study}

It was my intention for this study to elucidate participant voice and experience. However, as Maxwell (2005) argues, and is outlined in chapter two, there are two primary threats to the validity of a qualitative study: researcher bias and researcher influence. These two validity threats as they relate to this study, which due to the nature of qualitative research could not be removed only accounted for, are outlined below, followed by a discussion of the study's credibility and general limitations. The threats and limitations of the study are intentionally outlined in chapter five, because I believe it is important to know both the researcher and the participants via the earlier chapters, to truly understand how and why who we are affects the research. 


\section{Researcher Bias and Positionality}

Because this qualitative study, which used interviews, artifacts, observations, and email prompts, called for a lot of interactions between participants and researcher, my positionality was an influencer of the research findings. Objectivity was not possible, nor desired, for this study rooted in an AOP and AOE framework. Who I am will always affect the way I complete my research; my multiple identities and personal and educational experiences influenced how I viewed and conducted the research study, the questions I asked, the codes I chose, and the categories I created. Thus, to truly understand the way this study was formed as well as the findings, I must be transparent about who I am and how who I am impacts the study.

Although I have multiple identities that impact how I see the world, I think it is most important to discuss the ones that I believe specifically influence my research. I am a white, Jewish, middle-income, woman in my mid-thirties. I have spent many years analyzing and identifying the unearned privileges I receive as a middle-income, white person with higher-education degrees. Although I recognize the privileges my identities have afforded me, I also have come to understand that I will never know what it is like to live as a person who experiences overt oppression on a day to day basis. I came to my research aware that my lived experiences differ from the participants in the study, while also recognizing that we have some similarities. Throughout this research study I tried to be constantly aware of how who I am and who my participants are might affect my research. As with all my work, I intended to learn from and alongside the participants.

Further, I hold two master's degrees, one in curriculum and instruction with a specialization in early childhood education and the other in social work. I teach a few 
courses per year, primarily focusing on issues of guidance and equity, in Tallsee University's Graduate School of Education. In fact, as noted above, two of the participants were students in my courses. In the past I have worked as the executive director of a small nonprofit that offered inclusive early childhood education and family support services, as a preschool teacher, as a milieu staff member with children with mental health and behavioral issues in a residential treatment program, as a therapist for teen and adult trauma survivors, and as a parent educator for parents whose children were in foster care. Additionally, I am a foster and adoptive parent for children who have come to me through the child welfare system. My work, my educational background, and personal experience as a parent of children who have experienced trauma have informed my belief that all children deserve to be included and equitably supported in the classroom community. I wholeheartedly believe that children benefit from being in an inclusive environment where children have the experience of knowing and seeing that everyone belongs, and everyone is valued. This belief is what drives my research and my desire to support teachers and schools in creating supportive and inclusive classroom communities.

An anti-oppressive framework calls on a researcher to acknowledge the power relationships between researcher and participant within the research process (Strier, 2006). I acknowledge that my role as an instructor at TU and my identities influenced who joined the study and the ways participants perceived me, our interactions, and the conversations we had. Rather than denying that who I am influenced my research, I tried to explicitly address and be as transparent as possible about my position and role as a researcher (Swadener, et al., 2009). While completing my research I tried to affirm that I 
cared deeply about the participants' experiences and voices and that I wanted to learn from them. I answered questions that arose during interviews about who I am and how I came to this work.

I tried to alleviate any concerns they had by leaving room for them to ask a lot of questions and by being straightforward about my intent to create a nonjudgmental and open atmosphere between us. However, even while acknowledging this, I believe all of the participants still viewed me as someone they wanted to give the "right" answer to because they knew I was a doctoral student whose educational background was in both mental health and early childhood education and because they cared deeply about this field and wanted to say and do the right things. Sharing moments of confusion and moments of weakness can be intimate, vulnerable, and scary. While I of course attempted to put them at ease during the interviews and to stay in the background during the observations, the entire research study was a short process and did not afford much time to build our relationships.

Further, as a trained therapist I thought a lot about the ways that I asked questions and respond to participants, to try to stay away from therapizing the participants. Saldaña (2009) cautions, "if you're not trained in counseling be wary of playing amateur psychologist during fieldwork, and exercise ethical caution and support when interviewing people about sensitive matters which may generate strong and distressing emotions in recall" (p.89). Although I am trained in counseling, this was a good caution for me too; I needed to remember my role was that of a researcher, not of a therapist. As a therapist working with a new client, I would do very little leading in the beginning, I would allow my client to talk and explore as themes emerged. However, as a researcher, 
my role was much more direct; I had questions to ask and answers I wanted to make sure I recorded. I worked to ensure that my questions and responses stayed within the description of researcher, even while using the training I had received as a therapist (Merriam, 2009).

\section{Limitations}

All studies have some limitations. The most significant limitation of this study is also directly tied to its strength; the study dove deep into the experiences of the participants and shared their voices and stories. However, the lack of diversity within my participant pool (racial, ethnic, sex, socioeconomic, etc.) narrowed the impact of the findings. Any study grounded in AOP and AOE must acknowledge and be aware of whose voices are being lifted up and listened to within a study, and whose voices are not being heard. While yes, the qualitative nature of the study allowed for a powerful and intimate exploration of the experiences of the four participants, the homogeneity of the participant pool itself limited the findings in significant ways. All four of the participants were, like me, white, cisgender women and three of the four worked on college or university campuses in on-site early childhood education programs. While the data collected was rich and descriptive and brings value to the field, as a researcher whose intention and hope is always to share the voices of those who are often not heard, it is imperative that I acknowledge and explicitly state the impact having such a narrow participant pool has on my study. Further, by using a limited pool of participants I must acknowledge that I am missing many voices that are often left out of the field.

Because AOP and AOE are meant to share the voices of those whose stories and experiences are often overlooked, and to bring about social change by sharing their lived 
experiences, it is imperative that it is recognized and acknowledged that the voices shared are not the only voices within the teaching field. Thus, while the implications gathered from the findings of this study and this participant pool are significant, there are experiences within the teaching field that were not illuminated and deserve to be heard. This concept is reiterated again in the following section that recommends future research that allows for more diverse voices and experiences to be shared. More research that celebrates and honors participant voice is needed to truly understand why and how teachers do what they do in the classroom.

\section{Recommendations for Future Research}

This study has touched on many aspects of how students in an in-service teacher education program think about, emotionally react to, and engage with children who express challenges in the classroom. However, it only begins to reveal the unique experiences of these students and how what they know and who they are impacts the children they work with in the classroom. The findings from this study offer several new avenues for research that can elucidate the best ways to support teachers in successfully working with children with mental health and challenging behaviors:

1. Most early childhood educators who receive higher education degrees in the field attend two-year associate degree programs (Bureau of Labor Statistics, 2018). Therefore, repeating this study in an associate degree teacher preparation program could further illuminate the experiences of students in an in-service teacher preparation program. This study could provide some salient differences between students in associate degree programs and master's degree programs, so the needs 
of students in differing teacher preparation programs can be acknowledged and met.

2. This study found that when teachers feel under-resourced and overwhelmed when dealing with mental health and behavioral issues children and their families may be 'counseled out' of programs (instead of being 'expelled'). Therefore, it would be useful to learn more about the counseling out process; who is counseled out and why? What do the home-school relationships look like for these family? By exploring the process by which children's families voluntarily leave the program, we can learn more about the children's needs and ways to better support them in the classroom.

3. Significantly, this research included a fairly homogenous group of participants; all four participants were white women, and three out of the four participants worked in on-site early education programs in local college or university settings with predominantly white students. To expand on this research it would be both valuable and prudent to complete this study with a more diverse group of participants as well as within more diverse settings so to learn how participants of different genders and racial, ethnic, and cultural backgrounds think about, emotionally react to, and engage with children with mental health and behavioral issues in different classrooms. Further, this research could offer more insight into how teachers' perceptions, feelings, and reactions are different based on the race of their students.

4. Because this study was formed through the elucidation of just a few participant voices, I believe it would be beneficial to recreate this study using a bigger 
participant pool. Using more participants could offer new insights into the thoughts, feelings, and actions of participants while also allowing for different research methodologies to be used. With a much larger pool of participants surveys and statistical analysis could be incorporated into the research methods, which may allow for a more robust understanding of the research question and possibly generalizability.

5. Next, I believe it would be informative to continue this particular study by building on the implications and recommendations for teacher education programming. By studying the effects of teacher educators offering researchbased knowledge, hands-on tools, and reflective practices for students in an inservice teacher preparation program we can learn even more about what teachers need to best support all children.

6. Significantly, to even complete the research mentioned above within a teacher preparation program it may first be necessary to look at what teacher educators know and understand about supporting young children with mental health issues and challenging behaviors. This research could elucidate whether they are prepared to teach the research-based knowledge, hands-on tools, and reflective practices necessary to support the students in their programs, and it may offer insights into how to rectify the problem if they are not prepared.

\section{Concluding Thoughts}

While many researchers have studied the importance of early childhood mental health and supporting social emotional development in the classroom, few have studied the ways in which students in an in-service early childhood teacher education program 
think about, emotionally react to, and engage with children who experience mental health and behavioral challenges. Through a case study research design rooted in an antioppressive framework, this study attempted to offer rich, descriptive data that illuminated participant voice and experience. Looking at the cases individually and collectively, I found themes and subthemes that articulated participants' experiences working with children with challenges. Through this process I uncovered implications for practice that can help further the conversation about how to create supportive and responsive teacher education programs. Finally, I completed this research study by advocating for some recommendations for future research, ideas that expand on the present study as well as offer a fresh look at this phenomenon.

Early childhood educators are bound to run into children with mental health and behavioral issues in their classrooms (National Child Traumatic Stress Network, 2014; Roberts et al., 2012; van der Kolk, 2005; van der Kolk, 2014). Children's behavioral and emotional needs in the early years do not simply dissipate with time; children need consistent, safe, and informed adults to support them in learning tools to regulate and express themselves in productive ways. This study has elucidated the voices of four students in an in-service teacher education program who feel passionate about supporting and working with children who experience mental health and behavioral issues. They want more knowledge and tools to support the young children they love and care about. As a matter of equity and social justice, teachers, schools, as well as teacher education programs must learn to recognize and champion the needs of children with mental health and behavioral issues, so they too can receive the education they deserve. 
EARLY CHILDHOOD EDUCATION AND MENTAL HEALTH

\section{References}

Addy, S., \& Wight, V.R. (2012). Basic facts about low-income children, 2010: Children under age 6. New York, NY: Columbia University Mailman School of Public Health.

Almerico, G. M., Johnston, P., Henriott, D., \& Shapiro, M. (2011). Dispositions assessment in teacher education: Developing an assessment instrument for the college classroom and the field. Research in Higher Education Journal, 11, 1-19.

Badenoch, B. (2008). Being a brain-wise therapist: A practical guide to interpersonal neurobiology. New York, NY: W.W. Norton \& Company.

Baines, D. (2017). Anti-oppressive social work practice: Fighting for space, fighting for change. In D. Baines (Ed.), Doing Anti-Oppressive Practice: Social justice social work ( $3^{\text {rd }}$ ed.). (pp. 1-30). Halifax, OT: Fernwood Publishing.

Barnoff, L., \& Coleman, B. (2017). Strategies for integrating anti-oppressive principles: Perspectives from Feminist Agencies. In D. Baines (Ed.), Doing Anti-Oppressive Practice: Social justice social work ( $3^{\text {rd }}$ ed.). (pp. 31-49). Halifax, OT: Fernwood Publishing.

Beresford, P. (2002). Thinking about 'mental health:' Towards a social model. Journal of Mental Health, 11(6), 581-584.

Blair, K.S.C., Fox, L., \& Lentini, R. (2010). Use of positive behavior support to address the challenging behavior of young children within a community early childhood program. Topics in Early Childhood Special Education, 30(20), 68-79.

Borko, H., Liston, D., \& Whitcomb, J. A. (2007). Apples and fishes: The debate over dispositions in teacher education. Journal of Teacher Education, 58, 359-364. 
Bowlby, J. (1980). Attachment and loss, Vol 3: Loss, sadness, and depression. New York, NY: Basic Books.

Brennan, E.M., Ama, S.M., \& Gordon, L.J. (2002). Inclusion of Children with Emotional or Behavioral Challenges in Child Care Settings: An Observational Study. Portland, OR: Portland State University, Research and Training Center on Family Support and Children's Mental Health.

Brennan, E.M., Bradley, J.R., Ama, S.M., \& Cawood, N. (2003). Setting the pace: Modeling inclusive child care centers serving families of children with emotional or behavioral challenges. Portland, OR: Portland State University, Research and Training Center on Family Support and Children's Mental Health.

Briggs-Gowan, M.J., Carter, A.S., Skuban, E., \& Horwitz, S. (2001). Prevalence of social-emotional and behavioral problems in a community sample of 1- and 2year-old children. Journal of American Academy of Adolescent Psychiatry, 40(7), 811-819.

Bronfenbrenner, U. (1993). The ecology of cognitive development: Research models and fugitive findings. In R. Wonziak \& K. Fischer (Eds.), Development in Context: Acting and Thinking in Specific Environments (pp. 3-44). Hillsdale, NJ: Erlbaum. Brown, C. (2017). Feminist therapy, violence, problem drinking and re-storying women's lives: Reconceptualizing anti-oppressive feminist therapy. In D. Baines (Ed.), Doing Anti-Oppressive Practice: Social justice social work, $3^{\text {rd }}$ Edition (pp. 128144). Halifax, OT: Fernwood Publishing.

Bureau of Labor Statistics, U.S. Department of Labor (2018). Occupational outlook handbook, 2014-15 Edition. Retrieved from http://www.bls.gov/ooh/ 
EARLY CHILDHOOD EDUCATION AND MENTAL HEALTH

Buysse, V., Wesley, P.W., Bryant, D., \& Gardner, D. (1999). Quality of early childhood programs in inclusive and noninclusive settings, Exceptional Children, 65(3), 301-314.

Cadwell, L.B. (1997). Bringing Reggio Emilia home: An innovative approach to early childhood education. New York, NY: Teachers College Press.

Campbell, F., Conti, G., Heckman, J.J., Hyeok Moon, S., Pinto, R. Pungello, E. and Pan, Y. (2014). Early Childhood Investments Substantially Boost Adult Health. Science, 343 (6178): 1478-85.

Carlson, J. S., Mackrain, M. A., van Egeren, L. A., Brophy-Herb, H., Kirk, R. H., Marcin iak, D., Falvay, S., Zheng, Y., \& Tableman, B. (2012). Implementing a statewide early childhood mental health consultation approach to preventing childcare expulsion. Infant Menthal Health Journal, 3393), 265-273.

Center on the Developing Child at Harvard University. (2007). A science-based framework for early childhood policy: Using evidence to improve outcomes in learning, behavior, and health for vulnerable children. Cambridge, MA: Center on the Developing Child at Harvard University.

Cho Blair, K., Fox, L., \& Lentini, R. (2010). Use of positive behavior support to address the challenging behavior of young children within a community early childhood program, Topics in Early Childhood Special Education, 30, 68-79.

Choi, H.S., Benson, N.F., \& Shudak, N.J. (2016). Assessment of teacher candidate dispositions: Evidence of reliability and validity. Teacher Education Quarterly, 43(3), 71-89. 
Cole, S.F., A. Eisner, M. Gregory, \& J. Ristuccia. 2013. Helping Traumatized Children Learn 2: Creating and Advocating for Trauma Sensitive Schools. A Report and Policy Agenda. Boston: Massachusetts Advocates for Children. http://massadvocates.org/publications/helping-traumatized-children-learn-2/.

Cowen, E.L. (1994). The enhancement of psychological wellness: Challenges and opportunities. American Journal of Community Psychology, 22(2), 149-179.

Creswell, J.W. (2009). Research design: Qualitative, quantitative, and mixed methods approaches $\left(3^{\text {rd }}\right.$ Ed). Thousand Oaks, CA: Sage Publications.

Cummins, L. \& Asempapa, B. (2013). Fostering teacher candidate dispositions in teacher education programs. Journal of the Scholarship of Teaching and Learning, 13(3), 99-119.

Deater-Deckard, K., Dodge, K. A., Bates, J. E., \& Pettit, G. S. (1996). Physical discipline among African American and European American mothers: Links to children's externalizing behaviors. Developmental Psychology, 32, 1065-1072.

Delima, J., \& Vimpani, G. (2011). The neurobiological effects of childhood maltreatment: An often overlooked narrative related to the long-term effects of early childhood trauma?. Family Matters, 89, 42-52.

Dell'Antonia, K. (2010, May 16). The new inequality for toddlers: Less income; more Ritalin. The New York Times. Retrieved from http://parenting.blogs.nytimes.com/2014/05/16/the-new-inequality-for-toddlersless-income-more-ritalin/? $\mathrm{php}=$ true \& type $=\mathrm{b} \log \& \& \quad \mathrm{r}=0$

Delpit, L. (1995). Other people's children: Cultural conflict in the classroom. New York: The New Press. 
Dombro, A.L., Jablon, J., \& Stetson, C. (2011). Powerful Interactions: How to Connect with Children to Extend Their Learning. Washington, DC: National Association for the Education of Young Children (NAEYC).

Dominelli, L. (2002). Anti-oppressive social work theory and practice, Basingstoke: Palgrave, Macmillan.

Downey, D.B., \& Pribesh, S. (2004). When race matters: Teachers' evaluations of students' classroom behavior. Sociology of Education, 77, 267-282.

Edwards, C., Gandini, L., \& Forman, G. (Eds.). (1993). The hundred languages of children: The Reggio Emilia approach to early childhood education. Norwood, NJ: Ablex.

Egger, H. L., \& Angold, A. (2006). Common emotional and behavioral disorders in preschool children: Presentation, nosology, and epidemiology. Journal of Child Psychology and Psychiatry, 47, 313-337.

Egger, H.L., \& Emde, R.N. (2011). Developmentally sensitive diagnostic criteria for mental health disorders in early childhood: The Diagnostic and Statistical Manual of Mental Disorders_-IV, the Research Diagnostic Criteria-Preschool Age, and the Diagnostic Classification of Mental Health and Developmental Disorders of Infancy and Early Childhood-Revised. American Psychological Association, 66(2), 95-106.

Felitti, V., Anda, R.F., Nordenberg, D., Williamson, D.F., Spitz, A.M., Edwards, V., \& Koss, M.P. (1998). Relationship of childhood abuse and household dysfunction to many of the leading causes of death in adults: The adverse childhood 
EARLY CHILDHOOD EDUCATION AND MENTAL HEALTH

experiences (ACE) study. American Journal of Preventive Medicine, 14(4), 245258.

Flyvbjerg, B. (2006). Five misunderstandings about case-study research. Qualitative Inquiry, 12(2), 219-245.

Foster, S., Rollefson, M., Doksum, T., Noonan, D., Robinson, G., \& Teich, J. (2005). School Mental Health Services in the United States, 2002-2003. (DHHS Pub. No. SMA 05-4068). Rockville, MD: Center for Mental Health Services, Substance Abuse and Mental Health Services Administration.

Fox, L., \& Hemmeter, M. L. (2009). A Program-Wide Model for Supporting Social Emotional Development and Addressing Challenging Behavior in Early Childhood Settings. In W. Sailor, G. Dunlap, G. Sugai, and R. Horner (Eds.), Handbook of Positive Behavior Support (pp.177-202). New York: Springer.

Freire, P. (1970). Pedagogy of the oppressed. New York, NY: Seabury Press.

Freire, P. \& Faundez, A. (1989). Learning to question: A pedagogy of liberation. New York, NY: Continuum.

Fried, L. (2011). Teaching Teachers about Emotion Regulation in the Classroom. Australian Journal of Teacher Education, 36(2): 117-127.

García Coll, C., \& Magnuson, K. (2000). Cultural differences as sources of developmental vulnerabilities and resources. In J.P. Shonkoff \& S.J. Meisels (Eds.), Handbook of Early Childhood Intervention (pp. 94-114). Cambridge, MA: Cambridge U. Press.

Gilliam, W.S. (2005). Prekindergarteners left behind: Expulsion rates in state prekindergarten systems. New Haven, CT: Yale University Child Study Center. 
Gilliam, W.S. (2008). Implementing policies to reduce the likelihood of preschool expulsion. Foundation for Child Development Policy Brief No. 7.

Gilliam, W. S., Maupin, A. N., \& Reyes, C. R. (2016a). Early childhood mental health consultation: Results of a statewide random-controlled evaluation. Journal of The American Academy of Child \& Adolescent Psychiatry, 55(9), 754-761.

Gilliam, W., Maupin, A., Reyes, C., Accavitti, M. \& Shic, F. (2016b). Do early educators' implicit biases regarding sex and race relate to behavior expectations and recommendations of preschool expulsions and suspensions? Retrieved from: https://medicine.yale.edu/childstudy/zigler/publications/Preschool $\% 20$ Implicit $\% 2$ 0Bias\%20Policy\%20Brief_final_9_26_276766_5379_v1.pdf

Gilliam, W.S. \& Shahar, G. (2006). Preschool and child care expulsion and suspension: Rates and predictors in one state. Infants and Young Children, 19, 228-245.

Guba, E. G., \& Lincoln, Y. S. (2005). Paradigmatic controversies, contradictions, and emerging confluences. In N.K. Denzin \& Y.S. Lincoln (Eds.), The Sage handbook of qualitative research (3rd ed.) (pp. 191-216). Thousand Oaks, CA: Sage Publications.

Guzell-Roe, J., \& Stringer, S.A. (2005). Preservice teachers' perceived control over negative caregiving outcomes: Implications for early-childhood teacher preparation. Journal of Early Childhood Teacher Education, 25, 321-330.

Hagenauer, G., Hascher, T., \& Volet, S. (2015). Teacher emotions in the classroom: Associations with students' engagement, classroom discipline and the interpersonal teacher-student relationship. European Journal of Psychology of Education, 385-403. 
Head Start Bulletin. (2009). Mental Health (Issue 80). Washington, DC: Office of Head Start, Administration for Children and Families, U.S. Department of Health and Human Services.

Hemmeter, M. L., Fox, L., Jack, S., \& Broyles, L. (2007). A program-wide model of positive behavior support in early childhood settings. Journal of Early Intervention, 29, 337-355.

Hemmeter, M.L., Santos, R.M., \& Ostrosky, M.M. (2008). Preparing early childhood educators to address young children's social-emotional development and challenging behavior. Journal of Early Intervention, 30(4), 321-340.

Herman, J. (2015). Trauma and recovery: The aftermath of violence- from domestic abuse to political terror. New York, NY: Basic Books.

Hofer, B. (2004). Exploring the dimensions of personal epistemology in differing classroom contexts: Student interpretations during the first year of college. Contemporary Educational Psychology, 29, 129-163.

Ho, J. \& Funk, S. (2018). Promoting young children's social and emotional development. Young Children, 73(1). Retrieved from: https://www.naeyc.org/resources/pubs/yc/mar2018/promoting-social-andemotional-health

Hong, J., Y., (2007). Why do beginning teachers leave school?: Pre-service and beginning science teachers' professional identity and its relation to dropping out of the profession. (Doctoral Dissertation). University of Georgia. Retrieved from http://purl.galileo.usg.edu/uga_etd/hong_ji_y_200708_phd 
Hong, J., Y., (2010). Pre-service and beginning teachers' professional identity and its relation to dropping out of the profession. Teaching and Teacher Education, 26, 1530-1543.

hooks, B. (1994). Teaching to transgress: Education as the practice of freedom. New York, NY: Routledge.

Huffman, L. C., Mehlinger, S. L., \& Kerivan, A. S. (2000). Risk factors for academic and behavioral problems at the beginning of school. In Off to a good start: Research on the risk factors for early school problems and selected federal policies affecting children's social and emotional development and their readiness for school. Chapel Hill: University of North Carolina, FPG Child Development Center.

Hyland, N.E. (2010). Social justice in early childhood classrooms: What the research tells us. Young Children, 65(1), 82-90.

Jennings, P. A., \& Greenberg, M. T. (2009). The prosocial classroom: Teacher social and emotional competence in relation to student and classroom outcomes. Review of Educational Research, 79, 491-525.

Joint Consortium for School Health [JCSH]. (2010). Schools as a setting for promoting positive mental health: Better practices and perspectives. Retrieved from: http://www.jcsh-cces.ca/upload/PMH\%20July10\%202011\%20WebReady.pdf

Kauffman, J.M. (1999). How we prevent the prevention of emotional and behavioral disorders. Exceptional Children, 65(4), 448-468.

Kauffman, J.M. (2004). The President's Commission and the devaluation of special education. Education and Treatment of Children, 27(4), 307-324. 
Klehm, M. (2014). The effects of teacher beliefs on teaching practices and achievement of students with disabilities. Teacher Education and Special Education, 37, 216240.

Kvale, S. (2006). Dominance through interviews and dialogues. Qualitative Inquiry, $12(3), 480-500$.

Kvale, S. (1996). Interviews: an introduction to qualitative research interviewing. Thousand Oaks, CA: Sage Publications.

Kendall, P.C., \& Kessler, R.C. (2002). The impact of child psychopathology interventions on subsequent substance abuse: Policy implications, comments, and recommendations. Journal of Consulting and Clinical Psychology, 70(6), 13031306.

Kessler, R.C., Berglund, P., Demler, O., Jin, R., Merikangas, K.R., \& Walters, E.E. (2005). Lifetime prevalence and age-of-onset distributions of DSM-IV disorders in the national comorbidity survey replication. Archives of General Psychiatry, 62, 593-602.

Kontos, S., Moore, D. \& Giorgetti, K. (1998). The ecology of inclusion. Topics in Early Childhood Special Education, 18(1), 38-48.

Krathwohl, D. (2009). Methods of educational and social science research: The logic of methods, $3^{\text {rd }}$ Edition. Long Grove, IL: Waveland Press, Inc.

Kumashiro, K.K. (2000). Toward a theory of anti-oppressive education. Review of Educational research, 70(1), 25-53. 
EARLY CHILDHOOD EDUCATION AND MENTAL HEALTH

Kumashiro, K.K. (2001). "Posts" perspectives on anti-oppressive education in social studies, English, mathematics, and science classrooms. Educational Researcher, $30(3), 3-12$.

Lansford, J. E., Deater-Deckard, K., Dodge, K. A., Bates, J. E., \& G. S. Pettit. 2004. Ethnic differences in the link between physical discipline and later adolescent externalizing behaviors. Journal of Child Psychology and Psychiatry, 45: 801812.

Larson, G. (2008). Anti-oppressive practice in mental health. Journal of Progressive Human Services, 19(1), 39-54.

Larson, K., Russ, S.A., Crall, J.J., \& Halfon, N. (2008). Influence of multiple social risks on children's health. Pediatrics, 121(2), 337-344.

Leatherman, J.M. (2007). “I just see all children as children:” Teachers' perceptions about inclusion. The Qualitative Report, 12(4), 594-611.

Liu, J. (2004). Childhood externalizing behavior: Theory and implications. Journal of Child and Adolescent Psychiatric Nursing, 17(3), 93-103.

Malaguzzi, L. (1993). For an education based on relationships. Young Children, 49(1), $10-12$.

Massaquoi, N. (2017). Crossing boundaries to radicalize social work practice and education. In D. Baines (Ed.), Doing Anti-Oppressive Practice: Social justice social work ( $3^{\text {rd }}$ ed.). (pp. 176-190). Halifax, OT: Fernwood Publishing.

Maxwell, J. A. (2005). Qualitative research design: An interactive approach. Thousand Oaks, CA: Sage Publications. 
McCabe, L.A., \& Frede, E.C. (2007). Challenging behaviors and the role of preschool education. New Brunswick, NJ: National Institute for Early Education Research.

McLaren, P. 2016. Life in schools: An introduction to critical pedagogy and the foundations of education ( $6^{\text {th }}$ ed.). New York, NY: Routledge.

McLeod, J.D., \& Kaiser, K. (2004). Childhood emotional and behavioral problems and educational attainment. American Sociological Review, 69, 636-658.

Merrell, K.W., \& Walker, H.M. (2004). Deconstructing a definition: Social maladjustment versus emotional disturbance and moving the EBD field forward. Psychology in the Schools, 41(8), 899-910.

Merriam, S. B. (2009). Qualitative research design: A guide to design and implementation. San Francisco, CA: Jossey-Bass.

Moss, P. (2010). What is your image of the child? UNESCO Policy Brief on Early Childhood Education \#47.

Moore, J. (2013). Research summary: Resilience and at-risk children and youth. National Center for Homeless Education: https://nche.ed.gov/downloads/resilience.pdf

Nash, J.B., \& Schaefer, C.E. (2010). Clinical and developmental issues in psychotherapy with preschool children: Laying the groundwork for play therapy. In C.E. Schaefer (Ed.), Play Therapy for Preschool Children (pp.15-29). Washington, DC: American Psychological Association.

National Alliance of Mental Illness [NAMI]. (2007). An overview of multicultural issues in children's mental health. Retrieved from http://www.nami.org 
National Center for Mental Health Promotion and Youth Violence Prevention [NCMHPYV]. (2009). Connecting social and emotional learning with mental health. University of Illinois: Chicago.

National Child Traumatic Stress Network. 2014. Complex trauma: Facts for educators. Los Angeles, CA, \& Durham, NC: National Center for Child Traumatic Stress. National Council for Accreditation of Teacher Education [NCATE]. (2010). NCATE glossary. Retrieved from http://www.ncate.org/Standards/UnitStandards/Glossary/tabid/477/Default.aspx National Scientific Council on the Developing Child [NSCDC]. (2004). Children's emotional development is built into the architecture of their brains: Working Paper No. 2. Cambridge, MA: Center of the Developing Child.

National Scientific Council on the Developing Child [NSCDC]. (2008a). Children's emotional development is built into the architecture of their brains: Working Paper No. 2. Cambridge, MA: Center of the Developing Child.

National Scientific Council on the Developing Child [NSCDC]. (2008b). Mental health problems in early childhood can impair learning and behavior for life: Working Paper No. 6. Cambridge, MA: Center of the Developing Child.

Novinger, S., O'Brien, L., \& Sweigman, L. (2005). Challenging the culture of expertise: Moving beyond training the always, already failing early childhood education. In S. Ryan \& S. Grieshaber (Eds.), Practical Transformations and Transformational Practices: Globalization, Postmodernism, and Early Childhood Education (pp. 217-241). Oxford, UK: Elsevier. 
Odom, S.L. (2000). Preschool inclusion: What we know and where we go from here. Topics in Early Childhood Special Education, 20(1), 20-27.

Odom, S.L., \& Diamond, K.E. (1998). Inclusion of young children with special needs in early childhood education: The research base. Early Childhood Research Quarterly, 13(1), 3-25.

Perry, B.D., \& Szalavitz, M. (2107). The boy who was raised as a dog: And other stories from a child psychiatrist's notebook: What traumatized children can teach us about love, loss, and healing. New York, NY: Basic Books.

Phillippi, J., \& Lauderdale, J. (2018). A guide to field notes for qualitative research: Context and conversation. Qualitative Health Research, 28(3), 381-388. doi:10.1177/1049732317697102

Porges, S.W. (2004). Neuroception: A subconscious system for detecting threats and safety. Zero to Three: Bulletin of the National Center for Clinical Infant Programs, 24(5), 19-24.

President's New Freedom Commission on Mental Health. (2003). Achieving the promise: Transforming mental health care in America. Final Report. Rockville, MD: President's New Freedom Commission on Mental Health.

Quesenberry, A.C., Hemmeter, M.L., \& Ostrosky, M.M. (2011). Addressing challenging behavior in Head Start: A closer look at program policies and procedures. Topics in Early Childhood Special Education, 30, 209-220.

Reggio Children. (2010). Indications: Preschools and infant-toddler centres of the municipality of Reggio Emilia. Reggio Emilia, Italy: Reggio Children. 
Roberts A.L., Rosario M., Corliss H.L., Koenen K., \& Austin S.B. (2012). Childhood gender nonconformity: a risk indicator for childhood abuse and posttraumatic stress in youth. Pediatrics. 129(3): 410-417.

Rones, M., \& Hoagwood, K. (2000). School-based mental health services: A research review. Clinical Child and Family Psychology Review, 3, 223-241.

Rubin, H.J. \& Rubin, I.S. (1995). Qualitative interviewing: The art of hearing data. Thousand Oaks: Sage Publications.

Saldaña, J. (2009). The coding manual for qualitative researchers. Los Angles, CA: Sage Publications.

Schwartz, A. (2014, May 17). Thousands of toddlers are medicated for A.D.H.D., report finds, raising worries. The New York Times. Retrieved from http://www.nytimes.com/2014/05/17/us/among-experts-scrutiny-of-attentiondisorder-diagnoses-in-2-and-3-year-olds.html

Schulte, L.E., Edwards, S., \& Edick, N.A. (2008). The development and validation of the diversity dispositions index. Teacher Education Faculty Publications. Retrieved from https://digitalcommons.unomaha.edu/tedfacpub/17

Schulte, L .E., Edick, N., Edwards, S., \& Mackiel, D. (2004). The development and validation of the Teacher Dispositions Index. Essays In Education, 12.

Siegel, D. J., \& Bryson, T. P. (2012). The whole-brain child: 12 revolutionary strategies to nurture your child's developing mind. Brunswick, Vic.: Scribe Publications.

Severson, H.H., Walker, H.M., Hope-Doolittle, J., Kratochwill, T.R., \& Gresham, F.M. (2007). Proactive, early screening to detect behaviorally at-risk students: Issues, 
EARLY CHILDHOOD EDUCATION AND MENTAL HEALTH

approaches, emerging innovations, and professional practices. Journal of School Psychology, 45, 193-223.

Shaw, D.S., Gilliom, M., \& Ingoldsby, E.M. (2003). Trajectories leading to school-age conduct problems. Developmental Psychology, Special Issue: Violent Children, $39,189-200$.

Shonkoff, J.P., \& Phillips, D.A. (Eds.). (2000). From neurons to neighborhoods: The science of early childhood development. Washington DC: National Academy Press.

Skiba et al., R., Simmons, A., Ritter, S., Kohler, K., Henderson, M. \& Wu, T. (2006). The context of minority disproportionality: Practitioner perspectives on special education referral. Teachers College Record, 108(7), 1424-1459.

Smith, B. J., \& Fox, L. (2003). Systems of service delivery: A synthesis of evidence relevant to young children at risk of or who have challenging behavior. Center for Evidence-based Practice: Young Children with Challenging Behavior.

Stacks, A.M., \& Oshio, T. (2009). Disorganized attachment and social skills as indicators of Head Start children's school readiness skills. Attachment and Human Development, 11(2), 143-164.

Stewart, P., \& Davis, S. (2005). Developing dispositions of preservice teachers through membership in professional organizations. Journal of Authentic Learning, 2(1), $37-46$.

Streeck-Fischer, A., \& van der Kolk, B. (2000). Down will come baby, cradle and all: Diagnostic and therapeutic implications of chronic trauma on child development. Australian and New Zealand Journal of Psychiatry, 34, 903-918. 
Stubenbort, K., Cohen, M.M. \& Trybalski, V. (2010). The effectiveness of an attachment-focused treatment model in a therapeutic preschool for abused children. Clinical Social Work Journal, 38, 51-60.

Swadener, B.B., Aquino-Sterling, C.R., Nagasawa, M., \& Bartlett, M. (2009). Antioppressive pedagogy in early childhood teacher education: A conversation. In S.L. Groenke and J.A. Hatch (Eds.), Critical pedagogy and teacher education in the neo-liberal era: Small openings (pp. 99-112). New York: Springer.

Swanson, D.P., Spencer, M.B., Harplani, V., Dupree, D., Noll, E., Ginzburg, S., \& Seaton, G. (2003). Psychosocial development in racially and ethnically diverse youth: Conceptual and methodological challenges in the 21st century. Development and Psychopathology, 15(3), 743-771.

Swartz, R.A. \& McElwain, N.L. (2012). Preservice teachers' emotion-related regulation and cognition: Associations with teachers' responses to children's emotions in early childhood classrooms. Early Education and Development, 23, 202-226.

Switaji, E. (2010). Are children an oppressed class? Gender Across Boarders. Retrieved from http://www.genderacrossborders.com/2010/02/25/children-oppressed-class/

Takacs, D. (2002). Positionality, epistemology, and social justice in the classroom. Social Justice, 29(4), 168-181.

Takacs, D. (2003). How does your positionality bias your epistemology? The NEA Higher Education Journal, 14(2), 27-38.

Taylor, R.L. \& Wasicsko, M.M. (2000, November). The dispositions to teach. Paper presented at SRATE, Kentucky. Retrieved from 
https://inside.nku.edu/content/dam/coehs/old/docs/dispositions/resources/The_Dis positons to_Teach.pdf

The National Advisory Mental Health Council. (2001). Blueprint for change: Research on child and adolescent mental health. Washington DC: Workgroup on Child and Adolescent Mental Health Intervention Development and Deployment

Thomason, M.E. \& Marusak, H.A. (2017). Toward understanding the impact of trauma on the early developing human brain. Neuroscience, 7(342), 55-67.

U.S. Department of Health and Human Services (1999). Mental health: A report of the Surgeon General. Rockville, MD: U.S. Department of Health and Human Services, Substance Abuse and Mental Health Services Administration, Center for Mental Health Services.

van der Kolk, B. (2005). Developmental trauma disorder: Towards a rational diagnosis for chronically traumatized children. Psychiatric Annals, 35, 401-408.

van der Kolk, B. (2014). The body keeps the score: Brain, mind, and body in the healing of trauma. New York, NY: Penguin Books.

Visser, S. N., Lesesne, C. A., \& Perou, R. (2007). National estimates and factors associated with medication treatment for childhood attention-deficit/hyperactivity disorder. Pediatrics, 119, 99-106

Walker, H.M., \& Golly, A.M. (1999). Developing behavioral alternatives for antisocial children at the point of school entry. The Clearing House, 73(2), 104-106.

Walker, H.M., Kavanagh, K., Stiller, B., Golly, A.M., Severson, H.H., \& Feil, E.G. (1998). First step to success: An early intervention approach for preventing antisocial behavior. Journal of Emotional and Behavioral Disorders, 6(2), 66-80. 
Walker-Dalhouse, D. (2005). Discipline: Responding to socioeconomic and racial differences. Childhood Education, 82(1), 24-30.

Webster-Stratton, C., \& Reid, J. (2010). Parents, teachers, and therapists using childdirected play therapy and coaching skills to promote children's social and emotional competence and build positive relationships. In C.E. Schaefer (Ed.), Play Therapy for Preschool Children (pp. 245-273). Washington, DC: American Psychological Association.

Westling, D.L. (2010). Teachers and challenging behavior: Knowledge, views, and practices. Remedial and Special Education, 31(1): 48-63.

Whalley, P. (2015). Child neglect and Pathways Triple P: An evaluation of an NSPCC services offered to parents where initial concerns of neglect have been noted. London, NSPCC.

White, J.L., Moffitt, T.E., Earls, F., Robins L., \& Silva, P.A. (1990). How early can we tell? Predictors of childhood conduct disorder and adolescent delinquency. Criminology, 28(4), 507-533.

Whitebook, M., \& Sakai, L. (2003). Turnover begets turnover: an examination of job and occupational instability among child care center staff. Early Childhood Research Quarterly, 18(3), 273-293.

Whitebook, M., Phillips, D., \& Howes, C. (2014). Worthy work, STILL unlivable wages: The early childhood workforce 25 years after the national child care staffing study. Berkeley, CA: Center for the Study of Child Care Employment, University of California, Berkeley. 
Wilson, A., \& Beresford, P. (2000). 'Anti-oppressive practice': emancipation or appropriation? British Journal of Social Work, 30(5), 553-573.

Wilson, S. \& Cooney, T. (2002). Mathematics teacher change and development: The role of beliefs. In G. Leder, E Pehkonen, \& G Torner (Eds.). Beliefs: A hidden variable in mathematics education (pp. 127-148). Boston, MA: Kluwer Academic Publishing.

Winslade, J., \& Monk, G. (2007). Narrative counseling in schools: Powerful and brief (2nd ed.). Thousand Oaks, CA: Corwin Press.

Wolpow, R., Johnson, M.M., Hertel, R., \& Kincaid, S.O. (2009). The heart of learning and teaching: compassion, resiliency, and academic success. Retrieved from http://www.k12.wa.us/CompassionateSchools/Resources.aspx

Wood, B.K., Cho Blair, K.S., \& Ferro, J.B. (2009). Young children with challenging behavior: Function based assessment and intervention. Topics in Early Childhood Special Education, 29(2), 68-78.

Yin, R. K. (2014). Case study research: Design and methods. Los Angeles, CA: Sage. Zero to Three. (2004). Infant and early childhood mental health: Promoting healthy social and emotional development. Washington DC: National Center for Infants, Toddlers and Families. 


\section{Appendices}

\section{Appendix A: Letter of Informed Consent}

\section{A Case Study of How Students in an In-Service Early Childhood Teacher Education Program Experience Students who Express Mental Health Issues and Challenging Behaviors in their Classrooms.}

You are invited to participate in a research study conducted by Katie Statman-Weil, in the Graduate School of Education at Tallsee University (TU). The researcher hopes to learn how students in an in-service early childhood teacher education program think about, emotionally react to, and engage with children who express mental health issues and challenging behaviors in their classrooms. This project is conducted as partial fulfillment for a doctoral degree from TU. You were selected as a possible participant in this study because of your active role as a student in the Graduate School of Education at TU.

If you choose to participate in this study, the researcher will ask you to describe, through interviews and email prompts, your experiences with students who express mental health or challenging behaviors in your classroom. Two interviews will be conducted, and each will last 45-90 minutes and will be voice recorded. The researcher will also ask for artifacts from your classroom or school that relate to your experiences with these students. The researcher will also conduct three observations of you in the classroom as a means of understanding what your work with children expressing challenges looks like in action. Your projected involvement in this case study will be from early February 2016 to March 2016.

While the intention of this study is to understand one's thoughts, beliefs and experiences connected to teaching, it is possible that participation in this study may bring up both strong negative and positive emotions. It is hoped that the findings of this study can inform teacher educators in preparing students in early childhood teacher preparation programs to meet the needs of children experiencing mental health and behavioral challenges. As a participant you may not directly benefit from this study or its results. However, through the interviews and email prompts it is possible that you will be able to reflect on your own teaching practices, fostering your personal and professional growth.

Any information obtained about you in connection with this study will be kept confidential. Besides the researcher, the only other person who will have access to the interview transcripts will be the professional transcriber hired to transcribe the documents. Interview transcripts, voice recordings, and email prompts, as well as any other artifacts obtained during the study will be kept in a locked file cabinet by the researcher until they are either returned or destroyed. All confidential documents not returned to the participants that are connected to the study will be destroyed three years 
after the study is completed.

Your participation in this study is completely voluntary. You do not have to take part in this study and you may withdraw your participation from this study at any time and for any reason. Withdrawing your participation will not affect your relationship with TU or the researcher.

If you have questions or concerns about your participation in this study, your rights as a research participant, a research related injury, or to obtain information or offer input about this study please contact the Human Subjects Research Review Committee, Office of Research and Sponsored Projects, 100 Best Bldg., TU, (012) 345-6789. If you have any questions, concerns, or complaints about the study itself, contact Katie Statman-Weil at (123) 456-7890 or kstatman@tu.edu.

By signing below you are indicating that you have read and understand the information outlined above and that you agree to take part in this study. By signing, you are not waiving any legal claims, rights or remedies. The researcher will provide you with a photocopy of this signed form for your records.

Name

Signature

Date 
Appendix B: Data Collection Timeline

\begin{tabular}{|l|l|}
\hline \multicolumn{2}{|c|}{ Roxanne } \\
\hline Data Collection Method & Date \\
\hline Observation \#1 & March 10, 2017 \\
\hline Interview \#1 & March 12, 2017 \\
\hline Artifact \#1 & March 12, 2017 \\
\hline Observation \#2 & May 12, 2017 \\
\hline Interview \#2 & September 20, 2017 \\
\hline Artifact \#2 & September 20, 2017 \\
\hline Observation \#3 & November 10, 2017 \\
\hline Email \#1 & January 9, 2018 \\
\hline Email \#2 & February 11, 2018 \\
\hline
\end{tabular}

\begin{tabular}{|l|l|}
\hline \multicolumn{2}{|c|}{ Sophia } \\
\hline Data Collection Method & Date \\
\hline Observation \#1 & March 16, 2017 \\
\hline Interview \#1 & March 24, 2017 \\
\hline Artifact \#1 & March 24, 2017 \\
\hline Observation \#2 & April 7, 2017 \\
\hline Email \#1 & June 5, 2017 \\
\hline Interview \#2 & May 5, 2017 \\
\hline Artifact \#2 & May 5, 2017 \\
\hline Observation \#3 & May 20, 2017 \\
\hline Email \#2 & June 20, 2017 \\
\hline
\end{tabular}

\begin{tabular}{|l|l|}
\hline \multicolumn{2}{|l|}{ Livia } \\
\hline Data Collection Method & Date \\
\hline Observation \#1 & May 31, 2017 \\
\hline Interview \#1 & June 16, 2017 \\
\hline Artifact \#1 & June 16, 2017 \\
\hline Observation \#2 & August 3, 2017 \\
\hline Email \#1 & August 17, 2017 \\
\hline Interview \#2 & August 18, 2017 \\
\hline Artifact \#2 & August 18, 2017 \\
\hline Observation \#3 & September 8, 2017 \\
\hline Email \#2 & September 27, 2017 \\
\hline
\end{tabular}




\begin{tabular}{|l|l|}
\hline \multicolumn{2}{|c|}{ Mary } \\
\hline Data Collection Method & Date \\
\hline Observation \#1 & January 26, 2018 \\
\hline Interview \#1 & January 26, 2018 \\
\hline Artifact \#1 & January 26, 2018 \\
\hline Observation \#2 & February 2, 2018 \\
\hline Email \#1 $\#$ February 8, 2018 \\
\hline Interview \#2 & March 2, 2018 \\
\hline Artifact \#2 & March 2, 2018 \\
\hline Observation \#3 & March 16, 2018 \\
\hline Email \#2 & March 30, 2018 \\
\hline
\end{tabular}




\section{Appendix C: Interview Protocol}

\begin{tabular}{|l|l|}
\hline Participant: & Interview \#: \\
Date: & \\
Time: & \\
Location: & \\
\hline
\end{tabular}

1. Begin the interview reminding the participant of their rights and my obligations as a researcher: Thank you for participating in this study. Before we begin I wanted to confirm with you that this interview will be kept confidential. Pieces of this interview may be included in the final research paper, but under no circumstances will your name or identifying characteristics be included in the paper. If you still want to participate, is it all right for me to turn on the voice recorder now?

2. Remind participant of the purpose of the study: to understand how you think about, emotionally react to, and engage with children who express mental health issues and challenging behaviors in your classroom.

3. Facilitate an interview to identify and understand the participant's thoughts and emotions concerning children who express mental health and challenging behaviors.

Possible Focus for Interviews:

\begin{tabular}{|l|l|}
\hline Interview \#1 & $\begin{array}{l}\text { Thinking about children who express } \\
\text { mental health issues and challenging } \\
\text { behaviors in his or her classroom: } \\
\text { Where do you think mental health issues in } \\
\text { early childhood come from? How do you } \\
\text { think teachers should respond to children's } \\
\text { challenging behaviors? }\end{array}$ \\
& $\begin{array}{l}\text { Have you ever had child in your classroom } \\
\text { whose behavioral needs were beyond your } \\
\text { ability? } \\
\text { If so: What were their needs? What did you } \\
\text { do? }\end{array}$ \\
\\
If not: Do you think it's possible that you
\end{tabular}




\begin{tabular}{|c|c|}
\hline & $\begin{array}{l}\text { will encounter a child whose behavioral } \\
\text { needs are beyond your ability? Why or why } \\
\text { not? } \\
\text { *The interview will also include impromptu } \\
\text { questions connected to the artifacts brought } \\
\text { to the interview by the participant. }\end{array}$ \\
\hline Interview \#2 & $\begin{array}{l}\text { Articulating their emotional reactions to } \\
\text { young children's expression of mental } \\
\text { health and behavioral challenges in his or } \\
\text { her classroom: } \\
\text { How do you typically respond to a child } \\
\text { when they are not listening? What do you } \\
\text { do if a child hits another child? Or hits you? } \\
\text { Have you ever had an experience where } \\
\text { you have felt a child's behavior was out of } \\
\text { control in the classroom? What did you do? } \\
\text { Do you remember how you felt? } \\
\text { Does your co-teacher respond to } \\
\text { challenging behaviors in the same way? Do } \\
\text { the values of your administration align with } \\
\text { yours in terms of how you believe } \\
\text { children's behaviors should be handled? Do } \\
\text { the families you work with handle guidance } \\
\text { issues in the same ways that you do? } \\
\text { During this interview I will also ask } \\
\text { questions connected to specific instances I } \\
\text { observe in the classroom. } \\
\text { *The interview will also include impromptu } \\
\text { questions connected to the artifacts brought } \\
\text { to the interview by the participant. }\end{array}$ \\
\hline
\end{tabular}

During the interviews I will use open ended prompts to delve deeper into the participant's beliefs, such as:

- Can you say more about that?

- How did that happen?

- Can you give me an example?

- How did that make you feel?

- Do you have any ideas about why or how that happened?

- Can you describe [this artifact]? Why is this artifact significant for you? 
4. Consult calendar and confirm next interview if needed. If it is the last interview, thank participant for participating. 
Appendix D: Interview Cover Sheet

Participant:

Interview \#:

Date:

Time:

Location:

Researchers Initial Thoughts and Questions about the Interview: 
Appendix E: Artifact Cover Sheet

Artifact Name:

Participant:

Artifact Number:

Date received:

Description of the artifact:

Event and/or concept connected to the artifact:

Significance of the artifact: 
Appendix F: Observation Procedure Sheet

Participant being observed:

Observation \#:

Date:

Time:

Location:

Context (weather, number of children, number of adults, activity, etc.):

\begin{tabular}{|l|l|}
\hline Observation & Interpretation/Inferences \\
\hline & \\
& \\
& \\
\hline
\end{tabular}


Appendix G: Email Prompts

\begin{tabular}{|c|c|}
\hline Email Prompt \#1 & $\begin{array}{l}\text { Questions: } \\
\text { 1) What does "challenging behavior" mean } \\
\text { to you? } \\
\text { 2) What are the most important social- } \\
\text { emotional skills for young children to } \\
\text { learn? } \\
\text { 3) Individualized question } \\
\text { 4) Individualized question }\end{array}$ \\
\hline Email Prompt \#2 & $\begin{array}{l}\text { Questions: } \\
\text { 1) We have now had many different } \\
\text { conversations (through interview, artifact } \\
\text { description, and email) about young } \\
\text { children's behavioral and mental health } \\
\text { needs, is there anything else you would like } \\
\text { me to know about your thoughts or feelings } \\
\text { related to this issue? } \\
\text { 2) After thinking so deeply about young } \\
\text { children's mental health and behavioral } \\
\text { challenges, are you left with any big } \\
\text { questions about young children's } \\
\text { behavioral and mental health issues? } \\
\text { 3) Individualized question } \\
\text { 4) Individualized question }\end{array}$ \\
\hline
\end{tabular}

